\title{
Understanding social sustainability of capture fisheries
}

Linda J.L. Veldhuizen 


\section{Thesis committee}

\section{Promotor}

Prof. Dr I.J.M. de Boer

Professor of Animal Production Systems

Wageningen University

\section{Co-promotors}

Dr P.B.M. Berentsen

Associate professor, Business Economics Group

Wageningen University

Dr E.A.M. Bokkers

Associate professor, Animal Production Systems Group

Wageningen University

\section{Other members}

Prof. Dr S.R. Bush, Wageningen University

Prof. Dr A.D. Rijnsdorp, Wageningen Marine Research

Dr J.W. van de Vis, Wageningen Livestock Research

Dr F. Ziegler, SP Technical Research Institute of Sweden, Gothenburg, Sweden

This research was conducted under the auspices of the Graduate School of Wageningen Institute of Animal Sciences (WIAS) 


\section{Understanding social sustainability of capture fisheries}

Linda J.L. Veldhuizen

\section{Thesis}

submitted in fulfilment of the requirement for the degree of doctor at Wageningen University by the authority of the Rector Magnificus

Prof. Dr A.P.J. Mol, in the presence of the Thesis Committee appointed by the Academic Board to be defended in public on Friday 20 January 2017 at 1.30 p.m. in the Aula. 
Veldhuizen, Linda Johanna Liduina

Understanding social sustainability of capture fisheries 160 pages.

$\mathrm{PhD}$ thesis, Wageningen University, Wageningen, NL (2017)

With references, with summaries in English and in Dutch

ISBN 978-94-6257-964-4

DOI $10.18174 / 392826$ 


\section{Abstract}

Fishing companies are faced with decreasing profitability and increasing competition. These companies can try to gain a competitive advantage by differentiating their products, e.g. by marketing new product attributes that consumers are interested in such as attributes relating to sustainability. Although consumers could be considerably interested in social sustainability of fish, this sustainability dimension has received little research interest so far. The main objective of this thesis is to understand social sustainability of capture fisheries. Social sustainability can be understood by applying the framework for social sustainability assessment, which consists of stakeholder consultation and issue selection, indicator development and quantification, and interpretation of the results, to the case considered. The case considered in this thesis was capture fisheries in the northeast Atlantic. Stakeholder consultation resulted in the identification of 27 social sustainability issues relevant for capture fisheries in the northeast Atlantic. Overall, social sustainability issues concerning working conditions, employees' job fulfilment and fish welfare were seen as more important than other social sustainability issues. Indicators were defined for the most important social sustainability issues of capture fisheries in the northeast Atlantic. To interpret values for each indicator, rubrics were developed that articulated levels of performance. Application of these indicators and their accompanying rubrics to a Norwegian trawler demonstrated that the indicators and rubrics provide insight into social sustainability at the level of the vessel, which can be used to identify potential room for improvement. To determine whether social sustainability issues can be used for product differentiation, consumer interest in social sustainability issues of whitefish from the northeast Atlantic was studied. Results from a choice modelling survey demonstrated that consumers prefer the issue fish welfare over the issues product quality, worker safety and local employment. Given the lack of overview of the knowledge on fish welfare, the most important social sustainability issue for consumers, the literature on this topic was reviewed to determine how the capture process in capture fisheries affects fish welfare, using the indicators external injuries and mortality. This review showed that scale, skin and fin injuries occur more frequently in trawls, purse seines, gillnets, traps and seines than in hooks, whereas hooking injuries occur in hooks only. Pressure injuries can occur in all gear types when deployed at greater depth. Trawls, purse seines and seines result in higher mortality than gillnets, hooks and traps. Mortality appears to increase with decreasing fish length, and differs across fish species. A greater capture depth and a longer fishing duration were associated with more external injuries and higher mortality, whereas a large change in water temperature, a longer duration of air exposure and a high density in the net were associated with higher mortality only. This thesis shows that application of the framework for social sustainability assessment to capture fisheries in the northeast Atlantic leads to an understanding of social sustainability that fishing companies can use to their advantage. In addition, this thesis shows that fishing companies in the northeast Atlantic need to start paying attention to fish welfare because consumers consider fish welfare the most important social sustainability issue of capture fisheries in the northeast Atlantic. 



\section{Contents}

$\begin{array}{lll}\text { Chapter } 1 \quad \text { General introduction } & 9\end{array}$

Chapter 2 Social sustainability of cod and haddock fisheries in the $\quad 17$ northeast Atlantic: what issues are important?

Chapter 3 A method to assess social sustainability of capture fisheries: $\quad 39$ an application to a Norwegian trawler

Chapter 4 Consumer interest in social sustainability issues of whitefish $\quad 61$ from capture fisheries in the northeast Atlantic

Chapter 5 Fish welfare in capture fisheries: a systematic review of $\quad 85$ injuries and mortality

Chapter 6 General discussion

References

Summary 148

Samenvatting 151

Dankwoord 154

$\begin{array}{ll}\text { About the author } & 156\end{array}$

$\begin{array}{ll}\text { Publications } & 157\end{array}$

$\begin{array}{lr}\text { Education certificate } & 158\end{array}$

$\begin{array}{ll}\text { Colophon } & 160\end{array}$ 



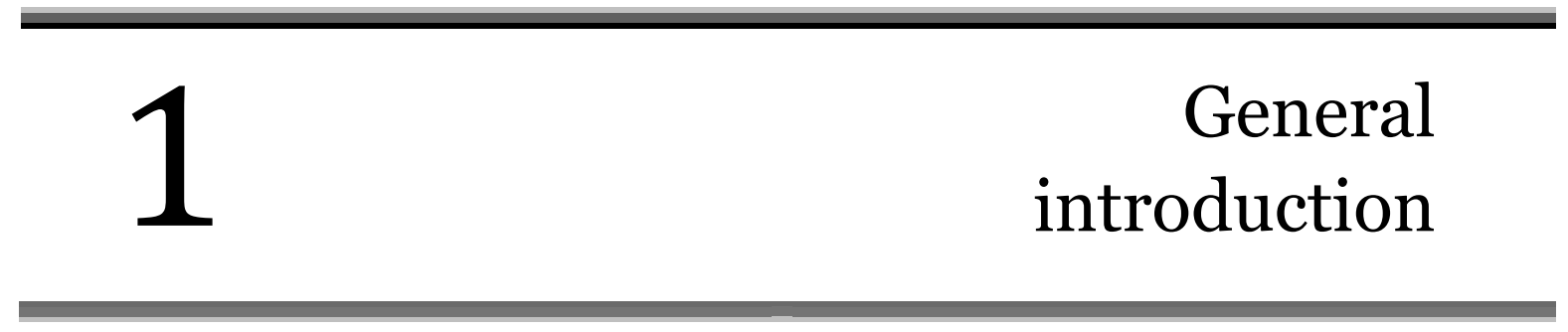




\section{Background}

The global human population is expected to grow from 7.3 billion in 2015 to 8.5 billion in 2030 (United Nations Population Division, 2015). This growing world population, coupled with growing per capita consumption, is expected to result in a 1.1\% annual increase in the demand for agricultural products (Alexandratos and Bruinsma, 2012). The increase in the demand for animal-source proteins is likely more pronounced due to expected increases in wealth and urbanization, resulting in a dietary shift towards more animal-source food products (WHO and FAO, 2003).

The growing demand for animal-source food products has been met thus far by increased production levels, which have been most notable for fish (Béné et al., 2015, FAO, 2014b). During the past 50 years, the global supply of fish from capture fisheries and aquaculture has, on average, increased with $3.2 \%$ per year (FAO, 2014b). The majority (approximately 63\% in 2012) of this global fish supply originates from capture fisheries (FAO, 2014d), which is the sum of all (commercial) fishing activities on wild fish (FAO, 1997). The growth in the global fish supply, however, has come at the cost of the world's fish stocks, with $30 \%$ being overexploited in 2009 (FAO, 2012).

In order to curb this overexploitation, various input and output controls have been put in place in fisheries worldwide (Worm et al., 2009). One commonly used output control is a reduction in total allowable catch (Worm et al., 2009), which limits the fishers' catch. This limited catch and stagnant prices for fish (World Bank and FAO, 2009) likely resulted in stagnant revenues for fishers. At the same time, harvesting costs have increased, causing profitability of fisheries worldwide to become negative (World Bank and FAO, 2009). This declining profitability, coupled with excess capacity in the fleet (World Bank and FAO, 2009), will have resulted in increased competition among fishers.

Companies faced with increasing competition can try to gain a competitive advantage by differentiating their products, e.g. by marketing new product attributes that consumers are interested in (Chamberlin, 1933). In recent years, consumers have displayed increasing interest in products with attributes relating to sustainability such as organic or Fairtrade products (Andorfer and Liebe, 2012, Tully and Winer, 2014). This makes it likely that consumers are also interested in sustainability of fish.

\section{Sustainability of capture fisheries}

Sustainability is generally composed of environmental, economic, and social sustainability (Jeswani et al., 2010, Kloepffer, 2008). Environmental sustainability of capture fisheries has attracted considerable scientific attention (e.g. Pelletier et al., 2007, Seves et al., 2016, Ziegler et al., 2003). Moreover, there 
is considerable consumer interest in environmental sustainability, given that, for example in the United Kingdom, consumers are currently paying price premiums of approximately $10 \%$ for fish labelled by the marine stewardship council (better known under the abbreviation MSC) as originating from sustainably managed stocks (Roheim et al., 2011, Sogn-Grundvåg et al., 2013). In contrast, economic sustainability (e.g. Barnes-Mauthe et al., 2013, Coglan and Pascoe, 2015, Whitmarsh et al., 2003) and social sustainability (e.g. Glaser and Diele, 2004, Van Holt et al., 2016) have attracted less scientific attention. Economic sustainability of capture fisheries is not so much of interest for consumers since this concerns fishing companies' viability, which is mainly of interest for these companies themselves and related economic actors such as suppliers and processors. Social sustainability of capture fisheries, however, could be of interest for consumers since a meta-analysis on willingness to pay for sustainability issues of products showed that consumers are generally more interested in social sustainability than in environmental sustainability (Tully and Winer, 2014).

Social sustainability is an abstract concept that concerns the human dimension of sustainability and represents various issues (Åhman, 2013) that depend on context and time (Boström, 2012). Therefore, studies on social sustainability of e.g. animal husbandry systems commonly use specific issues (i.e. relevant and important aspects of social sustainability) to operationalize this concept (Meul et al., 2008, Mollenhorst and De Boer, 2004, Van Calker et al., 2005). Examples of such social sustainability issues are working conditions, animal welfare, professional pride, and landscape management (Meul et al., 2008, Mollenhorst and De Boer, 2004, Van Calker et al., 2005).

Operationalization of social sustainability issues based on stakeholder perspectives is the first step in the framework used by several authors (e.g. Meul et al., 2008, Mollenhorst and De Boer, 2004, Van Calker et al., 2005) to assess social sustainability. The second step in this framework is to develop and quantify indicators that measure the state of these social sustainability issues. The information that these indicators provide can additionally be interpreted using performance reference points (Bell and Morse, 1999, UNEP/SETAC, 2009). This framework has been applied in sustainability assessment of animal husbandry systems, but not yet in social sustainability assessment of capture fisheries.

\section{Capture fisheries in the northeast Atlantic}

The northeast Atlantic (Figure 1.1) is the world's third most important fishing area in terms of volumes landed (FAO, 2014c) and includes many of Europe's seas, such as the Barents Sea, the North Sea and the Bay of Biscay (FAO, 2008). Fishers from 21 countries operate in this area and catch over 50 species of fish in volumes over 10,000 tonnes, of which herring, cod and mackerel are the main species (Statistics office Iceland, 2015). 


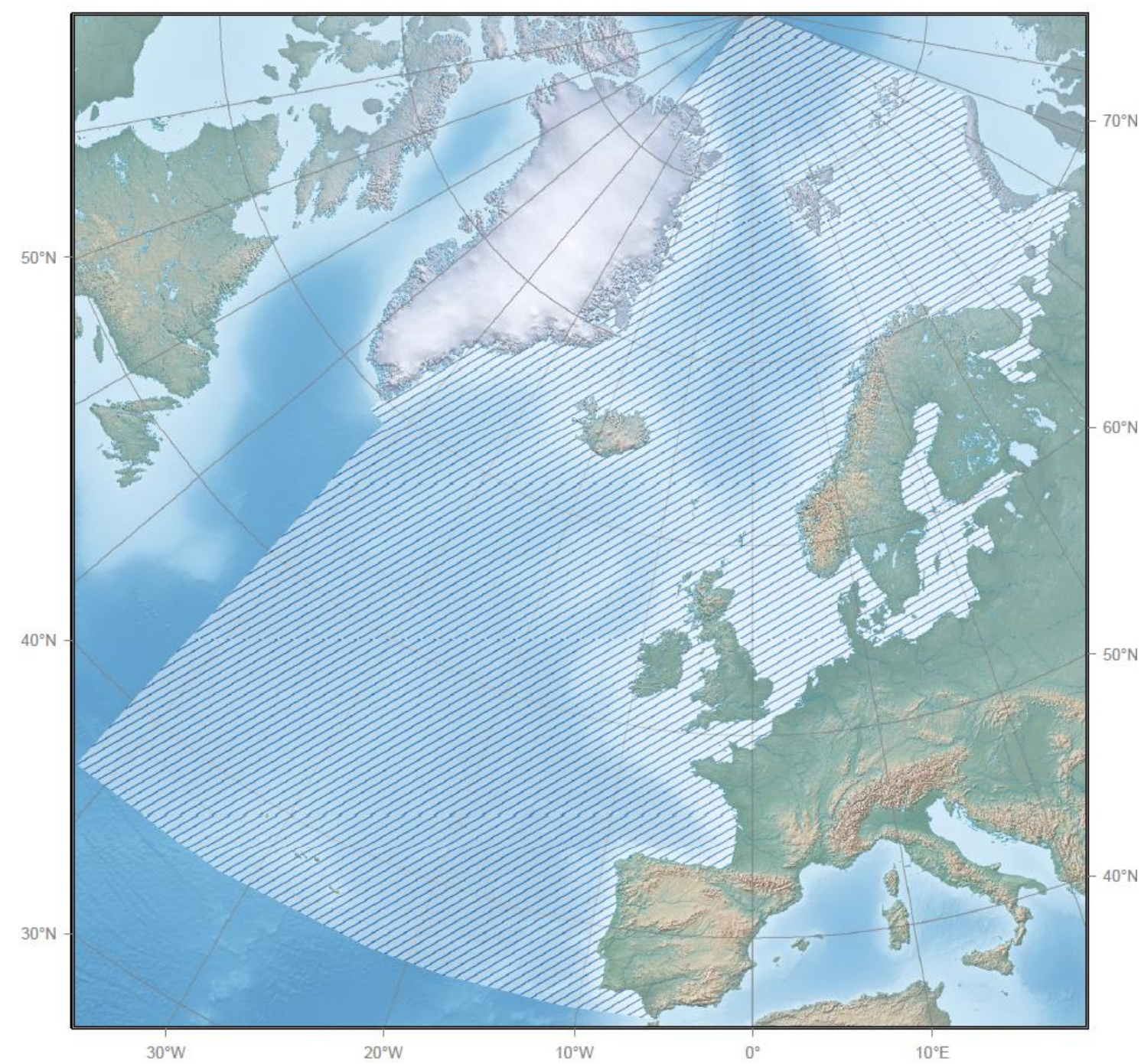

Figure 1.1: The Northeast Atlantic (Figure is based on spatial information from the International Council for the Exploration of the Sea (ICES, 2016))

Fishers in the northeast Atlantic not only face increased competition among themselves, but also fear the additional competition from aquaculture due to the growing supply of fish from aquaculture (FAO, 2010, FAO, 2014d). These fishers are concerned that consumers will substitute fish originating from capture fisheries with cheaper fish originating from aquaculture, which would cause prices to drop and profitability to decline further. Norwegian and Icelandic fishing companies targeting whitefish (e.g. cod, haddock, saithe), therefore, initiated the EU-project 'WhiteFish' with the aim of documenting their (social) sustainability impacts in order to gain a competitive advantage in markets for whitefish. 


\section{Social sustainability of whitefish from the northeast Atlantic}

Thus far, one study focused on social sustainability of whitefish from the northeast Atlantic. This study dealt with Norwegian cod fisheries and included the social sustainability issues accident risk and employment (Utne, 2007). Although Utne (2007) recognizes that stakeholders can offer various perspectives on social sustainability, stakeholders were not consulted on relevant issues. Hence, issue identification based on stakeholder perspectives likely results in more or other social sustainability issues relevant for northeast Atlantic fisheries that are currently not known.

The social sustainability issues that are at stake in a given case provide an operationalization of social sustainability, but these issues in themselves do not provide information on the state of social sustainability. Such information is provided by indicators, but no indicators currently exist to assess social sustainability of whitefish from the northeast Atlantic other than Utne's (2007) indicators for accident risk and employment in Norwegian cod fisheries.

Fishing companies could use the information from a social sustainability assessment to differentiate their products and to improve their social sustainability. However, consumer interest is important or even essential for any of these applications of a social sustainability assessment. For example, product differentiation based on social sustainability can only occur when consumers are interested in and value such a product characteristic (Chamberlin, 1933). Moreover, consumer interest in social sustainability issues can help prioritize improvement options and identify potential reputational risks such as the use of child labour. As mentioned earlier, results from Tully and Winer (2014) on general willingness to pay for sustainability issues of products indicate that consumers are more interested in social than in environmental sustainability. Results from McClenachan et al. (2016) on willingness to pay in the USA for sustainability labels of fish, however, indicate the opposite, i.e. consumers are more interested in environmental than in social sustainability. Hence, the level of consumer interest in social sustainability issues of whitefish from the northeast Atlantic is not clear.

Animal welfare is considered an important social sustainability issue in animal husbandry systems (Broom, 2010, Napolitano et al., 2010) that is partly driven by consumer interest in this topic (Gracia et al., 2011, Nocella et al., 2010, Van Loo et al., 2014). This consumer interest in animal welfare could extend from animal husbandry to capture fisheries. In capture fisheries, however, no overview is available of the current knowledge on fish welfare (Huntingford et al., 2006). Such knowledge on the effects of the capture process in capture fisheries on fish welfare is essential for debates on fish welfare and for fishers who want to reduce 
their impact on fish welfare (Metcalfe, 2009). A lack of knowledge, combined with consumer interest in fish welfare, could pose a reputational risk to fishers.

\section{Objective and outline of the thesis}

The objective of this thesis is to understand social sustainability of capture fisheries. Given that social sustainability is context-specific, this thesis focuses specifically on capture fisheries in the northeast Atlantic.

The first step towards understanding social sustainability of capture fisheries in the northeast Atlantic is to understand what social sustainability in this context is about. In Chapter 2, therefore, relevant and important social sustainability issues for cod and haddock fisheries in the northeast Atlantic are determined based on input from a heterogeneous group of stakeholders.

The next step is to assess social sustainability of capture fisheries in the northeast Atlantic by determining the state of the relevant and important social sustainability issues. In Chapter 3, therefore, a method is developed that consists of indicators and rubrics (i.e. categories that articulate levels of performance) for the issues of Chapter 2 to assess social sustainability of capture fisheries. This method is subsequently applied to a Norwegian trawler that targets cod and haddock in the northeast Atlantic to determine whether this method provides vessel-specific information on social sustainability that can be used to identify potential improvement options.

Companies that want to improve their social sustainability, gain a competitive advantage or identify potential reputational risks need to understand consumer preferences for social sustainability issues. In chapter 4 , therefore, a consumer survey is developed to determine consumer preferences for social sustainability issues of whitefish from the northeast Atlantic. In addition, consumer characteristics are investigated to explore what explains these preferences.

The social sustainability issue that is most likely to form a reputational risk for fishing companies is fish welfare. In Chapter 5 , therefore, a systematic literature review is performed to determine what is known about the effects of the capture process in capture fisheries on fish welfare.

Finally, in Chapter 6, the understanding of social sustainability of capture fisheries in the northeast Atlantic that arises in this thesis is discussed. In addition, recommendations are provided for the fishing sector, researchers, certification organizations and policy-makers. 


Social sustainability of cod and haddock fisheries in the northeast Atlantic: what issues are important?

L.J.L. Veldhuizen, P.B.M. Berentsen, E.A.M. Bokkers, I.J.M. de Boer Journal of Cleaner Production 94 (2015) 76-85 


\begin{abstract}
Research on the sustainability of capture fisheries has focused more on environmental and economic sustainability than on social sustainability. To assess social sustainability, first relevant and important social sustainability issues need to be identified. The objective of this study was to identify relevant social sustainability issues for cod and haddock fisheries in the northeast Atlantic and to determine the importance of these issues based on stakeholder input. A heterogeneous group of stakeholders was invited to take part in two consecutive surveys on social sustainability issues. The first survey $(n=41)$ resulted in a long list of 27 relevant social sustainability issues, including six issues that were not identified in previous studies and that address aspects of fish welfare, employees' training and education opportunities, and employees' time off from work. The second survey $(n=51)$ resulted in a ranking of the social sustainability issues in order of importance. The most important issues are worker safety, product freshness and companies' salary levels. In general, social sustainability issues concerning working conditions, employees' job fulfilment and fish welfare are seen as more important than other social sustainability issues. A main discussion point concerns the relation between the importance of a social sustainability issue on the one hand and the type of need that the issue relates to and the state of the issue on the other hand. From the study it can be concluded that the relative importance of social sustainability issues differs per stakeholder group depending on the relation between the stakeholder group and each particular issue. This demonstrates the importance of consulting different stakeholder groups in future studies on social sustainability in order to get a balanced view on the importance of social sustainability issues. Results on the relevance and importance of social sustainability issues for cod and haddock fisheries in the northeast Atlantic enable the fishing industry and policy-makers to direct improvement efforts towards the more important issues.
\end{abstract}




\section{Introduction}

Since the release of 'Our Common Future' (Brundtland, 1987), sustainability assessment of food production has been an important research domain. Sustainability assessment concerns environmental, economic and social sustainability, as well as the inter-linkages between these pillars of sustainability (Lozano and Huisingh, 2011). Methodologies for environmental sustainability assessment (e.g. life cycle assessment), however, are far better developed than methodologies for economic or social sustainability assessment (Finkbeiner et al., 2010, Kloepffer, 2008, Martínez-Blanco et al., 2014).

Environmental sustainability assessment of capture fisheries (i.e. the sum of all fishing activities on wild fish; FAO, 1997) has attracted considerable scientific attention (e.g. Pelletier et al., 2007, Thrane, 2006, Ziegler et al., 2003). Research has focused on traditional impact categories such as global warming potential and eutrophication (e.g. Ellingsen and Aanondsen, 2006, Vázquez-Rowe et al., 2010, Ziegler et al., 2011), and biological impact categories such as overfishing (depletion of natural resources), discarding and by-catch (e.g. Emanuelsson et al., 2014, Hornborg et al., 2013, Langlois et al., 2014). Some of these impacts have been addressed by policy responses such as total allowable catch, individual transferable quotas, marine protected areas and effort restrictions (e.g. Chu, 2009, Côté et al., 2001, Karagiannakos, 1996). Economic sustainability assessment of capture fisheries has received little scientific attention, as evidenced by the limited number of publications on this topic (i.e. Glaser and Diele, 2004, Pelletier et al., 2009, Utne, 2007, Whitmarsh et al., 2003). Since social sustainability assessment has received even less scientific attention (Glaser and Diele, 2004, Utne, 2007), social sustainability is the focal point of this study.

A social sustainability assessment should start with a description of the (problem) situation (Mollenhorst and De Boer, 2004, Van Calker et al., 2005). The situation considered in this study concerns a group of cod and haddock fishing companies in the northeast Atlantic that initiated and participated in the EU-project 'WhiteFish'. The study described in this paper formed part of this EU-project. These Norwegian and Icelandic fishing companies employ trawlers, longliners, auto-liners, and Danish seiners in coastal and offshore fisheries to produce fresh and frozen fillets. The second step in social sustainability assessment is identification of social sustainability issues (SSIs) (Mollenhorst and De Boer, 2004, Van Calker et al., 2005), i.e. aspects of social sustainability that should be considered in an assessment. In general, SSIs have been identified in the context of various initiatives (Parris and Kates, 2003), such as social life cycle assessment (Benoit-Norris et al., 2011) and the global reporting initiative (Parris and Kates, 2003). There is no consensus, however, on the set of issues that should be

\footnotetext{
${ }^{1}$ WhiteFish is a research project on the automated and differentiated calculation of sustainability impact for cod and haddock products that ran from January 2012 to December 2014. Visit http://www.whitefishproject.org/ for more information on this project.
} 
addressed in social sustainability assessments (Hutchins and Sutherland, 2008, Parris and Kates, 2003). Since it is not practicable nor desirable to consider all SSIs identified (Mitchell et al., 1995), social sustainability assessment should concentrate on the most important issues.

The importance of SSIs depends on the cultural, political, social and economic context of the situation considered (Benoît-Norris et al., 2011, Glaser and Diele, 2004). Therefore, stakeholder input should be used to identify SSIs for cod and haddock fisheries in the northeast Atlantic. Stakeholders are those individuals or organizations that can affect or are affected (Freeman, 1984) by the activities of the cod and haddock fishing companies in the northeast Atlantic. This approach has been used successfully to identify SSIs for egg production systems (Mollenhorst and De Boer, 2004), dairy farming systems (Meul et al., 2008, Van Calker et al., 2005) and aquaculture (Caffey et al., 2000), but not for capture fisheries.

So far, SSIs for capture fisheries have been identified by FAO (1999), Utne (2007) and Kruse et al. (2009). FAO (1999), however, only provided eight examples of SSIs such as employment and income, recognizing that the set of issues that should be addressed in an assessment depends on the context of the situation considered. Utne (2007) identified accident risk and employment as important SSIs for Norwegian cod fisheries, though she did not specify the method used to identify issues. These two SSIs cannot adequately address social sustainability of Norwegian cod fisheries, since social sustainability concerns a diversity of stakeholders with different interests (Caffey et al., 2000, Van Calker et al., 2005). Kruse et al. (2009) identified 11 SSIs such as fair wage and employment benefits as important issues for salmon production systems (i.e. capture fisheries and aquaculture). The method used to identify SSIs was a combined top-down and bottom-up approach, using international conventions while taking into account industry specific impacts. As SSIs identified by Kruse et al. (2009) covered only industry specific impacts, it is unlikely that these issues will also cover interests of other stakeholders.

The objective of this study is to identify relevant SSIs for cod and haddock fisheries in the northeast Atlantic and to determine the importance of these issues based on stakeholder input. Since social sustainability concerns a diversity of stakeholders with different interests, a heterogeneous group of stakeholders was consulted in order to get a representative set of issues (Caffey et al., 2000, Meul et al., 2008, Mollenhorst and De Boer, 2004, Van Calker et al., 2005).

\section{Methods}

Stakeholders were invited to take part in two consecutive surveys on SSIs. The first survey served to compile a long list of relevant SSIs. The second survey 
served to determine the importance of each issue on the long list of relevant issues that resulted from the first survey. Similar to Caffey et al. (2000) and Van Calker et al. (2005), surveys were chosen rather than focus groups as in Mollenhorst and De Boer (2004), because surveys allow more structured data collection and because the geographical scope of the study precluded the use of focus groups. Surveys, however, do not allow for interaction between respondents.

\subsection{Stakeholder identification}

Stakeholders for the two surveys were identified from the value chain characterization. This value chain characterization (Table 2.1) starts with the five fishing companies participating in the EU-project. At this stage of the value chain, four different types of vessels are employed in Norway's offshore waters and in Iceland's coastal and offshore waters. Catch of these fishing vessels is processed into fillets in China, Iceland and the UK, either by separate processing companies that purchase catch in auction markets or by the same companies that own these vessels. Processed fillets are then sold in Iceland, the UK and the rest of Europe.

Owners and employees of these fishing companies were identified as stakeholders and regarded as separate stakeholders because the interests of owners and employees can differ. Other value chain actors, i.e. processing companies (both company owners and employees), merchants and retailers were identified as stakeholders because their mutual dependency in the value chain means that they all can affect and are affected by the activities of the fishing companies. Fishing company associations, labour unions, processing company associations and consumer organizations were identified as stakeholders because they represent the interests of different value chain actors, i.e. fishing companies, employees, processing companies and consumers, respectively. Municipalities where the vessels are harboured were identified as stakeholders because fishing companies' decisions can affect these communities. Governments' fisheries departments were identified as stakeholders because any change in policy can affect the fishing companies' activities. Certifiers of stock sustainability were identified as stakeholders because future assessments of stock sustainability may be extended to include social sustainability. Organizations promoting the sector were identified as stakeholders because social sustainability might become another factor that these organizations can use to promote the sector. Finally, a fish welfare organization was identified as a stakeholder because concerns for fish welfare (Chandroo et al., 2004a, Huntingford et al., 2006, Robb and Kestin, 2002) might affect the fishing companies in the near future.

Based on this stakeholder identification, seven distinct stakeholder groups were defined: fishing companies, fishing company employees, suppliers and processors, sales organizations, consumers, policy-makers, and fish welfare organizations. These stakeholder groups encompass multiple stakeholders who 


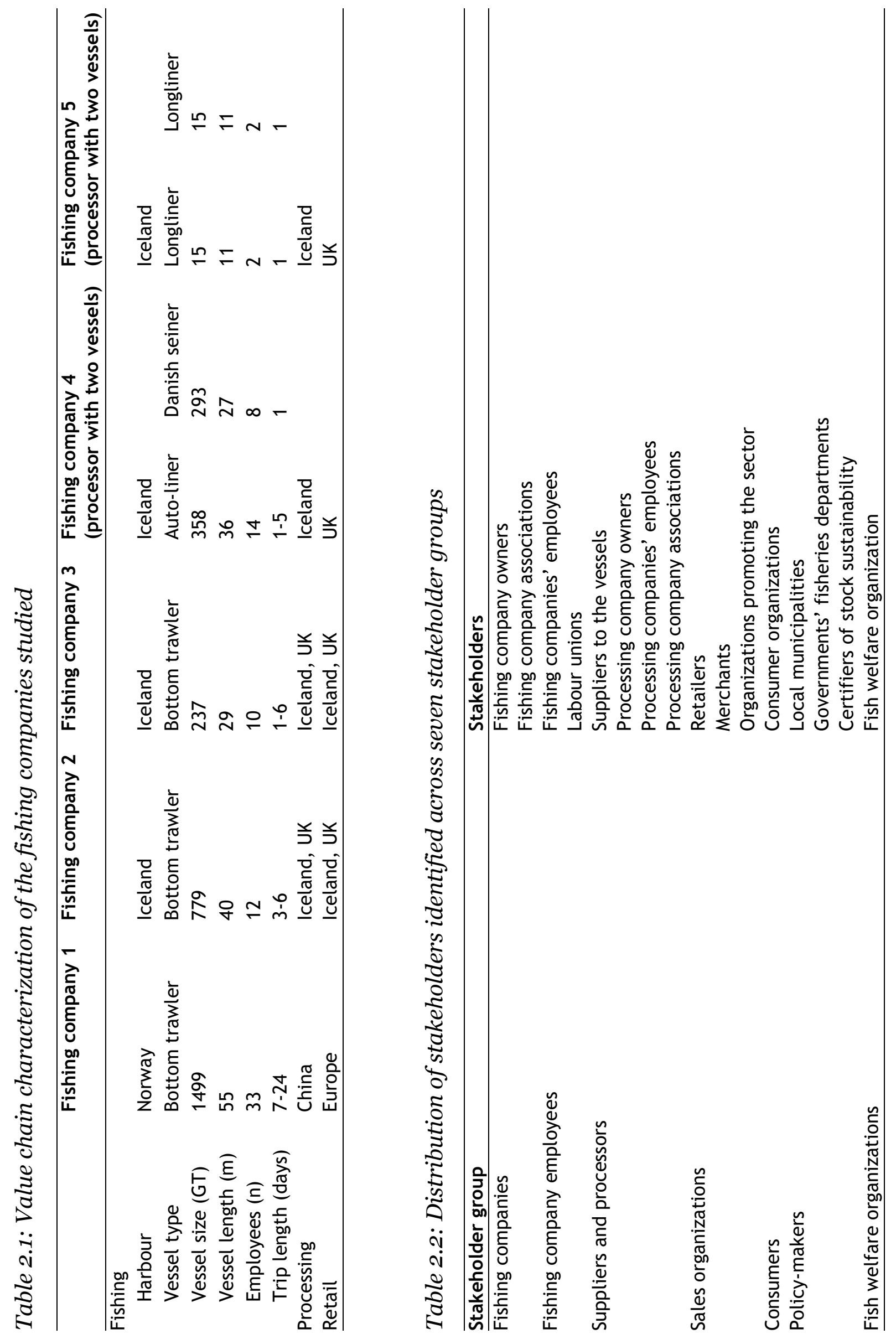




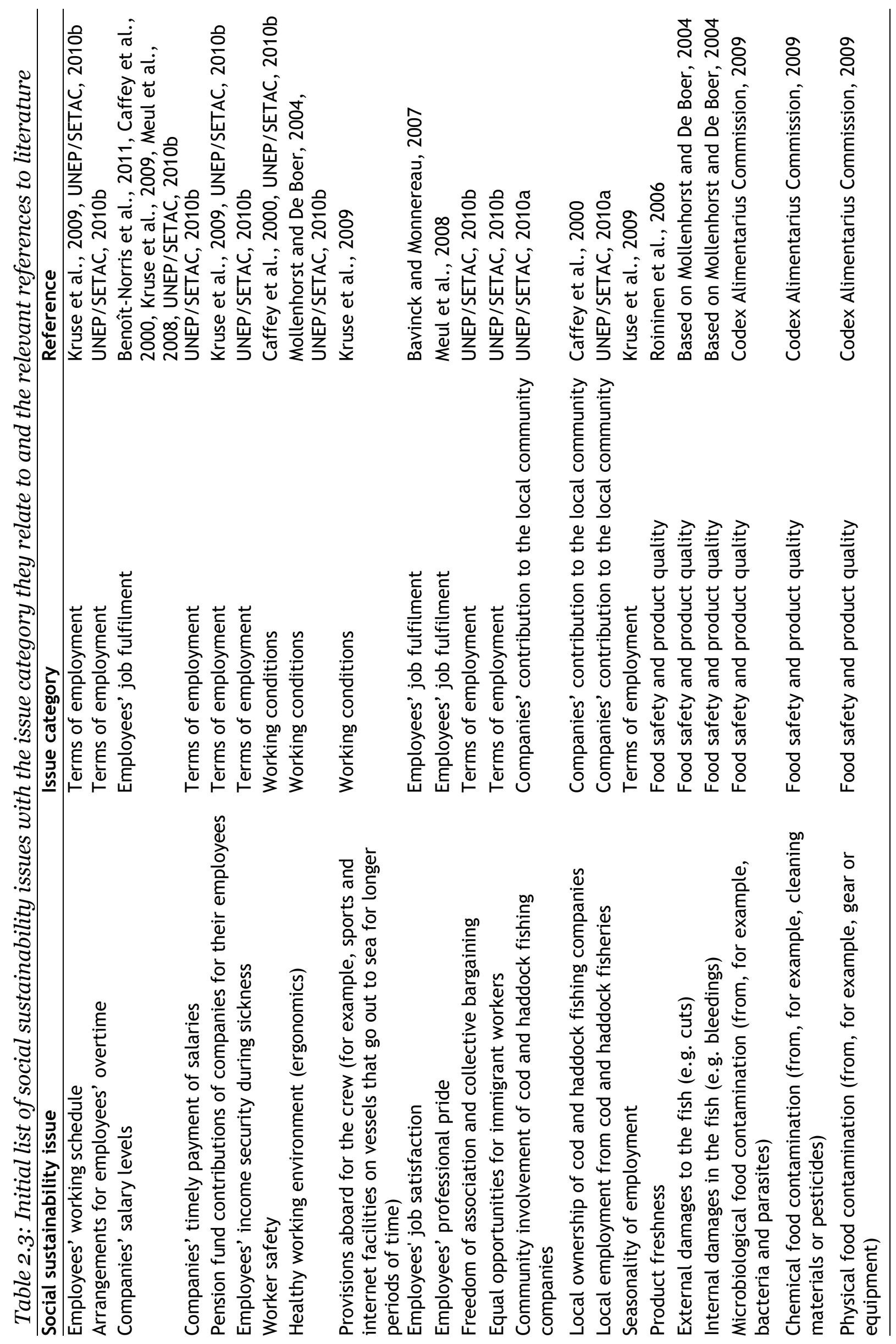


share similar interests. Table 2.2 presents the distribution of stakeholders across these seven stakeholder groups.

\subsection{Survey 1}

The first survey focused on the relevance of SSIs for cod and haddock fisheries in the northeast Atlantic and served to compile a long list of relevant issues as input for the second survey. This first survey started with a short introduction on social sustainability and on the survey. Then, an initial list with possible SSIs was provided (Table 2.3). These issues were extracted from studies that include social sustainability in capture fisheries and outside the area of capture fisheries. SSIs on this initial list can be classified into five issue categories that encompass issues concerning similar aspects in relation to employees, the company or the product (Table 2.3). Issues relating to employees can be classified into the issue categories concerning working conditions, terms of employment, or employees' job fulfilment. Issues relating to the company can be classified into the issue category concerning companies' contribution to the local community. Issues relating to the product can be classified into the issue category concerning food safety and product quality.

In the first survey, respondents gave input on SSIs by 1) indicating whether each issue on the initial list is relevant or not for cod and haddock fisheries in the northeast Atlantic and 2) adding new issues in case of deficiencies. The survey ended with questions on respondents' occupation, an opportunity for respondents to comment on the survey, and an announcement of and an invitation to the second survey.

This first survey was translated from English to Icelandic and Norwegian. To avoid erroneous translations, the survey was discussed with translators before it was translated. Moreover, the translations were checked by translating them back to English using translating software. The paper version of this survey was introduced and distributed to those stakeholders who were present at a fishing industry meeting in March, 2013 in Reykjavik, Iceland. Fishing company associations present at that meeting were asked to distribute the survey among their members to increase the number of fishing companies reached. Paper versions of the survey were distributed among fishing companies in Iceland and Norway. Owners of these fishing companies were asked to fill out the survey and to distribute copies among their employees. An online version of the survey was used for all other stakeholders in Iceland, Norway and the UK who were invited via e-mail to take part in the survey.

The goal of the first survey was to compile a long list of relevant SSIs as input for the second survey. When at least one respondent indicated that an issue on the initial list of SSIs was relevant, then this issue was added to the long list. If any stakeholder mentioned a new issue, this issue was added to the long list as long as 
the issue was clear, concerned social sustainability and did not overlap with any of the issues on the initial list.

\subsection{Survey 2}

The second survey focused on the intrinsic and relative importance of each SSI on the long list of issues. Intrinsic importance relates to the importance of each issue in itself, whereas relative importance relates to the importance of each issue in relation to the other issues.

The second survey started with a short introduction on social sustainability and on the survey. Then, respondents were asked to indicate how important (i.e. important, neutral, unimportant, don't know) they considered each SSI on the long list of issues. The order in which these issues were presented was randomized to ensure that respondents focused on intrinsic importance only. Respondents were reminded explicitly that even if an SSI was arranged very well in cod and haddock fisheries in the northeast Atlantic, this did not necessarily mean that the issue as such was unimportant. In addition, respondents were instructed to list an SSI as unimportant in case they really thought that the issue was not relevant, since there was no full agreement on the relevance of SSIs in the first survey. After that, respondents were asked to put the five SSIs they found most important in order of importance.

For most SSIs, the direction leading to higher social sustainability is evident. More job satisfaction, for example, is preferred over less job satisfaction. The desired direction, however, was not evident for all SSIs. Seasonality of employment, for example, means that employees do not have a steady income year-round, but also that they can spend more time with their families, so seasonality of employment might be judged negative by one stakeholder and positive by another stakeholder. Therefore, the survey additionally contained 14 statements (Appendix 2.1) to determine the desired direction of SSIs for which this was not evident. For each statement, respondents were asked to indicate whether they agreed with the statement, disagreed, were neutral or did not know. The survey ended with two questions on respondents' occupation to determine their stakeholder affiliation.

This survey was translated from English to Icelandic and Norwegian following the same procedure used for the first survey, and distributed from October to November 2013. Paper versions of the second survey were sent to fishing companies in Iceland and Norway. Owners of these fishing companies were asked to fill out the survey and to distribute copies among their employees. In addition, paper versions of the second survey were distributed via contact persons to certain Icelandic and Norwegian stakeholders of cod and haddock fisheries in the northeast Atlantic. An online version of the survey was used for all other 
stakeholders in Iceland, Norway and the UK who were invited via e-mail to take part in the survey.

The analysis of the second survey focused on responses per stakeholder group in order to correct for unequal numbers of responses between stakeholder groups. The analysis of the intrinsic importance of SSIs was based on the proportion of responses (i.e. important, neutral, unimportant and don't know) in each stakeholder group $\left(P_{i j k}\right)$. These proportions were used to calculate the overall proportion of responses $\bar{P}_{i j}$ for issue $i$ per response category $j$ as follows:

$$
\bar{P}_{i j}=\frac{\sum_{k=1}^{k} P_{i j k}}{n_{k}},
$$

where $P_{i j k}$ is the proportion of responses for issue $i$ per response category $j$ in stakeholder group $k$, and $n_{k}$ is the total number of stakeholder groups $k$ distinguished.

The analysis of the relative importance of SSIs was based on respondents' rankings of the five most important issues in order of importance. For each respondent, five SSIs were scored 1 to 5 points, where 1 point was assigned to the issue that the respondent ranked lowest and 5 points were assigned to the issue that the respondent ranked highest. These individual scores were used to calculate the average score $\bar{S}_{i k}$ for issue $i$ and stakeholder group $k$ as follows:

$$
\bar{S}_{i k}=\frac{\sum_{l=1}^{l} s_{i l k}}{n_{l k}}
$$

where $S_{i l k}$ is the score for issue $i$ of respondent $l$ in stakeholder group $k$ and $n_{l k}$ is the number of respondents $l$ in stakeholder group $k$. Then, the overall score $\bar{S}_{i}$ for issue $i$ was calculated as follows:

$$
\bar{S}_{i}=\frac{\sum_{k=1}^{k} \bar{S}_{i k}}{n_{k}}
$$

where $\bar{S}_{i k}$ is the average score for issue $i$ and stakeholder group $k$, and $n_{k}$ is the total number of stakeholder groups $k$. To gain more insight into the relative importance of SSIs, the analysis additionally focused on the relative importance of the issue categories concerning working conditions, terms of employment, employees' job fulfilment, companies' contribution to the local community, food safety and product quality, and fish welfare. The average score $\bar{S}_{g k}$ for issue category $g$ and stakeholder group $k$ was calculated as follows:

$$
\bar{S}_{g k}=\frac{\sum_{i=1}^{i} \bar{s}_{i g k}}{n_{i g}},
$$

where $\bar{S}_{i g k}$ is the average score for issue $i$ in issue category $g$ for stakeholder group $k$ and $n_{i g}$ is the number of issues $i$ in issue category $g$. Then, the overall score $\bar{S}_{g}$ for issue category $g$ was calculated as follows:

$$
\bar{S}_{g}=\frac{\sum_{k=1}^{k} \bar{S}_{g k}}{n_{k}},
$$


where $\bar{S}_{g k}$ is the average score for issue category $g$ and stakeholder group $k$, and $n_{k}$ is the total number of stakeholder groups $k$.

The analysis of the statements on the desired direction of certain SSIs was based on the proportion of responses (i.e. agree, neutral, disagree and don't know) in each stakeholder group $\left(P_{s j k}\right)$. These proportions were used to calculate the overall proportion of responses $\bar{P}_{s j}$ for statement $s$ per response category $j$ as follows:

$$
\bar{P}_{s j}=\frac{\sum_{k=1}^{k} P_{s j k}}{n_{k}},
$$

where $P_{s j k}$ is the proportion of responses for statement $s$ per response category $j$ in stakeholder group $k$, and $n_{k}$ is the total number of stakeholder groups $k$ distinguished.

\section{Results}

In this section, results from the first stakeholder survey are presented first, followed by results from the second stakeholder survey.

\subsection{Survey 1}

In total, 41 surveys were returned from April to August 2013 via mail, e-mail and online. Table 2.4 reports the targeted sample and the number of responses per stakeholder group for the first survey. The targeted sample refers to the numbers of respondents that were intended to receive the survey. This sample comprises the fishing and processing companies participating in this research, their employees, and other relevant stakeholders. Because of the ways the survey was distributed, it cannot be stated with certainty that the actual sample equalled the targeted sample. Fishing companies, for example, were asked to distribute the survey to their employees, which means that the exact number of employees who received the survey is not known. Moreover, multiple entries per organization were allowed, which means that the exact number of individuals within these organizations who received the survey is not known either. As a result, it is not possible to determine response rates for the survey.

Each SSI on the initial list was selected by at least 5 and at most 33 respondents. This indicated that all issues on the initial list had to be included in the long list of SSIs for the second survey.

In addition, seven respondents suggested 14 new issues. Six of these issues were added to the long list of SSIs, namely: fish welfare during capture, humane slaughter of fish, opportunities for life-long learning, on-the-job training, employees' travel time from home to work and back, and time at home. The remaining eight issues suggested were not added to the long list because they did 


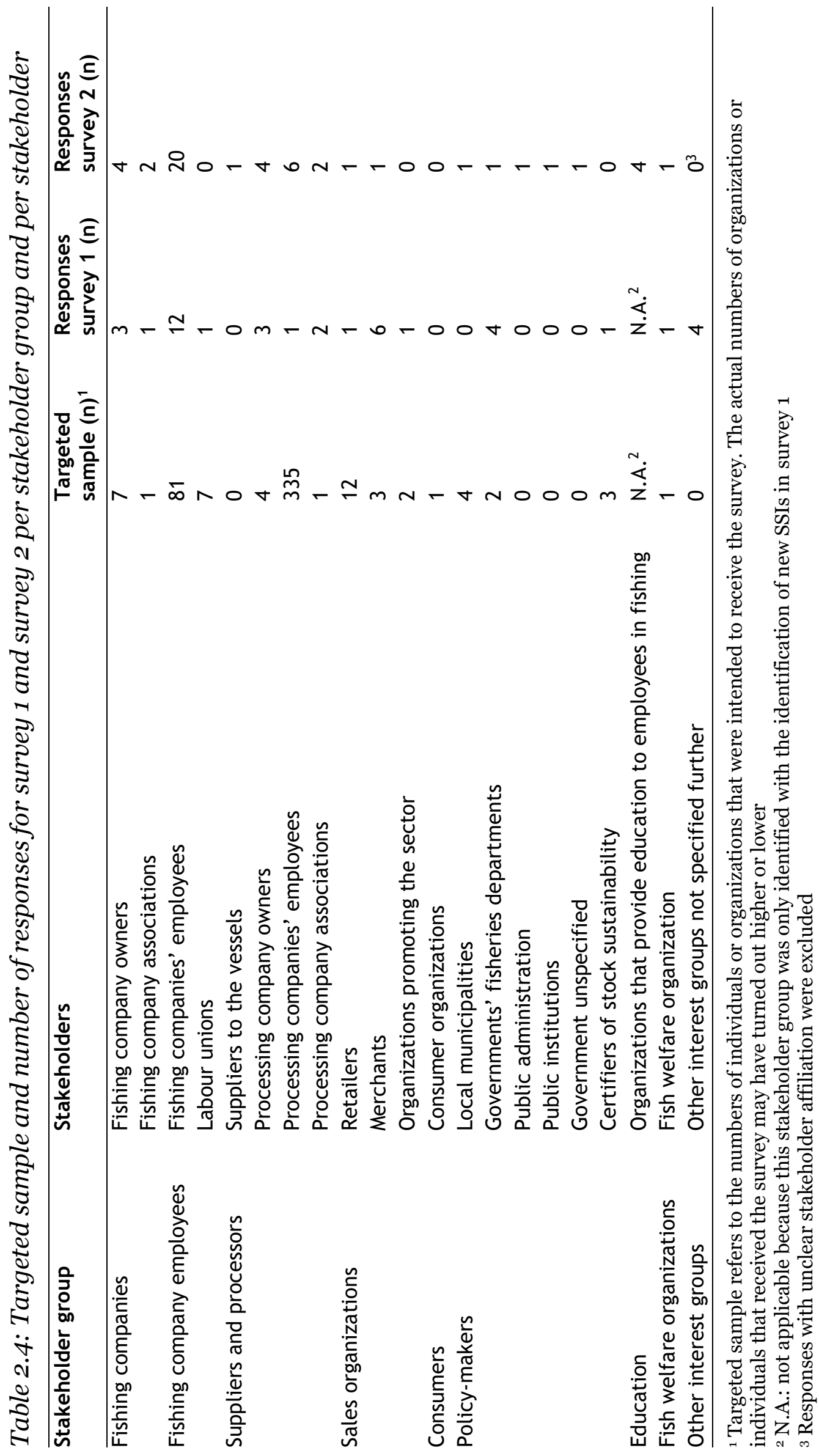


not refer to social but to economic sustainability (four issues), they highly overlapped with other issues (one issue), or they were not clear and not explained further by the respondents (three issues).

Even though the SSIs internal damages in the fish and external damages to the fish were found to be relevant in the first survey, they were excluded from the long list of SSIs for the second survey. The added SSI fish welfare during capture implicitly included internal and external damages to fish. As such, the first survey resulted in a long list of 27 relevant SSIs that was used as input for the second survey.

One stakeholder was added to the initial stakeholder identification (Table 2.2) based on results from the first survey. The newly identified SSIs opportunities for life-long learning and on-the-job training made clear that organizations providing education to employees in fishing companies had to be added to the list of stakeholders consulted for the second survey (Table 2.4).

\subsection{Survey 2}

In total, 66 surveys were returned from October to December 2013 via e-mail and online. Seven surveys were excluded because they were incomplete and no stakeholder affiliation was entered. In addition, eight surveys were excluded because stakeholder affiliation was either unclear or irrelevant. Unclear stakeholder affiliation concerned, for example, respondents who ticked stakeholder affiliation other and specified this only as fisheries or stakeholder association. Irrelevant stakeholder affiliation concerned, for example, respondents from universities who did not fit in the definition of a stakeholder as an organization or individual that can affect or is affected by the activities of the fishing companies concerned. Table 2.4 reports the targeted sample and the number of responses per stakeholder group for the second survey. Responses from employees in fishing companies represent the largest share of responses. As for the first survey, the response rate for this survey could not be determined because the actual sample size was not known.

The analysis of the second survey first focused on the intrinsic importance of each SSI on the long list of issues. Figure 2.1 presents the proportion of responses $\left(\bar{P}_{i j}\right)$ for these issues, presented per issue category. The three issues with the highest proportion of responses for important are: healthy working environment, worker safety and physical food contamination. The three issues with the lowest proportion of responses for important are: seasonality of employment, local employment from cod and haddock fisheries, and arrangements for employees' overtime. The three issues with the highest proportion of responses for unimportant are: humane slaughter of fish, seasonality of employment and fish welfare during capture. 


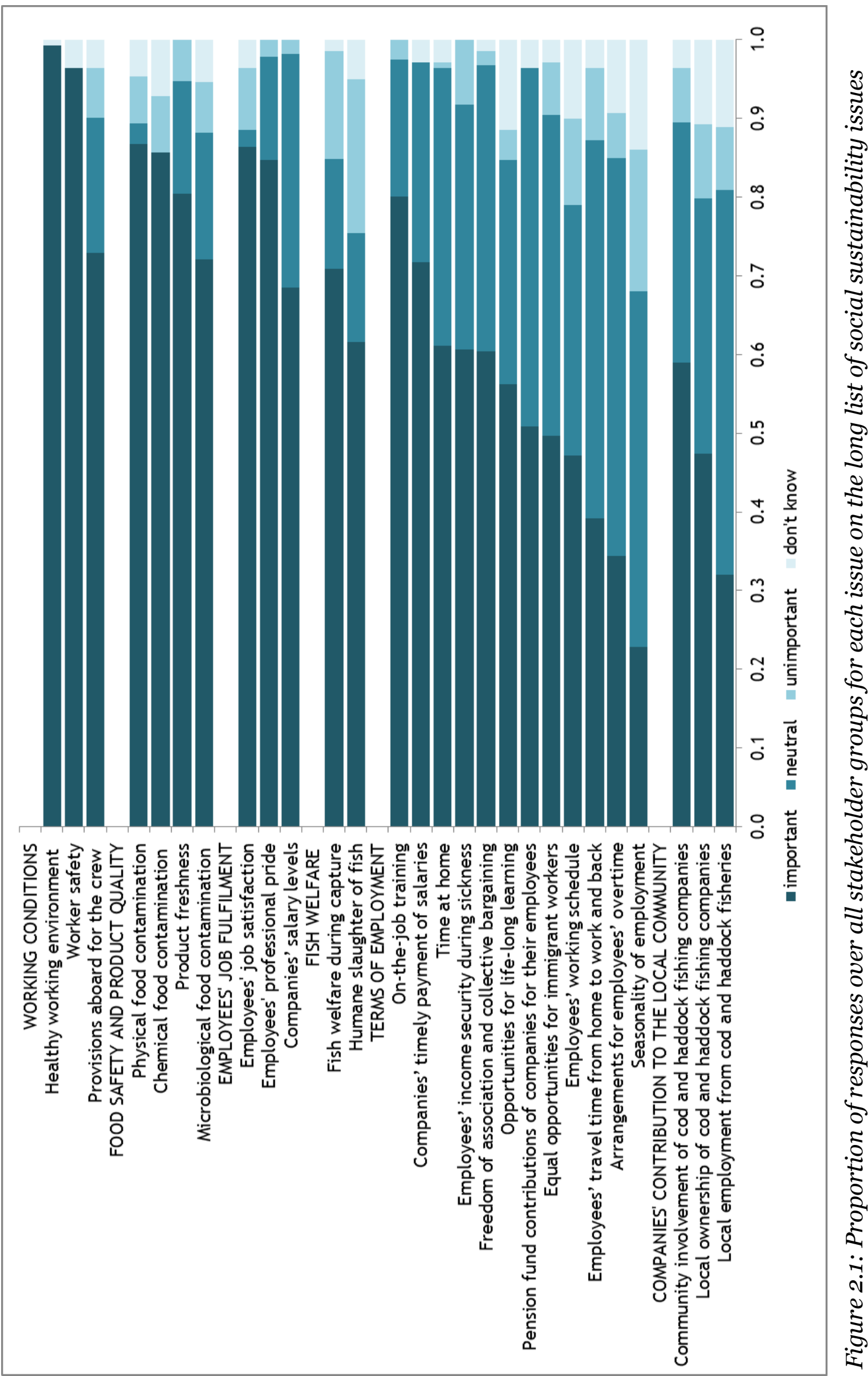


Table 2.5: Overall scores and ranks indicating the relative importance of social sustainability issues presented per issue category

\begin{tabular}{|c|c|c|}
\hline Issues per issue category & $\begin{array}{l}\text { Overall } \\
\text { score }\end{array}$ & Rank \\
\hline \multicolumn{3}{|l|}{ Working conditions } \\
\hline Worker safety & 1.99 & 1 \\
\hline Healthy working environment & 1.20 & 4 \\
\hline Provisions aboard for the crew & 0.28 & 16 \\
\hline Average for issue category working conditions & 1.16 & \\
\hline \multicolumn{3}{|l|}{ Employees' job fulfilment } \\
\hline Companies' salary levels & 1.34 & 3 \\
\hline Employees' job satisfaction & 0.86 & 6 \\
\hline Employees' professional pride & 0.85 & 7 \\
\hline Average for issue category employees' job fulfilment & 1.02 & \\
\hline \multicolumn{3}{|l|}{ Fish welfare } \\
\hline Fish welfare during capture & 1.03 & 5 \\
\hline Humane slaughter of fish & 0.84 & 8 \\
\hline Average for issue category fish welfare & 0.93 & \\
\hline \multicolumn{3}{|l|}{ Food safety and product quality } \\
\hline Product freshness & 1.46 & 2 \\
\hline Physical food contamination & 0.55 & 11 \\
\hline Chemical food contamination & 0.37 & 15 \\
\hline Microbiological food contamination & 0.17 & 20 \\
\hline Average for issue category food safety and product quality & 0.64 & \\
\hline \multicolumn{3}{|l|}{ Companies' contribution to the local community } \\
\hline Community involvement of cod and haddock fishing companies & 0.75 & 9 \\
\hline Local ownership of cod and haddock fishing companies & 0.69 & 10 \\
\hline Local employment from cod and haddock fisheries & 0.14 & 21 \\
\hline $\begin{array}{l}\text { Average for issue category companies' contribution to the local } \\
\text { community }\end{array}$ & 0.53 & \\
\hline \multicolumn{3}{|l|}{ Terms of employment } \\
\hline Companies' timely payment of salaries & 0.53 & 12 \\
\hline On-the-job training & 0.49 & 13 \\
\hline Opportunities for life-long learning & 0.48 & 14 \\
\hline Employees' income security during sickness & 0.24 & 17 \\
\hline Pension fund contributions of companies for their employees & 0.24 & 18 \\
\hline Time at home & 0.19 & 19 \\
\hline Employees' travel time from home to work and back & 0.12 & 22 \\
\hline Freedom of association and collective bargaining & 0.06 & 23 \\
\hline Employees' working schedule & 0.06 & 24 \\
\hline Equal opportunities for immigrant workers & 0.02 & 25 \\
\hline Seasonality of employment & - & 26 \\
\hline Arrangements for employees' overtime & - & 26 \\
\hline Average for issue category terms of employment & 0.24 & \\
\hline
\end{tabular}

The analysis of the second survey then focused on the relative importance of the SSIs on the long list. Table 2.5 presents the relative importance of SSIs in terms of overall scores $\left(\bar{S}_{i}\right)$ and consequential ranks, presented per issue category $\left(\bar{S}_{g}\right)$ and ordered according to overall scores per issue category and per issue. The three most important SSIs are worker safety, product freshness and companies' salary levels, as indicated by the highest overall scores for these issues. The three least important SSIs are seasonality of employment and arrangements for employees' overtime, which were not ranked by any respondent, and equal opportunities for 

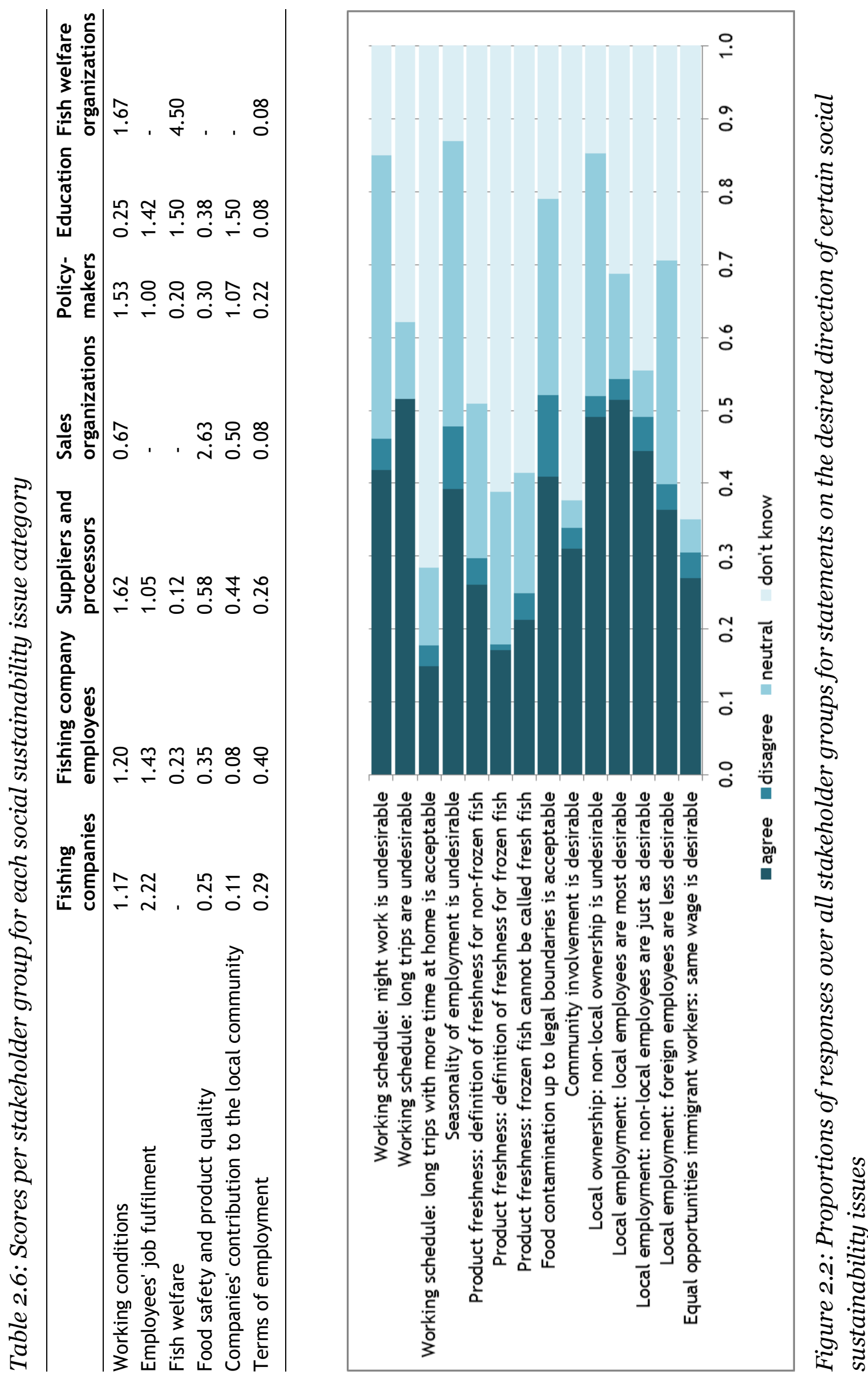
immigrant workers.

The analysis of the second survey then zoomed in on the relative importance of the issue categories per stakeholder group. Table 2.6 presents average scores per stakeholder group $\left(\bar{S}_{g k}\right)$ for the six issue categories. For certain issue categories, average scores of specific stakeholder groups are larger than average scores of the other stakeholder groups. Consider for example the issue category concerning employees' job fulfilment. Average scores for this issue category are higher for fishing companies, fishing company employees and education that for the other stakeholder groups. Similarly, average scores for the issue category concerning food safety and product quality are higher for sales organizations than for the other stakeholder groups. Moreover, average scores for the issue category concerning companies' contribution to the local community are higher for education and policy-makers than for the other stakeholder groups.

Lastly, the analysis of the second survey focused on the desired direction of SSIs for which this was not evident (Figure 2.2). The combined proportions of responses $\left(\bar{P}_{s j}\right)$ for neutral and don't know varied from 0.46 to 0.82 , indicating a lack of strong opinions on several statements. Proportions of responses for agree, however, illustrate that community involvement, local ownership and local employment are desirable, whereas night work, longer fishing trips and seasonality of employment are undesirable.

\section{Discussion}

The first stakeholder survey resulted in the identification of 27 relevant SSIs for cod and haddock fisheries in the northeast Atlantic. These 27 issues include six issues that were not considered in any of the studies that were used to form the initial list of SSIs for the first survey (see Table 2.3). These six newly identified issues address aspects of employees' training and education opportunities, employees' time off from work and fish welfare. Despite emerging concerns for fish welfare in recent years (Braithwaite and Boulcott, 2007, Galhardo and Oliveira, 2009, Mood, 2010), issues addressing aspects of fish welfare were not considered before in studies on social sustainability of capture fisheries. Aspects of animal welfare are often considered in studies on social sustainability of other animal production systems (Caffey et al., 2000, Meul et al., 2008, Mollenhorst and De Boer, 2004, Van Calker et al., 2005).

The second stakeholder survey established the intrinsic and relative importance of the 27 relevant SSIs. With regard to the intrinsic importance of these issues, there was almost full agreement on the intrinsic importance of the issues healthy working environment, worker safety and physical food contamination. There was disagreement, however, on the intrinsic importance of the issues seasonality of employment, fish welfare during capture and humane slaughter of fish. 
Disagreement on the intrinsic importance of the latter two issues is likely to be a result of the relative novelty of the research area concerning fish welfare. With regard to the relative importance of SSIs, the most important issues for cod and haddock fisheries in the northeast Atlantic are worker safety, product freshness and companies' salary levels. Worker safety (Kruse et al., 2009, Utne, 2007) and companies' salary levels (Kruse et al., 2009) were identified as important issues in other studies on social sustainability of capture fisheries before, but product freshness was not.

This study covers a larger number of SSIs than previous studies on capture fisheries, which covered between two (Utne, 2007) and eleven issues (Kruse et al., 2009). This difference probably occurred because a larger number of different stakeholders was consulted in the present study and because issues were defined at a relatively high level of detail. The issues physical food contamination, chemical food contamination and microbiological food contamination could have been combined into the less detailed issue food safety (Van Calker et al., 2005). Similarly, the issues worker safety, healthy working environment and provisions aboard for the crew could have been combined into the less detailed issue working conditions (which was labelled as an issue category here) (Van Calker et al., 2005). In this study, however, ranks for the individual issues relating to food safety ranged from 11 to 20, and ranks for the individual issues relating to working conditions ranged from 1 to 16 . The large range of these ranks indicates that a high level of detail in SSI definition provides extra information which will be lost when these issues would be combined.

Results on the relative importance of issue categories per stakeholder group show that the importance of SSIs partly depends on the stakeholder group that the issue relates to. This demonstrates the value of consulting a heterogeneous group of stakeholders on the importance of SSIs. Next to the stakeholder group that the issue relates to, two other factors might influence the importance of SSIs. The first one is the type of need that the issue relates to: basic needs, social needs, or needs for self-actualization (Bavinck and Monnereau, 2007). These three types of needs show a similarity with Maslow's (1954) hierarchy of needs where the satisfaction of basic needs is a prerequisite to pursuing the satisfaction of other types of needs. This factor could explain why issues relating to basic needs (e.g. worker safety and companies' salary levels) were ranked higher than most other SSIs. The second factor that might influence the importance of issues is the state of these issues, which depends on the context of the case considered. This factor could explain why the issue worker safety, for example, was the most important issue in this study, since fishing at sea is considered a dangerous occupation (Hisamune et al., 2006, Roberts, 2010). Understanding which factors influence the importance of SSIs can help to simplify SSI identification. 
It is important to consider to what extent results on the importance of SSIs for cod and haddock fisheries in the northeast Atlantic are applicable beyond the context of this case. This applicability depends on the context-specificity of the three factors that could influence the importance of an SSI as discussed in the previous paragraph. Of these three factors, the state of an SSI is the only factor that depends on the context of the case considered. The context of the case considered in this study is mainly connected to the type of fishing technique used and the region considered. In this study, several different types of fishing techniques were considered (i.e. trawling, seining, auto-lining and long-lining in coastal and offshore waters), whereas only one region was considered. As such, the context of cod and haddock fisheries in the northeast Atlantic is mainly determined by the regional setting of this case. This means that similar results on the importance of SSIs can be expected for other capture fisheries (e.g. herring or mackerel fisheries) in the northeast Atlantic and its subareas, and for capture fisheries in similar regions (e.g. the northwest Atlantic).

Results presented on the relevance and importance of SSIs for cod and haddock fisheries in the northeast Atlantic were based on the relatively low number of 51 responses to the second survey. A larger number of responses to the second survey would have been preferable, but consulting a diversity of stakeholders was prioritized over consulting a large number of respondents. Consulting a diversity of stakeholders was accomplished, although there were no responses from consumers, one of the seven stakeholder groups distinguished. Therefore, this perspective on social sustainability should be addressed in future research.

The 51 responses to the second survey were unevenly distributed across stakeholder groups. The largest number of responses per stakeholder group was 20, whereas the smallest number of responses per stakeholder group was one. Not correcting for this uneven distribution of responses across stakeholder groups would have resulted in a disproportionately large influence of certain stakeholder groups at the expense of other stakeholder groups. This was corrected for by first determining proportions of responses (intrinsic importance SSIs) or average scores (relative importance SSIs) per stakeholder group and then averaging these proportions of responses or average scores over all stakeholder groups.

All in all, the present study adds to the current literature on social sustainability assessment by presenting a systematic approach to identification of relevant and important SSIs. This approach was applied to cod and haddock fisheries in the northeast Atlantic, which is one of the stages in the cod and haddock value chain. To accommodate for social life cycle assessment, issues for other stages of this value chain would need to be identified by using the same approach. 


\section{Conclusion}

This study resulted in 27 relevant SSIs for cod and haddock fisheries in the northeast Atlantic, including six issues that were not identified in previous studies and that address aspects of fish welfare, employees' training and education opportunities, and employees' time off from work. The 27 issues identified were classified into issue categories concerning working conditions, terms of employment, employees' job fulfilment, companies' contribution to the local community, food safety and product quality, and fish welfare.

The most important SSIs are worker safety, product freshness and companies' salary levels. In general, issues in the issue categories concerning working conditions, employees' job fulfilment and fish welfare are seen as more important than issues in the remaining issue categories.

The relative importance of SSIs differs per stakeholder group depending on the relation between the stakeholder group and each particular issue. This demonstrates the importance of consulting different stakeholder groups in future studies on social sustainability in order to get a balanced view on the importance of SSIs.

For most SSIs identified, the direction leading to higher social sustainability is evident. Several statements on desired direction of issues for which this was not evident clarified that stakeholders value fishing companies' influence on the often small communities they are located in and want residents of these communities to benefit from these fishing companies.

This study on the relevance and importance of SSIs for cod and haddock fisheries in the northeast Atlantic informs stakeholders, and especially the fishing industry and policy-makers, about the relevant SSIs and their valuation by different stakeholders. This enables the fishing industry and policy-makers to direct improvement efforts towards the more important SSIs. In the next step, indicators will be designed to assess the state of these SSIs, which further assists the fishing industry in directing improvement efforts towards the more important and urgent SSIs.

\section{Acknowledgements}

This research is supported by the project 'WhiteFish', a research project to the benefit of small and medium enterprise associations that is funded by the European Commission (286141) under the Seventh Framework Program (FP7). The authors would like to thank Jónas Viðarsson, Kathryn Donnelly, Kine Mari Karlsen and Christoffer Krewer for their help in translating and distributing the surveys, and all stakeholders for participating in the surveys. 


\title{
Appendix 2.1
}

\begin{abstract}
Statements used to determine desired direction of social sustainability issues for which this was not evident, presented in the format that was used in the second survey
\end{abstract}

\begin{tabular}{|c|c|c|c|c|}
\hline & $\begin{array}{l}\text { I } \\
\text { disagree }\end{array}$ & $\begin{array}{l}\text { I neither agree } \\
\text { or disagree }\end{array}$ & $\begin{array}{l}\text { I } \\
\text { agree }\end{array}$ & $\begin{array}{l}\text { I don't } \\
\text { know }\end{array}$ \\
\hline Working at night in fishing companies is undesirable & $\mathrm{O}$ & $\mathrm{O}$ & O & O \\
\hline $\begin{array}{l}\text { Being out to sea for longer periods of time per fishing } \\
\text { trip is undesirable from a family life point of view }\end{array}$ & $\mathrm{O}$ & $\mathrm{O}$ & $\mathrm{O}$ & $\mathrm{O}$ \\
\hline $\begin{array}{l}\text { Being out to sea for longer periods of time per fishing } \\
\text { trip is acceptable when this is compensated with } \\
\text { longer periods of time at home }\end{array}$ & O & $\mathrm{O}$ & O & $\mathrm{O}$ \\
\hline $\begin{array}{l}\text { Seasonality of employment in cod and haddock } \\
\text { fisheries is undesirable }\end{array}$ & O & O & O & $\mathrm{O}$ \\
\hline $\begin{array}{l}\text { Product freshness of non-frozen fish is about the } \\
\text { time between catching and selling the fish }\end{array}$ & $\mathrm{O}$ & O & O & O \\
\hline $\begin{array}{l}\text { Product freshness of frozen fish is about the time } \\
\text { between surfacing and freezing the fish }\end{array}$ & O & $\mathrm{O}$ & O & $\mathrm{O}$ \\
\hline $\begin{array}{l}\text { You cannot call fish fresh when the fish has been } \\
\text { frozen }\end{array}$ & O & O & O & O \\
\hline $\begin{array}{l}\text { Food contamination (either microbiological, } \\
\text { chemical or physical) up to legally defined barriers is } \\
\text { acceptable }\end{array}$ & O & $\mathrm{O}$ & $\mathrm{O}$ & O \\
\hline $\begin{array}{l}\text { Fishing companies should be involved in the } \\
\text { communities they are located in }\end{array}$ & $\mathrm{O}$ & O & $\mathrm{O}$ & $\mathrm{O}$ \\
\hline $\begin{array}{l}\text { It is undesirable when a fishing company is owned by } \\
\text { somebody from outside the local community }\end{array}$ & O & $\mathrm{O}$ & O & 0 \\
\hline $\begin{array}{l}\text { In fishing companies, hiring local people should be } \\
\text { preferred over hiring people from outside the area }\end{array}$ & $O$ & 0 & 0 & 0 \\
\hline $\begin{array}{l}\text { Hiring workers from outside the area who are willing } \\
\text { to move to the local area should be just as preferred } \\
\text { as hiring local people }\end{array}$ & 0 & 0 & 0 & 0 \\
\hline $\begin{array}{l}\text { In fishing companies, hiring national residents } \\
\text { should be preferred over hiring immigrant workers }\end{array}$ & $O$ & 0 & 0 & 0 \\
\hline $\begin{array}{l}\text { In fishing companies, immigrant workers should be } \\
\text { paid the same wage as native workers }\end{array}$ & $O$ & 0 & 0 & 0 \\
\hline
\end{tabular}





\section{A method to assess social sustainability of capture fisheries: an application to a Norwegian trawler}

L.J.L. Veldhuizen, P.B.M. Berentsen, E.A.M. Bokkers, I.J.M. de Boer

Environmental Impact Assessment Review 53 (2015) 31-39 


\begin{abstract}
Social sustainability assessment of capture fisheries is, both in terms of method development and measurement, not well developed. The objective of this study, therefore, was to develop a method consisting of indicators and rubrics (i.e. categories that articulate levels of performance) to assess social sustainability of capture fisheries. This method was applied to a Norwegian trawler that targets cod and haddock in the northeast Atlantic. Based on previous research, 13 social sustainability issues were selected. To measure the state of these issues, 17 process and outcome indicators were determined. To interpret indicator values, rubrics were developed for each indicator, using standards set by international conventions or data retrieved from national statistics, industry agreements or scientific publications that explore rubric scales. The indicators and rubrics were subsequently used in a social sustainability assessment of a Norwegian trawler. This assessment indicated that overall, social sustainability of this trawler is relatively high, with high rubric scores, for example, for worker safety, provisions aboard for the crew and companies' salary levels. The assessment also indicated that the trawler could improve on healthy working environment, product freshness and fish welfare during capture. This application demonstrated that our method provides insight into social sustainability at the level of the vessel and can be used to identify potential room for improvement. This method is also promising for social sustainability assessment of other capture fisheries.
\end{abstract}




\section{Introduction}

Northeast Atlantic fisheries produced 8.3 million tonnes of fish in 2011, accounting for approximately $10 \%$ of the global production of fish from capture fisheries (Statistics Office Iceland, 2013b). In the northeast Atlantic, demersal fisheries, targeting species living close to the ocean floor, comprise the majority of fisheries and nearly a third of these demersal fisheries targeted cod and haddock in 2011 (Statistics Office Iceland, 2013a). Recently, fishing companies that target cod and haddock in the northeast Atlantic have expressed interest in assessing and improving sustainability of their products at the level of the fishing vessel. These Norwegian and Icelandic fishing companies, therefore, initiated the WhiteFish project on sustainability of cod and haddock fisheries in the northeast Atlantic, which was funded under the $\mathrm{EU} 7^{\text {th }}$ Framework Programme for Research.

Sustainability is generally composed of environmental, economic, and social sustainability (Jeswani et al., 2010, Kloepffer, 2008). Assessment of environmental performance is well developed (e.g. life cycle assessment; ISO, 2006a, 2006b). Economic sustainability or viability (e.g. profitability) is a prerequisite for companies to stay in business, so this is generally well monitored by companies themselves. Assessment of social sustainability is, however, both in terms of method development and measurement, not well developed.

Increasing interest of companies in social sustainability can be viewed in light of wider changes in welfare economics from a traditional focus on profitability and income to a more inclusive view on welfare based on Sen's $(1984,1993)$ capabilities approach. This approach considers welfare not only in terms of utility as quantified by profitability and income, but also in terms of, for example, individual freedom, non-material values and equal opportunities. At the company level, this capabilities approach has given rise to a focus on corporate social responsibility (CSR) to consider environmental and social sustainability in addition to profitability. The standard on CSR of the international organization for standardization (ISO, 2010) however, does not provide methodological assistance on social sustainability assessment. One method that is often proposed for social sustainability assessment is social life cycle assessment (S-LCA) (Benoit-Norris et al., 2011, UNEP/SETAC, 2009). S-LCA however, focuses on the value chain rather than on the single company or vessel.

Thus far, social sustainability of capture fisheries has been studied using qualitative methods (e.g. Glaser and Diele, 2004, Glass et al., 2015, Reed et al., 2013) and quantitative methods (e.g. Ceriola et al., 2008, Guyader et al., 2013, Utne, 2007). Qualitative methods such as semi-structured interviews and field observations have been used in sustainability assessments of a Brazilian mangrove crab fishery (Glaser and Diele, 2004), the Alaskan weathervane scallop 
fishery (Glass et al., 2015) and inshore fisheries in the UK (Reed et al., 2013). Quantitative methods have been used in sustainability assessments of the Southern Adriatic trawl fishery (Ceriola et al., 2008), European small scale fisheries (Guyader et al., 2013) and Norwegian cod fisheries (Utne, 2007). These social sustainability assessments performed thus far concerned fisheries as a whole and hence do not inform individual companies about their social sustainability. When companies would know about their social sustainability, they can improve their social sustainability and communicate outcomes from their assessment to consumers.

Sustainability assessment starts with a description of the (problem) situation (Mollenhorst and De Boer, 2004, Van Calker et al., 2005). The situation considered in this study concerns cod and haddock fishing companies that participate in the WhiteFish project and that employ trawlers, longliners, autoliners, and Danish seiners in coastal and offshore fisheries to produce fresh and frozen fillets. The second step in sustainability assessment is the identification of social sustainability issues (Mollenhorst and De Boer, 2004, Van Calker et al., 2005), i.e. aspects of social sustainability that are important to consider in an assessment. This step was performed for cod and haddock fisheries in the northeast Atlantic by Veldhuizen et al. (2015) who identified social sustainability issues based on stakeholder input. The third step in sustainability assessment consists of determining suitable indicators for the issues identified (Mollenhorst et al., 2006, Van Calker et al., 2004, Van Calker et al., 2007) and quantifying these indicators to measure the state of the social sustainability issues (Bell and Morse, 1999). Application of this third step to cod and haddock fisheries in the northeast Atlantic is the subject of the present paper.

Fishing companies that want to assess and improve their social sustainability need to be able to interpret indicator values, for example, by using performance reference points that provide target or threshold values based on conventions or best practice (UNEP/SETAC, 2009). A scoring system that can include performance reference points and that can be used to interpret indicator values is a rubric assessment, which is an overall assessment of performance based on a series of rubrics. Rubrics are categories that articulate levels of performance, from poor to excellent (Goodrich, 1997, Hafner and Hafner, 2003). The advantage of applying a rubric assessment is that it explicates desired directions, and desirable and undesirable values (Jonsson and Svingby, 2007). As a result, social sustainability assessment based on rubrics informs companies about their performance and about potential room for improvement. In addition, the use of rubrics ensures that the social sustainability assessment is transparent (Jonsson and Svingby, 2007). Rubric assessment is traditionally applied in education (Hafner and Hafner, 2003), but it has also been applied in other areas, e.g. sustainability assessment (e.g. FAO, 2014a, Häni et al., 2003, Zahm et al., 2008), 
certification of buildings (e.g. BREEAM, LEED and CEEQUAL Sev, 2011) and fisheries management (Pitcher et al., 1998, 2013, Pitcher and Preikshot, 2001).

The objective of this study was to develop a method consisting of indicators and rubrics to assess social sustainability of capture fisheries. To demonstrate this method, the indicators and the accompanying rubrics were used to determine social sustainability of a Norwegian fishing company from Tromsø that operates a trawler to target cod and haddock in the northeast Atlantic.

\section{Methods}

\subsection{Selection of issues}

Social sustainability issues for cod and haddock fisheries in the northeast Atlantic were previously identified through two consecutive stakeholder surveys (Veldhuizen et al., 2015). In these two surveys $(n=41$ and $n=51)$, stakeholders from seven stakeholder groups were consulted, i.e. fishing companies, fishing company employees, suppliers and processors, sales organizations, consumer organizations, policy-makers (at the national and at the local level), and fish welfare organizations. The first stakeholder survey resulted in the identification of 27 relevant issues. These issues were subsequently grouped into issue categories entitled working conditions, employees' job fulfilment, terms of employment, food safety and product quality, fish welfare, and companies' contribution to the local community. Since it is not practical nor desirable to consider all issues identified as relevant in a social sustainability assessment (Mitchell et al., 1995), a second survey was used to determine the importance of each issue (Veldhuizen et al., 2015). For the present study, issues were selected that were considered important by at least a two-thirds weighted majority of respondents. Table 3.1 shows the resulting 13 issues and the issue categories these selected issues belong to.

\subsection{Determining indicators}

Outcome and process indicators (Evans et al., 2011, Good et al., 1999) were determined for the 13 important social sustainability issues of cod and haddock fisheries in the northeast Atlantic. An outcome indicator measures the state of a sustainability issue, whereas a process indicator measures factors that influence the state of a sustainability issue. Outcome and process indicators can be both quantitative (e.g. number of workplace accidents) and qualitative (e.g. severity of workplace accidents).

To warrant quality and practicability, according to Mitchell et al. (1995), indicators should be: 1) valid, i.e. provide accurate and precise information, 2) measurable, i.e. easily measured given time and budget constraints, 3) sensitive, i.e. show changes in the state of the issue, 4) simple, i.e. easily understood by users, and 5) accompanied by performance reference points that assist in the 
Table 3.1: Social sustainability issues selected based on the proportion of stakeholders that consider each issue important, ordered per issue category (based on Veldhuizen et al., 2015)

\begin{tabular}{ll}
\hline Issues per issue category & Proportion \\
\hline Working conditions & \\
Healthy working environment & 0.99 \\
Worker safety & 0.96 \\
Provisions aboard for the crew & 0.73 \\
Employees' job fulfilment & \\
Employees' job satisfaction & 0.86 \\
Employees' professional pride & 0.85 \\
Companies' salary levels & 0.69 \\
Terms of employment & 0.80 \\
On-the-job training & 0.72 \\
Companies' timely payment of salaries & \\
Food safety and product quality & 0.87 \\
$\quad$ Physical food contamination & 0.86 \\
Chemical food contamination & 0.80 \\
Product freshness & 0.72 \\
Microbiological food contamination & \\
Fish welfare & 0.71 \\
Fish welfare during capture & \\
\hline
\end{tabular}

interpretation of indicator values. Outcome indicators provide direct information on the state of an issue, whereas process indicators provide only indirect information on the state of an issue. Therefore, outcome indicators were the preferred indicator type. In case an outcome indicator for an issue failed to meet the indicator criteria, process indicators were determined.

\subsection{Rubric development}

Rubrics with scores ranging from 1 to 5 (integers only) were developed for all indicators to interpret indicator values. In all cases, a rubric score of 1 represents the least desirable value for an indicator and a rubric score of 5 represents the most desirable value for an indicator. Note that these rubric scores indicate relative levels of social sustainability and not absolute levels of social sustainability (i.e. sustainable, unsustainable) as Pope et al. (2004) advocate.

Rubrics were preferably developed based on international conventions since international conventions represent values that are assumed to be broadly recognized (Kruse et al., 2009, UNEP/SETAC, 2009). In the absence of international conventions, rubrics were developed based on data retrieved from national statistics, industry agreements, scientific publications or unpublished data that explore rubric scales. Rubric scores for quantitative indicators were determined by linearly distributing the possible range of indicator values across rubric scores. Only when additional information on this range indicated that a non-linear distribution of indicator values across rubric scores was more appropriate, a non-linear approach was applied. Rubric scores for qualitative 
indicators were based on the different levels that could be distinguished for these rubrics. All rubrics were developed for cod and haddock fisheries in the northeast Atlantic and only specified to the case of a Norwegian trawler where necessary.

\subsection{Social sustainability assessment applied to a Norwegian trawler}

The derived indicators and rubrics for cod and haddock fisheries in the northeast Atlantic were used for social sustainability assessment of a Norwegian trawler. This trawler mainly targets cod and haddock in the Barents Sea, the Norwegian Sea, and the North Sea on fishing trips that last between one and four weeks. The trawler has 33 employees: one works onshore and 32 work on the trawler in two shifts of 16 that succeed one another every four weeks.

Data on the different social sustainability issues were collected through selfadministered questionnaires for the manager and for the employees of this trawler. The questionnaire for the manager contained 25 questions on all indicators. Responses to some of these questions immediately resulted in the establishment of indicator values, whereas remaining indicator values were established after additional questions. The questionnaire for employees contained nine questions on indicators that concerned the trawler's employees and on certain indicators that the manager provided information on as well, as an extra check. This check did not reveal any discrepancies between responses of the manager and responses of the employees, or among responses of the employees. All responses of employees to the questionnaires were anonymous and treated confidentially. As for the manager, responses of employees to some questions resulted in the direct establishment of indicator values, whereas remaining indicator values had to be established through additional questions.

\section{RESULTS}

\subsection{Indicators and rubrics for cod and haddock fisheries in the northeast Atlantic}

In this section, indicators and rubrics are determined for the 13 social sustainability issues that were selected for cod and haddock fisheries in the northeast Atlantic (Table 3.1). The indicators and the accompanying rubrics for each issue are presented and discussed for each of the five issue categories distinguished (see Table 3.2 to 3.6).

\subsubsection{Issue category 'working conditions'}

The issue worker safety is assessed on the basis of outcome indicators that concern the occurrence and severity of workplace accidents. However, such outcome indicators violate the indicator criterion of sensitivity since a lack of accidents on single vessels (especially on vessels with a relatively low number of employees) in a given time period could either be coincidental or a result of 


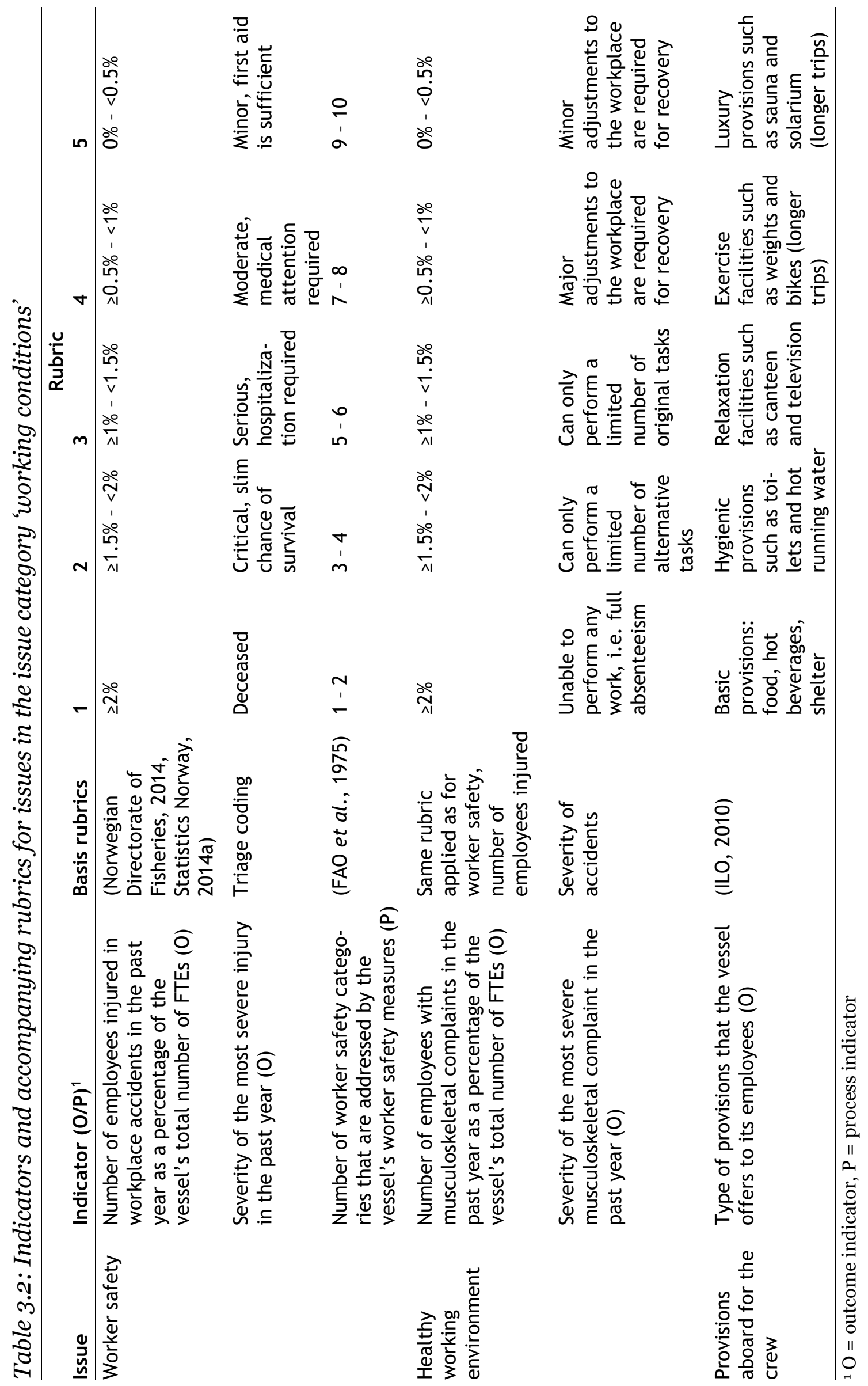


effective worker safety measures. Therefore, an additional process indicator was determined for this issue as well. The first outcome indicator concerns the number of employees injured in workplace accidents in the past year, expressed as a percentage of the vessel's total number of employees in that year (expressed in full-time equivalents, or FTEs). The accompanying rubric is based on the number of workplace accidents that occurred in Norwegian fisheries from 2000 to 2013 , as a percentage of the total number of people employed in Norwegian fisheries each year. During that period, on average $1.29 \%$ of people employed in fishing were injured each year, with percentages generally decreasing from $2.15 \%$ in 2000 to $0.80 \%$ in 2013 (Norwegian Directorate of Fisheries, 2014, Statistics Norway, 2014a). Given these percentages and similar percentages for Iceland (Ziegler et al., 2014), the possible range of values for this indicator was set between $0 \%$ to $2 \%$, and intermediate rubric scores were based on the linear distribution of this range across rubric scores (Table 3.2). The second outcome indicator for worker safety concerns the severity of the most severe workplace accident that occurred aboard the vessel in the past year. This indicator is accompanied by a rubric based on triage coding, which is used to prioritize patients based on the severity of their injuries in, for example, emergency rooms or field hospitals (Table 3.2). Finally, the process indicator for worker safety concerns the number of worker safety categories that are addressed by worker safety measures aboard. The rubric for this indicator is based on the ten worker safety categories for fishing vessels that were formulated by the FAO, IMO and ILO (FAO et al., 1975). Since there is no prioritization in these worker safety categories, the number of categories addressed is linearly distributed across rubric scores (Table 3.2).

The first outcome indicator for the issue healthy working environment concerns the number of employees with musculoskeletal complaints in the past year, as a percentage of the vessel's total number of employees in that year (expressed in FTEs). No data exist, however, that could be used to develop a rubric for this indicator. Instead, the rubric for percentage of musculoskeletal complaints resembles the rubric for percentage of accidents for the issue worker safety (Table 3.2). The second outcome indicator for healthy working environment concerns the severity of the most severe musculoskeletal complaint that occurred aboard the vessel in the past year. This rubric is based on the degree to which musculoskeletal complaints disable an employee to perform tasks aboard the vessel (Table 3.2).

The indicator for the issue provisions aboard for the crew is an outcome indicator that assesses such provisions on the basis of the type of needs that these provisions fulfil (i.e. basic needs or higher order needs; Maslow, 1954). The lowest rubric scores (i.e. 1 and 2) for provisions aboard for the crew are assigned when the vessel has basic provisions or basic provisions plus hygienic provisions, respectively. The higher rubric scores for this issue (i.e. 3, 4 and 5) are assigned 


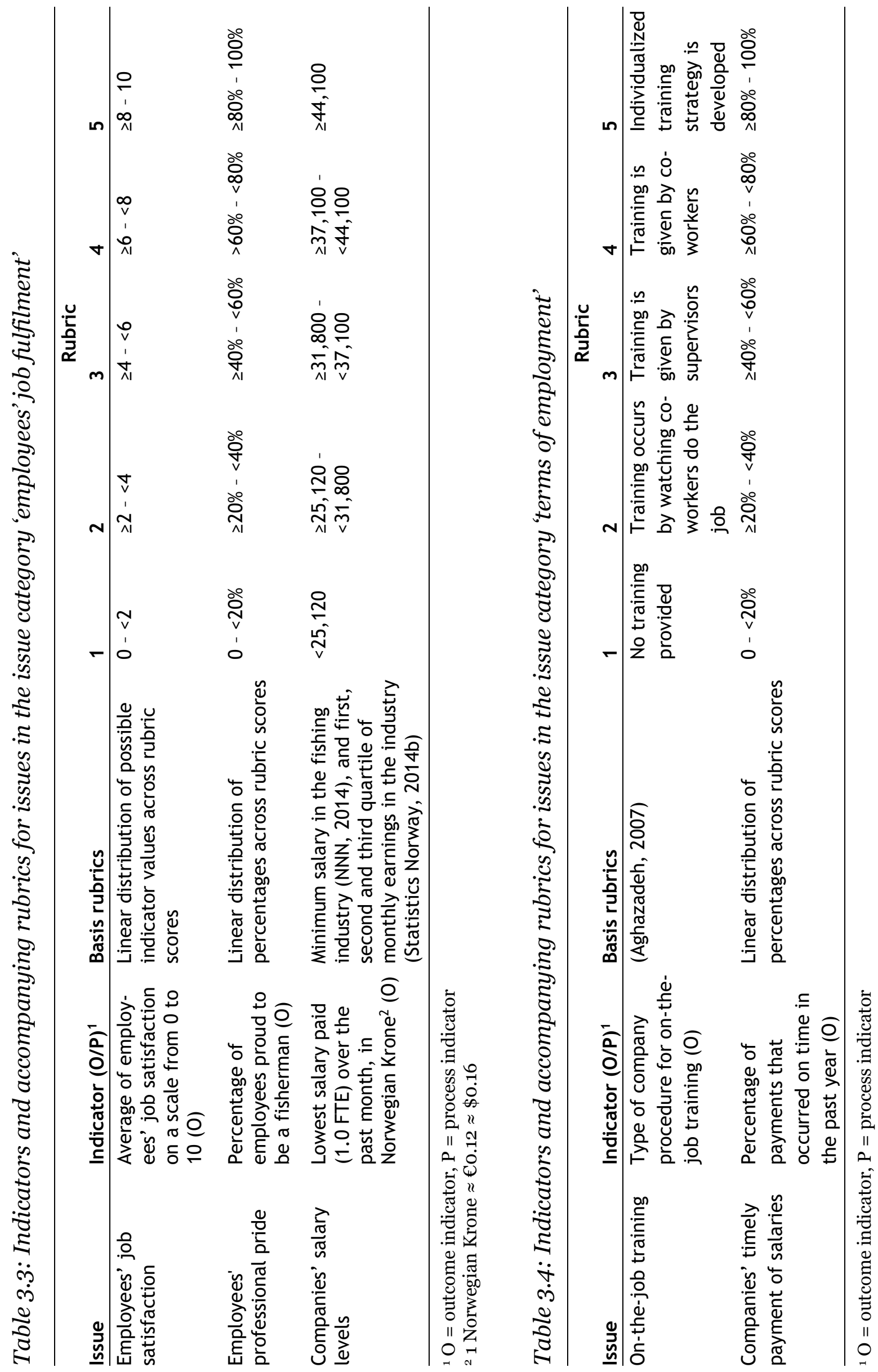


when the vessel has provisions that also fulfil employees' higher order needs, as listed in the ergonomic checkpoints of the International Labour Organization (ILO, 2010) (Table 3.2). Note that the relevance of this issue increases with the duration of trips.

\subsubsection{Issue category 'employees' job fulfilment'}

The indicator for the issue employees' job satisfaction is an outcome indicator that concerns employees' subjective perception of their job in all its facets (Bavinck and Monnereau, 2007). This indicator is expressed as the average of employees' job satisfaction on a scale from 0 to 10, where 0 stands for very dissatisfied and 10 stands for very satisfied. The rubric for this indicator is based on the linear distribution of possible indicator values across rubric scores (Table 3.3).

Employees' professional pride is addressed by an outcome indicator that measures the percentage of employees proud to be a fisherman. As for the rubric for employees' job satisfaction, this rubric is based on the linear distribution of possible indicator values (i.e. $0 \%$ - 100\%) across rubric scores (Table 3.3).

The indicator for the issue companies' salary levels is an outcome indicator that concerns the lowest salary paid aboard in the past month. When this salary is at an acceptable level, it is assumed that all other salaries paid aboard are at an acceptable level as well. The rubric for lowest salary paid aboard is, in this case, based on Norwegian data on salaries paid in the fishing industry. The minimum salary in the fishing industry (NNN, 2014) is used to define the boundary between a rubric score of 1 and a rubric score of 2 . The boundaries between rubric scores of 2 and 3, 3 and 4, and 4 and 5 are defined by the salary levels earned by 25\%, $50 \%$ and $75 \%$ of the industry's employees (Statistics Norway, 2014b) (Table 3.3).

\subsubsection{Issue category 'terms of employment'}

Aghazadeh (2007) describes that the effectiveness of on-the-job training depends on the way in which employees are trained. Therefore, the outcome indicator for on-the-job training concerns the type of company procedure for on-the-job training. The rubric for this indicator is based on the types of procedures for onthe-job training distinguished by Aghazadeh (2007) (Table 3.4).

The indicator for the issue companies' timely payment of salaries is an outcome indicator that concerns the percentage of payments that occurred on time in the past year, where 'timely' is interpreted as the pre-determined moment specified in employees' contracts plus two days (in case payments occur monthly; one day in case payments occur every two weeks). The rubric for companies' timely payment of salaries, as for employees' professional pride, is based on the linear distribution of percentages across rubric scores (Table 3.4). 


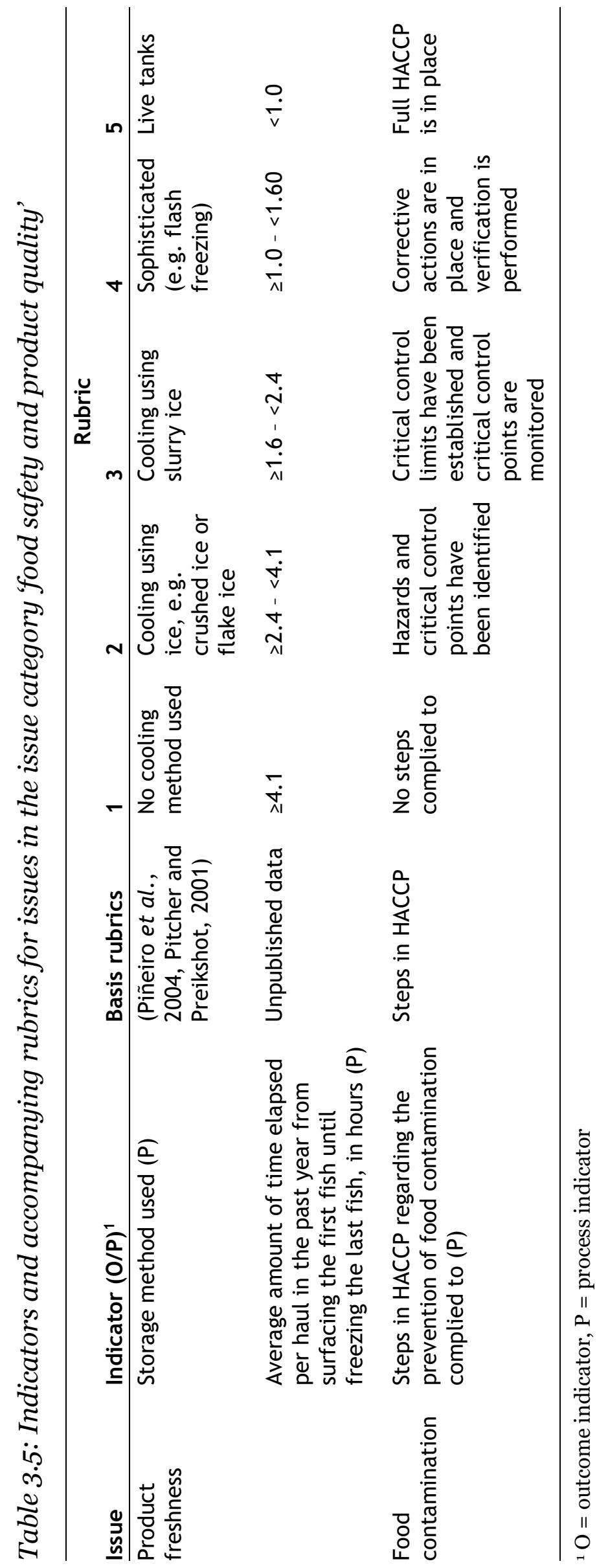




\subsubsection{Issue category 'food safety and product quality'}

The issue product freshness concerns an individual's subjective perception of a product's features resulting from post-catch handling of this product. An outcome indicator for this issue that would focus on these perceptions violates the indicator criterion of measurability because it is difficult to determine such perceptions and to connect these to products originating from specific vessels. Therefore, this issue is addressed by two process indicators that concern the two main factors of post-catch handling affecting product freshness, i.e. storage methods (i.e. cooling) and the amount of time elapsed since surfacing the fish (Giannakourou et al., 2005, Taoukis et al., 1999). The process indicator storage method used is accompanied by a rubric that is based on the storage methods and the ordering from bad to good defined by Pitcher and Preikshot (2001), supplemented with findings from Piñeiro et al. (2004) that slurry ice has a more beneficial impact on product freshness than flake ice (Table 3.5). Use of the process indicator average amount of time elapsed from surfacing until freezing assumes that product freshness of frozen fish does not decrease further once the fish is frozen. The rubric for this indicator is based on (unpublished) data of a Norwegian trawler on the amount of time registered per haul $(n=1022)$ that had elapsed before catch was frozen. The distribution of this data is positively skewed and ranges from 2.7 hours to 17.7 hours. Therefore, rubric scores are based on quintiles in this dataset rather than on the linear distribution of these data points across rubric scores. Boundaries between rubric scores of 1 and 2, 2 and 3, 3 and 4 , and 4 and 5 are thus defined by the amounts of time associated with the first, second, third and fourth quintiles in this dataset (Table 3.5).

Outcome indicators for the issues physical, chemical and microbiological food contamination cannot be determined because incidences of food contamination are often only identified at the consumption link of the value chain and can hardly be traced back to individual vessels (Karlsen et al., 2012). Therefore, process indicators are determined for these issues that concern hazards analysis and critical control points (i.e. HACCP). Since HACCP does not distinguish between the different types of food contamination, the three issues relating to food contamination are assessed jointly by one process indicator, i.e. steps in HACCP regarding the prevention of food contamination complied to (Table 3.5). The rubric for this indicator is based on the steps in HACCP, i.e. 1) conduct hazard analysis, 2) determine critical control points, 3) establish critical limits, 4) monitor critical control points, 5) establish corrective actions, 6) perform verification and 7) ensure recordkeeping. These steps of HACCP are consecutive and provide a prioritization that is used to develop the rubric for food contamination (Table 3.5).

\subsubsection{Issue category 'fish welfare'}

Two outcome indicators and one process indicator are determined for the issue fish welfare during capture because the impact of the capture process on fish 
52 | Chapter 3

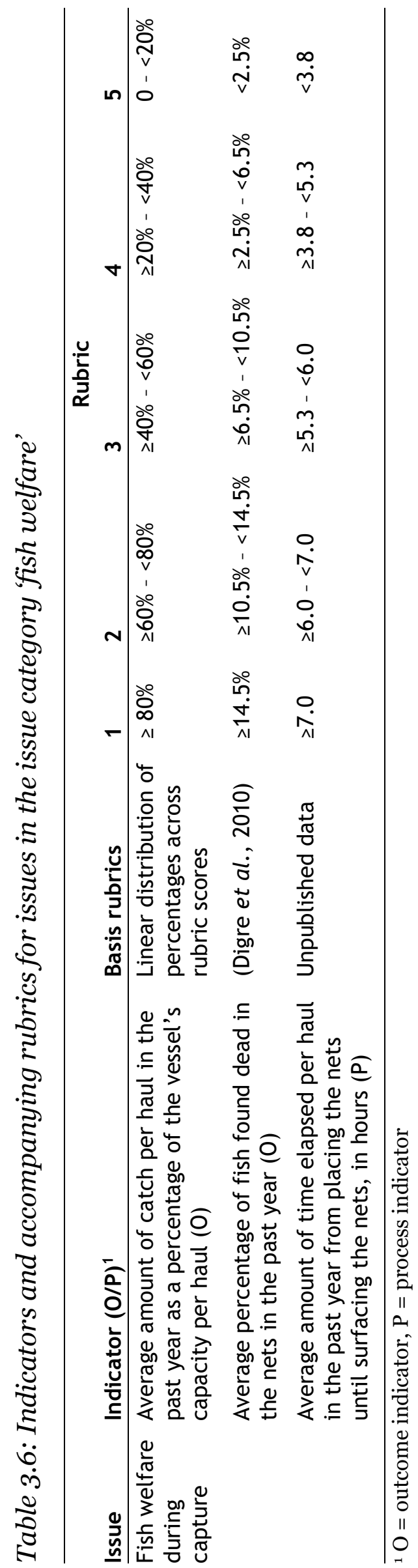


welfare depends on the combined outcome of numbers of fish affected (i.e. outcome indicator), severity of impacts (i.e. outcome indicator) and duration of fishing (i.e. process indicator) (Mood, 2010). The first outcome indicator for this issue concerns the vessel's average amount of catch per haul in the past year as a percentage of this vessel's maximum capacity per haul. This indicator concerns crowding in the nets, which is likely to have a detrimental effect on fish welfare (Hattula et al., 1995). The rubric for this indicator is based on a linear distribution of percentages across rubric scores (Table 3.6). The second outcome indicator for fish welfare during capture concerns the percentage of fish found dead in the nets in the past year. The rubric for this indicator is based on findings on fish mortality that were reported in a study on quality parameters for cod and haddock (Digre et al., 2010). The percentage of cod and haddock that was reported dead upon surfacing in that study was $2.5 \%$ for cod and $14.3 \%$ for haddock. Digre et al. (2010) did not provide an explanation for this difference in mortality, so in developing rubrics, a rubric score of 1 was assigned to the highest percentage, a rubric score of 3 was assigned the average of these two percentages and a rubric score of 5 was assigned to the lowest percentage (Table 3.6). The third indicator for fish welfare during capture is a process indicator that concerns the average amount of time elapsed per haul in the past year from placing the nets until surfacing, which is the potential amount of time during which fish are affected by the capture process. The rubric for this indicator is based on (unpublished) data of a Norwegian trawler on the amount of time registered per haul $(n=999)$ that had elapsed between placing the nets and surfacing. The distribution of this data is positively skewed and ranges from 1.1 hours to 7.8 hours. As for time elapsed from surfacing until freezing, rubric scores for time elapsed from placing the nets until surfacing are based on quintiles in the dataset rather than on the linear distribution of these data points across rubric scores (Table 3.6).

\subsection{Social sustainability assessment of a Norwegian trawler}

Responses of the Norwegian trawler's manager and employees to their questionnaires were used to perform social sustainability assessment of this trawler. Results from this assessment in Table 3.7 show that the trawler had a rubric score of 1 for o indicators, a rubric score of 2 for 2 indicators, a rubric score of 3 for 3 indicators, a rubric score of 4 for 3 indicators and a rubric score of 5 for 9 indicators.

The Norwegian trawler has high rubric scores for the three indicators of the issue worker safety, the first issue in the issue category working conditions. These rubric scores indicate that this trawler's percentage of employees injured in workplace accidents was below the long-term average for Norway, that the severity of these injuries was moderate at most and that all worker safety categories are addressed by worker safety measures aboard this vessel. Rubric scores for the issue healthy working environment, the second issue in the issue 


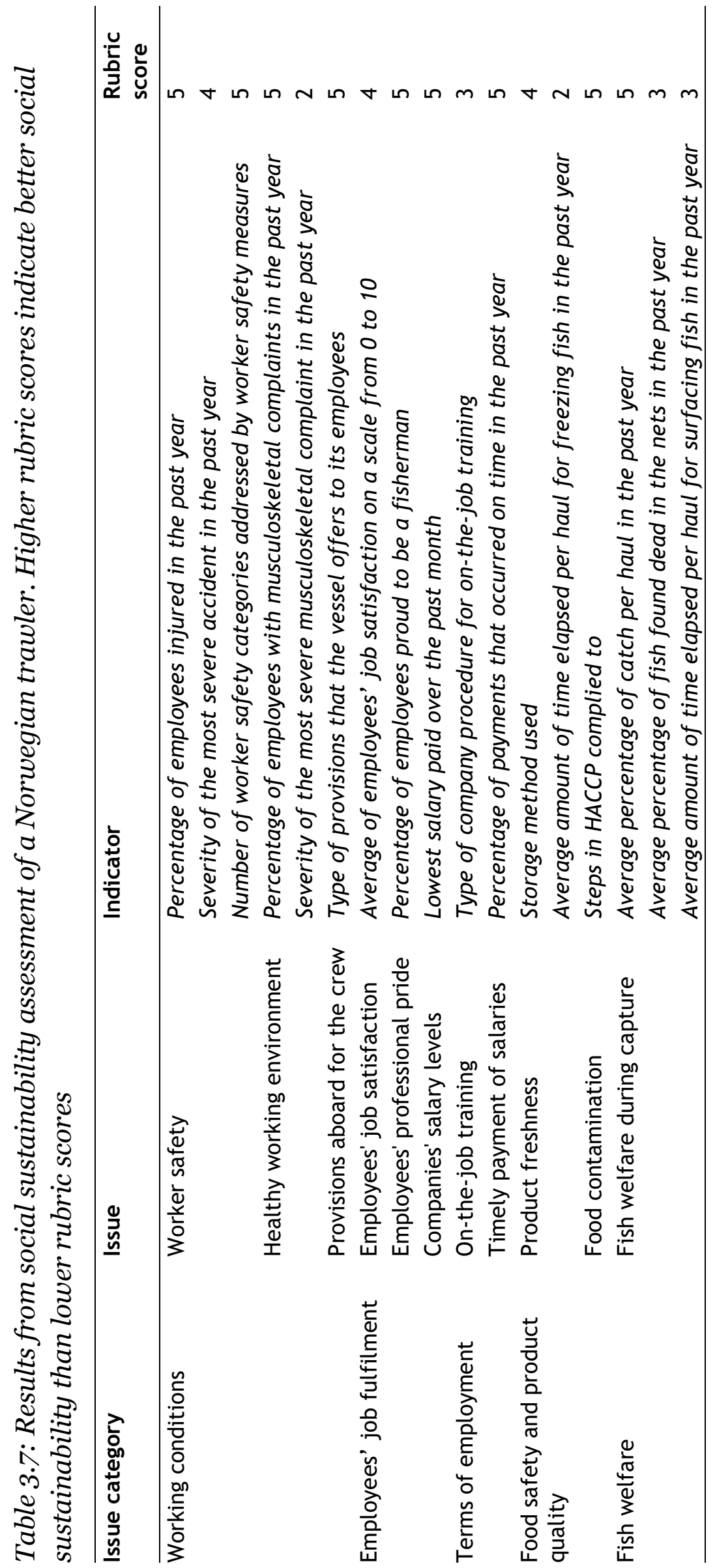


category working conditions, indicate that although the Norwegian trawler had a low incidence of musculoskeletal complaints, these complaint(s) were severe (Table 3.7). The Norwegian trawler has a rubric score of 5 for the issue provisions aboard for the crew, the third issue in the issue category working conditions (Table 3.7). This score reflects, in part, that the trawler stays out to sea for periods of up to four weeks, but also that this trawler has better provisions than is to be expected of a vessel that stays out to sea for longer periods of time.

The Norwegian trawler has a rubric score of 4 for employees'job satisfaction and a rubric score of 5 for employees' professional pride and for companies' salary levels, the three issues in the issue category employees' job fulfilment (Table 3.7). These rubric scores indicate that employees' job fulfilment from working for this trawler is high.

A rubric score of 3 for on-the-job training, the first issue in the issue category terms of employment, indicate that employees of this Norwegian trawler are commonly trained by their supervisors. A rubric score of 5 for the issue timely payment of salaries, the second issue in the issue category terms of employment, indicates that the vast majority of salaries is paid at the time specified in employees' contracts (Table 3.7).

Rubric scores for the issue product freshness, the first issue in the issue category food safety and product quality, indicate that although the Norwegian trawler has good storage facilities with advanced freezing methods, it can take quite long to freeze all catch from a haul (Table 3.7). A rubric score of 5 for food contamination, the second issue in this issue category, indicates that the vessel performs well in terms of preventive measures against food contamination (Table 3.7).

A rubric score of 5 for the issue average amount of catch per haul, the first issue in the issue category fish welfare, indicates that crowding in the nets of the Norwegian trawler is low (Table 3.7). The trawler performs less well, however, for the indicators percentage of fish found dead and time elapsed, with a rubric score of 3 for both indicators (Table 3.7).

\section{Discussion}

A method consisting of indicators and rubrics was developed for social sustainability assessment of capture fisheries and applied to a Norwegian trawler that targets cod and haddock in the northeast Atlantic. Two important choices were made in developing this method. First, the method focused only on social sustainability rather than on all pillars of sustainability (i.e. environmental, economic, and social sustainability) as in, for example, Glaser and Diele (2004), Ceriola et al. (2008) and Utne (2007). This exclusive focus on social 
sustainability was chosen because methods for environmental sustainability assessment are generally well developed (e.g. life cycle assessment; ISO, 2006a, 2006b) and because economic sustainability at the company level is considered to be monitored well by companies themselves. Second, in the present study, indicators and rubrics were developed for 13 issues that were selected based on the importance of these issues in cod and haddock fisheries in the northeast Atlantic (Veldhuizen et al., 2015). The importance of social sustainability issues depends on the context of the case considered (Veldhuizen et al., 2015) and thus varies between cases. As a result, the issues, indicators and rubrics used in the present study are applicable to fisheries in the northeast Atlantic and its subareas, and possibly also to fisheries in similar regions such as the northwest Atlantic. However, they are not very likely to be applicable to fisheries in very different regions such as the western Indian ocean where different degrees of importance may be attached to social sustainability issues and where different issues altogether may be at stake.

The method that was used in the present study enables quick assessment at the level of the company and informs a company of its strengths and potential areas of concern in terms of social sustainability, in line with this study's objective. Recognizing that this method is rather quantitative and could thus result in the exclusion of more qualitative aspects, indicators were determined in the present study that addressed both quantitative aspects (e.g. number of workplace accidents) and qualitative aspects (e.g. severity of workplace accidents). These indicators were subject to indicator criteria to ensure that the indicators were determined based on their quality and not on alternative, possibly more biased, considerations. In order to minimize bias in rubric development as well, a procedure was presented for developing these rubrics, and the steps that were taken in developing rubrics were explicated in the present study.

In total, 17 process and outcome indicators were determined for the 13 social sustainability issues that were selected. Indicators could be determined for all issues selected because process indicators were determined as an alternative to outcome indicators for certain issues. As a result, indicators could be determined for the issues product freshness and food contamination that, therefore, did not have to be omitted. Process indicators were also determined in addition to outcome indicators for certain issues, which enhanced assessment of the issues worker safety and fish welfare during capture.

The quality of indicators presented in this study was safeguarded through the use of five indicator criteria, i.e. validity, measurability, sensitivity, simplicity, and identifiability of performance reference points. These indicator criteria, or subsets thereof, are commonly used in defining indicators (e.g. Caffey et al., 2000, Kruse et al., 2009, Mollenhorst et al., 2006). In general, indicators in the present study met these indicator criteria. However, the validity of the indicators for employees' 
job satisfaction and employees' professional pride cannot be guaranteed since employees might not feel completely free to respond truthfully to questions on job satisfaction and professional pride. Validity of the indicators time elapsed until freezing and time elapsed during fishing is not optimal because these indicators consider the total amount of time elapsed, even though fish enter the nets at different times, are surfaced all at once and are frozen at different times again. Finally, the indicator percentage of fish found dead in the nets is difficult to measure. A lack of movement of fish, for example, can indicate death, but a lack of movement can also occur as a result of temporary unconsciousness or paralysation (Gregory, 1998).

The indicators for social sustainability assessment of cod and haddock fisheries in the northeast Atlantic were each accompanied by a rubric, which resulted in 17 rubrics in total. Rubrics that were based on international conventions or that were developed by linearly distributing the full range of possible indicator values (e.g. 0-100\%) across rubric scores are generally applicable. The rubric for companies' salary levels, on the other hand, only applies to Norway because this rubric was based on national statistics. Although rubrics for percentage of employees injured and percentage of musculoskeletal complaints were also based on national statistics, these rubrics may also apply to other countries where similar accident rates can be expected, e.g. in countries with similar safety laws and regulations. The rubric for on-the-job training was based on a publication that was not specific to capture fisheries and is thus more generally applicable. The rubric for storage method used, however, was based on publications that concerned capture fisheries and is thus only applicable to capture fisheries. The rubric for percentage of fish found dead in the nets was based on a single publication that reported fish mortality from trawling and is thus not applicable beyond trawling. Rubrics for time elapsed until freezing and time elapsed during fishing were based on data from one cod and haddock fishing company in the northeast Atlantic and may thus not be applicable to other fisheries either.

In general, rubrics articulate levels of performance that inform companies about their performance and about potential room for improvement. An alternative, and perhaps more common method to achieve the same outcome is benchmarking, where a company's performance for a certain indicator(s) is compared to best practice in the sector for that indicator(s), or against performance of a range companies in the sector for that indicator(s). However, indicator values are not available at the sector level for many social sustainability indicators, which means that the use of benchmarks is mostly not possible for social sustainability assessment.

A disadvantage of rubrics is that a loss of information occurs when continuous variables are transformed into rubrics, which are categorical variables. When, for example, the exact monthly salary is known, this value is transformed into a 
rubric score that includes a much larger range of salaries, which is a loss of information. Such a loss of information can be reduced by defining more rubric scores, e.g. seven or ten instead of five. In the present study, however, only five rubric scores at most could be determined for certain indicators. Any loss of information was compensated, however, by the possibility to include indicators in the interpretation of results that would otherwise be excluded.

The indicators and rubrics for cod and haddock fisheries in the northeast Atlantic were applied in a social sustainability assessment of a Norwegian trawler. This assessment made clear that social sustainability of the trawler was at an undesirable level for 2 indicators (i.e. rubric score of 1 or 2), at an acceptable level for 3 indicators (i.e. rubric score of 3 ) and at a desirable level for 12 indicators (i.e. rubric score of 4 or 5 ). This result indicates that social sustainability of the trawler is relatively high in comparison to standards set by international conventions and performance in the industry. Although certain rubrics are country-specific, this result is likely to also be high in comparison to other countries since Norway has a high standard of living and strict regulations in the fishing industry. Still, improvement opportunities exist for the trawler in terms of healthy working environment, product freshness and fish welfare during capture, among others.

Rubric scores from the social sustainability assessment of the Norwegian trawler were presented for each indicator individually, and not aggregated per issue because the relative weight of each indicator cannot be determined. Likewise, rubric scores were not aggregated across issues. The relative importance of each social sustainability issue was known from Veldhuizen et al. (2015), but scores from that study expressing the relative importance of the issues were not cardinal and could thus not be used for aggregation. These scores might be used by the trawler, however, to prioritize between indicators with identical rubric scores.

\section{Conclusion}

In this study, a method was presented for assessing social sustainability of capture fisheries. This method enables the inclusion of quantitative and qualitative aspects in one assessment by determining process and outcome indicators, and developing rubrics for these indicators. This method was applied in a social sustainability assessment of a Norwegian trawler that targets cod and haddock in the northeast Atlantic, but is also promising for social sustainability assessment of other capture fisheries. Assessment of the Norwegian trawler demonstrated that the method provides insight into social sustainability at the level of the vessel. Companies can use results from such an assessment to improve social sustainability by focusing improvement efforts towards issues with less desirable rubric scores, and to communicate outcomes from the assessment to consumers and as a result possibly receive market benefits such as price premiums or access to niche markets. Crucial for this is the recognition by 
consumers of the value of social sustainability of cod and haddock fisheries in the northeast Atlantic. Therefore, consumer interest in social sustainability of cod and haddock fisheries in the northeast Atlantic should be studied.

\section{Acknowledgements}

This research is supported by the project 'WhiteFish', a research project to the benefit of small and medium enterprise associations that is funded by the European Commission (286141) under the Seventh Framework Program (FP7). The authors would like to thank the manager and the employees of the Norwegian trawler for their participation in this research. 



\section{Consumer interest in social sustainability issues of whitefish from capture fisheries in the northeast Atlantic}

L.J.L. Veldhuizen, I.A. van der Lans, P.B.M. Berentsen, I.J.M. de Boer, E.A.M. Bokkers

Fish and Fisheries, accepted 


\begin{abstract}
Capture fisheries in the northeast Atlantic account for approximately $10 \%$ of all fish consumed from capture fisheries globally. Literature shows that consumers show considerable interest in social sustainability of products in general and of fish specifically. This interest, however, has not yet been investigated for fish from the northeast Atlantic. The first objective of this study, therefore, was to investigate whether consumers are interested in social sustainability issues of whitefish from the northeast Atlantic by determining preferences for four social sustainability issues with distinct benefits in relation to a known reference point (i.e. approach to overfishing). The second objective of this study was to determine to what degree case-specific and general psychographic consumer characteristics explain preferences for these issues. Choice modelling results from an online survey among 457 Dutch consumers show that consumers have the strongest preference for the environmental sustainability issue approach to overfishing. In addition, results on the social sustainability issues showed that consumers prefer fish welfare over product quality, worker safety and local employment, indicating that in this case, consumers place animal benefits over personal, worker and community benefits. The case-specific psychographic characteristic concern contributed most to explaining preferences for the environmental sustainability issue, whereas the general psychographic characteristic personal relevance contributed most to explaining preferences for the social sustainability issues. This result is likely explained by the principal focus on MSC certification in markets for fish products, which caused consumers to form opinions (e.g. concern) on overfishing, but not on social sustainability.
\end{abstract}




\section{Introduction}

Global consumption of fish increases with approximately 3\% per year (FAO, 2014c) and accounts for one-sixth of the global intake of animal proteins (FAO, 2011). Although an increasing share of fish consumed originates from aquaculture, the majority still originates from capture fisheries (approximately $63 \%$ in 2012) (FAO, 2014d). Capture fisheries in the northeast Atlantic, the world's third most important fishing area, account for approximately $10 \%$ of all fish from capture fisheries globally (FAO, 2014c).

Recently, fishing companies targeting whitefish (i.e. gadoids such as cod, haddock, whiting and saithe) in the northeast Atlantic initiated the EU $7^{\text {th }}$ Framework research project 'WhiteFish' to enable them to document sustainability of their products. A study on social sustainability issues within this research project showed that fishing companies attach most importance to issues concerning the well-being of employees (e.g. job fulfilment, working conditions and terms of employment), some importance to issues concerning product quality and local communities, but no importance to issues concerning fish welfare (Veldhuizen et al., 2015). Although the aforementioned study included the views of various stakeholders, consumers were not included.

Companies can use consumer views on the importance of social sustainability issues (i.e. consumer interest in social sustainability issues) to their advantage. A company that wants to improve its social sustainability, for example, can prioritize its improvement efforts based on consumer interest in various social sustainability issues (Veldhuizen et al., 2015). In addition, a company can use the knowledge about consumer interest in social sustainability issues to market the most valued issues and in that way differentiate their products from other, seemingly similar products (Chamberlin, 1933).

A meta-analysis on willingness to pay for sustainability issues demonstrated that consumers show considerable interest in social sustainability of products in general (Tully and Winer, 2014). In a choice experiment on seafood restaurants with different sustainability labels, McClenachan et al. (2016) found that consumers are interested in social sustainability of fish products, although willingness to pay for social sustainability was lower than for local sourcing and environmental sustainability. The aforementioned authors did not investigate why consumers have such preferences, although they did find that the benefits respondents associated with locally sourced seafood highly overlapped with the benefits they associated with social sustainability. A further investigation of social sustainability issues with distinct benefits such as personal, worker and community benefits could clarify why consumers prefer one social sustainability issue over another. 
64 | Chapter 4

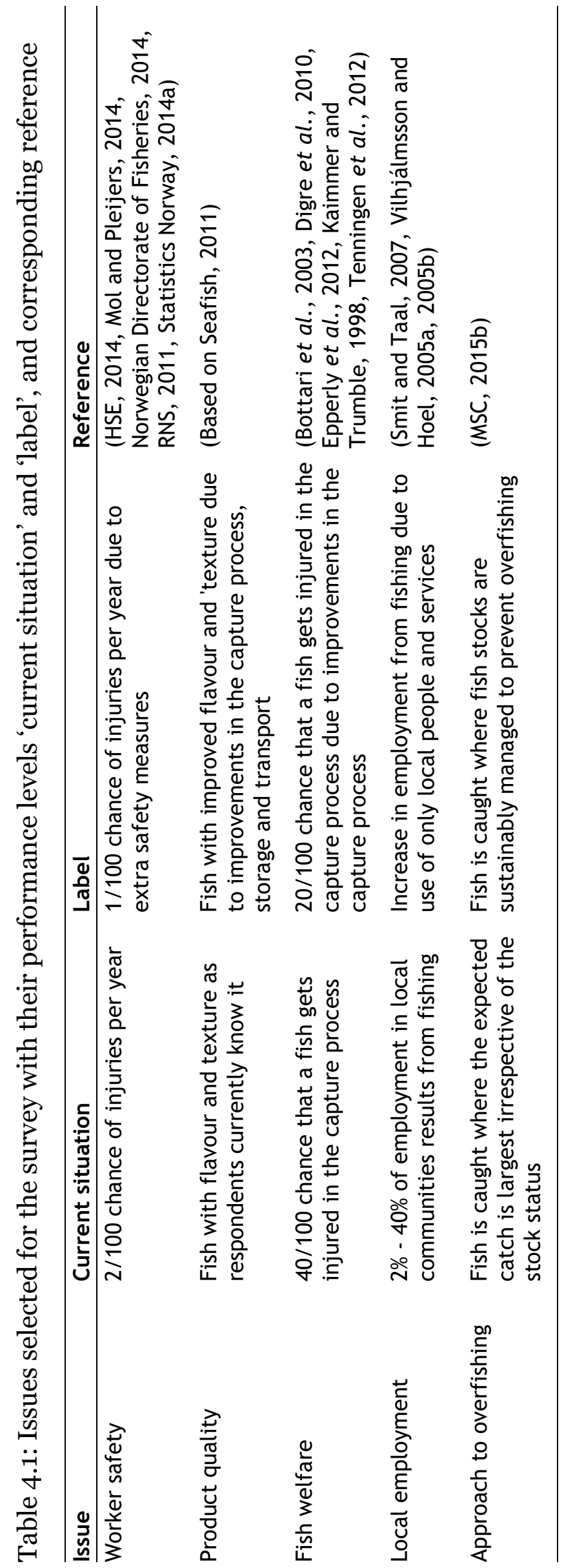


Consumers may differ in their perception of benefits associated with social sustainability issues due to their psychographic characteristics (Andorfer and Liebe, 2012), which can be case-specific or general. Case-specific psychographic characteristics, such as concern (De Pelsmacker and Janssens, 2007, Toma et al., 2011) and trust (De Pelsmacker et al., 2005), vary depending on context, object and time. General psychographic characteristics, on the other hand, are independent from context, object or time. Examples of general psychographic characteristics are personal relevance, which reflects importance at a high level of abstraction (Van Dam and Van Trijp, 2013) and value orientation (De Groot and Steg, 2008, 2010), which is a specific grouping of values (a value is "a desirable trans-situational goal varying in importance, which serves as a guiding principle in the life of a person" (Schwartz, 1992: 21)).

The first objective of this study was to investigate consumer interest in social sustainability issues of whitefish from the northeast Atlantic. Consumer interest was investigated by determining consumer preferences for several social sustainability issues with distinct benefits in relation to approach to overfishing, a known reference point. The second objective of this study was to determine to what degree case-specific and general psychographic characteristics explain preferences for sustainability issues.

\section{Methods}

\subsection{Choice modelling}

Choice modelling was used to determine consumer preferences for social sustainability issues of whitefish from the northeast Atlantic. In a choice modelling survey, respondents are asked to select their preferred product from among a number of products in multiple choice sets. These products are described by several features (e.g. in case of bicycles, the features could be the price, model and colour) that vary across products. The choices that respondents make can be used to determine preferences for the product features (Ben-Akiva and Lerman, 1985, Hensher et al., 2005).

\subsection{Survey}

An online survey was developed that consisted of questions on whitefish consumption and food purchases in general, the choice task and questions measuring psychographic characteristics. This survey was distributed by a Dutch research company from 2 to 9 November 2015 (see Section 2.3 for details on survey distribution).

\subsubsection{Choice task}

In the choice task of the survey, each respondent received ten choice sets. Each choice set consisted of two products that were described by their performance on five sustainability issues (Table 4.1), and an opt-out, i.e. the option to choose 
Which of the products below would you choose? Please answer this question as if you are considering to purchase whitefish.

\begin{tabular}{|l|l|l|}
\hline $\begin{array}{l}\text { Whitefish product 1, with labels } \\
\text { for: }\end{array}$ & $\begin{array}{l}\text { Whitefish product 2, with labels } \\
\text { for: }\end{array}$ & Neither \\
$\begin{array}{l}\text { Improved product quality } \\
\text { Improved fish welfare }\end{array}$ & $\begin{array}{l}\text { Improved worker safety } \\
\text { Improved approach to overfishing } \\
\text { Improved local employment }\end{array}$ & \\
\hline
\end{tabular}

Figure 4.1: An example of a choice set from the survey (translated from Dutch)

neither of the two products described. The issues worker safety, product quality, fish welfare, and local employment concern social sustainability and correspond to issue categories that were identified after consulting stakeholders on social sustainability issues relevant for cod and haddock fisheries in the northeast Atlantic (Veldhuizen et al., 2015). Worker safety concerns worker benefits, product quality concerns personal benefits, fish welfare concerns animal benefits and local employment concerns community benefits. The fifth issue approach to overfishing concerns environmental sustainability and is similar to the MSC label, a known reference point and the world's leading eco-label for capture fisheries (Ward and Philips, 2008) despite critique on subjectivity of its scoring process for certification (Christian et al., 2013, Jacquet et al., 2010) and the exclusion of, for example, small-scale fishers it can create (Hadjimichael and Hegland, 2016).

The performance of the five sustainability issues was varied across two levels, i.e. 1) the current situation in northeast Atlantic fisheries, or 2) a substantial improvement to this current situation, as indicated by a label (Table 4.1). Therefore, each product (see Figure 4.1) was described by one or more labels, where each label indicated a substantial improvement in the performance with respect to a particular issue, whereas the absence of a label indicated that the product did not entail any improvement.

An efficient selection of ten choice sets was obtained using the SAS macro \%choiceff (Kuhfeld, 2010). Pre-tests with a preliminary design showed that whenever a choice set contains two products that differ in the sheer number of labels by more than one, some respondents only considered the number of labels in making their choice, without considering the content of the labels. Therefore, a choice set design was generated by first selecting five choice sets where products with one label were compared with each other in a cyclic fashion (i.e. worker safety versus product quality, product quality versus fish welfare, fish welfare 
versus local employment, local employment versus approach to overfishing, and approach to overfishing versus worker safety). The macro \%choiceff was used to select five additional choice sets, maximizing D-efficiency under the constraint that the difference in the number of labels for the products was not larger than one. The latter constraint on the choice set design resulted in a selection of five additional choice sets where three labels were compared to two labels (see Figure 4.1 for an example). To avoid any possible bias due to the arbitrary pairing of labels in the first five choice sets, a second selection of ten choice sets (for a second version of the questionnaire) was generated by placing the remaining five pairs of labels in the first five choice sets, and the remaining combinations of three versus two labels in the last five choice sets. The relative D-efficiency was $51.8 \%$ for both designs. In both versions of the survey, the five choice sets in which respondents compared one label to another were shown first (in a randomized order) as these choice sets helped respondents to get familiar with the labels and the choice task. The five choice sets where three labels were compared to two labels were shown next, also in a randomized order.

\subsubsection{Psychographic characteristics}

The survey included six blocks of questions to determine four psychographic characteristics, i.e. concern, trust (i.e. trust in ability, trust in benevolence and trust in integrity; Mayer et al., 1995), personal relevance and value orientations (Table 4.2).

A higher level of concern for an issue was expected to lead to a stronger preference for improved performance on this issue, e.g. a higher level of concern for current worker safety in whitefish fisheries in the northeast Atlantic was expected to lead to a stronger preference for the issue worker safety. Likewise, a higher level of trust in the ability of fishing companies to accomplish the improvement to the current situation that the label for an issue represented was expected to lead to a stronger preference for improved performance on this issue. A higher level of trust in benevolence or integrity was expected to lead to a preference for the issues over the opt-out. A higher level of personal relevance for the sustainability issue related to food products in general was expected to lead to a stronger preference for improved performance on the corresponding sustainability issue in the survey. Finally, a higher score for the egoistic value orientation was expected to lead to a stronger preference for improved performance on the issue product quality, a higher score for the altruistic value orientation was expected to lead to a stronger preference for improved performance on the issues worker safety and local employment, and a higher score for the biospheric value orientation was expected to lead to a stronger preference for improved performance on the issues approach to overfishing and fish welfare. 


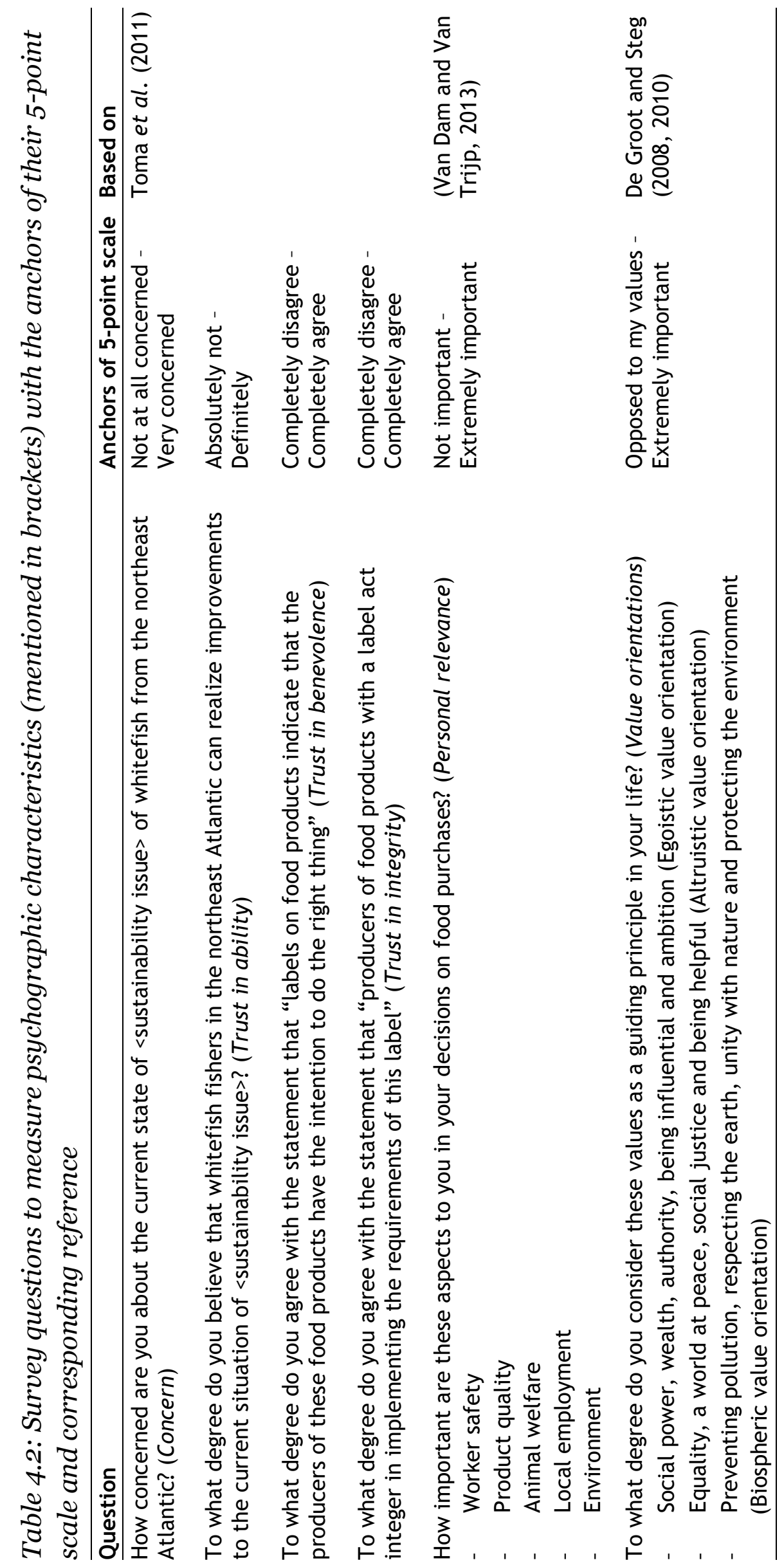




\subsection{Survey sampling}

The survey was aimed at consumers of whitefish in the Netherlands and was distributed by a commercial research company from the Netherlands among a subsection of their consumer panel. This subsection was selected to represent the Dutch population in terms of age, gender and education level. Respondents who did not consume any whitefish were redirected to the end of the survey.

Sample size was set at 400 surveys completed by consumers of whitefish, which was comparable to sample sizes used in studies by Auger et al. (2003), Mauracher et al. (2013) and Janssen and Hamm (2012) on consumer interest in social and environmental sustainability issues. This sample size considerably exceeds the minimum sample size of 50 that is obtained by following Orme's (2010) rule-ofthumb based on number of choice sets, number of alternatives per choice set, and the maximum number of attribute levels. This was done to account for the fact that a no-choice option was included in each choice set, the fractional factorial design had a D-efficiency of just over $50 \%$, and a number of moderating effects would be estimated. An evaluation of sample size using the guideline suggested by Louviere et al. (2000) reveals that a sample size of 400 respondents gives a 95\%confidence interval of \pm 0.015 around a probability of 0.50 , which was deemed sufficiently small. Power calculations using the procedure and R-code from De Bekker-Grob et al. (2015) indicate that a sample size of 400 gives a power of $80 \%$ to detect coefficients (i.e. a change in log odds) of 0.122 for sustainability labels in the main-effects conditional logit model, when determining significance at the level of $5 \%$. A coefficient of 0.122 corresponds to an increase in probability of 0.03 in situations in which the product without labels has a probability of 0.50 , and an increase of 0.02 when the product without labels has a probability of 0.20 .

\subsection{Analysis}

The analysis of the survey data consisted of two parts. The first part aimed to determine consumer preferences for the sustainability issues (main effects). The second part aimed to determine to what degree these preferences and variability therein were explained by case-specific and by general psychographic characteristics (moderating effects).

\subsubsection{Analysis of main effects}

Results from the choice sets were analysed using Stata statistical software, version 13 (StataCorp., 2013). The basis for these analyses lied in McFadden's (1974) random utility theory, which stipulates that within a given population, one can expect:

$$
U_{i j}=V_{j}+\varepsilon_{i j}
$$

where the utility $U_{i j}$ that individual $i$ derived from product $j$ consists of a systematic component $V_{j}$ that reflects the preferences of a population and an unobserved component $\varepsilon_{i j}$ that reflects the random component for individual $i$. 
To determine the main effects from the choice data, a conditional logit model was estimated where the systematic component $V_{j}$ was specified as:

$$
\begin{gathered}
V_{j}=\beta_{1} * \text { Opt }_{j}+\beta_{2} * \text { Worker }_{j}+\beta_{3} * \text { Quality }_{j}+\beta_{4} * \text { Fish }_{j}+\beta_{5} * \text { Local }_{j}+ \\
\beta_{6} * \text { Overfishing }_{j},
\end{gathered}
$$

where $\beta_{1}$ to $\beta_{6}$ are coefficients for the contribution of Optj, Worker $j$, Qualityj,

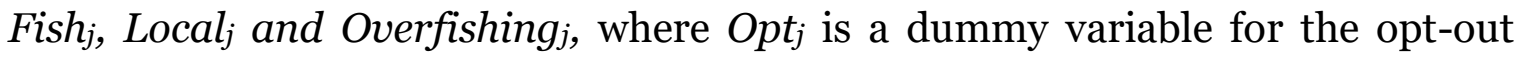
(with o for whitefish product, and 1 for the opt-out), and where Worker ${ }_{j}$, Qualityj, Fish $_{j}$, Local $_{j}$ and Overfishing ${ }_{j}$ are dummy variables for the presence of labels (with $\mathrm{o}=$ no label (current situation) and $1=$ label) for the issues worker safety, product quality, fish welfare, local employment and approach to overfishing, respectively.

\subsubsection{Analysis of moderating effects}

The second part of the data analysis aimed to determine the moderating effects of the psychographic characteristics on the main effects in the survey data. This part of the data analysis consisted of three steps, i.e. 1) validating the measuring of value orientations, 2) determining separate interaction models for each psychographic characteristic to select interaction terms for a final model, and 3) estimating the final model.

\section{Validating the measuring of value orientations}

Confirmatory factor analysis was performed to validate the 3 -factor model for the egoistic, altruistic and biospheric value orientations as identified by De Groot and Steg (2008, 2010). Model fit indices for this 3-factor model of 0.106 for the root mean square error of approximation (RMSEA) and 0.876 for the comparative fit index (CFI) (Table 4.3) are not in the acceptable ranges of <0.1 for RMSEA and $>0.9$ for CFI (Hair et al., 2006). However, a standardized root mean square residual (SRMR) of 0.088 is within the acceptable range of $<|4.0|$ (Hair et al., 2006).

Model fit of this confirmatory factor analysis was likely lowered by the egoistic value orientation, as indicated by low factor loadings for the values wealth, being influential and ambition on the egoistic value orientation (Table 4.3). Inspection of Pearson correlations among the values of each value orientation confirms this; correlations of the egoistic value orientation ranged from 0.21 to 0.60 , whereas correlations of the altruistic and biospheric value orientations ranged from 0.46 to 0.59 and from 0.41 to 0.78 , respectively. Modification indices following confirmatory factor analysis indicate that model fit could be improved by including the values being influential, social power and ambition in the altruistic value orientation rather than in the egoistic value orientation. However, these values have better factor loadings on the egoistic value orientation (0.398, 0.744 and 0.377 , respectively) than on the altruistic value orientation $(0.179,-0.352$ and 0.123, respectively). Therefore, the value orientations identified by De Groot and 
Table 4.3: Results from confirmatory factor analysis ${ }^{1}$ on the 3-factor model for the egoistic, altruistic and biospheric value orientation as identified by De Groot and Steg $(2008,2010)$

\begin{tabular}{lllll}
\hline Value orientation & Value & $\begin{array}{l}\text { Factor } \\
\text { loading }\end{array}$ & $\begin{array}{l}\text { Standard } \\
\text { error }\end{array}$ & P-value \\
\hline Egoistic value orientation & Social power & 0.744 & 0.007 & $<0.001$ \\
(Cronbach's a: 0.699) & Wealth & 0.471 & 0.008 & $<0.001$ \\
& Authority & 0.813 & 0.007 & $<0.001$ \\
& Being influential & 0.398 & 0.008 & $<0.001$ \\
& Ambition & 0.377 & 0.008 & $<0.001$ \\
Altruistic value orientation & Equality & 0.752 & 0.005 & $<0.001$ \\
(Cronbach's a: 0.821) & A world at peace & 0.716 & 0.005 & $<0.001$ \\
& Social justice & 0.731 & 0.005 & $<0.001$ \\
& Being helpful & 0.735 & 0.005 & $<0.001$ \\
Biospheric value orientation & Preventing pollution & 0.863 & 0.003 & $<0.001$ \\
(Cronbach's a: 0.881) & Respecting the earth & 0.767 & 0.004 & $<0.001$ \\
& Unity with nature & 0.722 & 0.005 & $<0.001$ \\
& Protecting the & 0.879 & 0.003 & $<0.001$ \\
& environment & & & \\
\hline
\end{tabular}

${ }^{1}$ Root mean square error of approximation (RMSEA): 0.106, standardized root mean square residual (SRMR): 0.088, comparative fit index (CFI): 0.876 .

Steg $(2008,2010)$ were maintained. The Cronbach's a's reported in Table 4.3 for these value orientations are satisfactory.

Interaction models

The second step in the analysis of moderating effects was to add interactions between each psychographic characteristic and the sustainability issues (following the hypotheses specified in Section 2.2.2) to the conditional logit model specified in Equation (2). An example of such a separate interaction model for one psychographic characteristic can be seen in Equation 3:

$$
\begin{gathered}
V_{j}=\beta_{1} * \text { Opt }_{j}+\beta_{2} * \text { Worker }_{j}+\beta_{3} * \text { ConcernW }_{i} * \text { Worker }_{j}+\beta_{4} * \\
\text { Quality }_{j}+\beta_{5} * \text { Concern }_{i} * \text { Quality }_{j}+\beta_{6} * \text { Fish }_{j}+\beta_{7} * \text { Concern }_{i} * \\
\text { Fish }_{j}+\beta_{8} * \text { Local }_{j}+\beta_{9} * \text { Concern }_{i} * \text { Local }_{j}+\beta_{10} * \text { Overfishing }_{j}+\beta_{11} * \\
\text { ConcernO }_{i} * \text { Overfishing }_{j},
\end{gathered}
$$

where Concern $_{i}$, Concern $_{i}$, Concern $_{i}$, Concern $_{i}$ and Concern $O_{i}$ indicate individual is concern about the current situation for worker safety, product quality, fish welfare, local employment, and approach to overfishing, respectively, and all other elements are as previously defined.

The significance of each interaction in the separate interaction models was assessed through likelihood ratio (LR) tests comparing the separate interaction model with all interactions against the same model without that particular interaction. In addition, the relative size of the contribution of each interaction was determined using the Bayesian information criterion (BIC). The BIC is a 


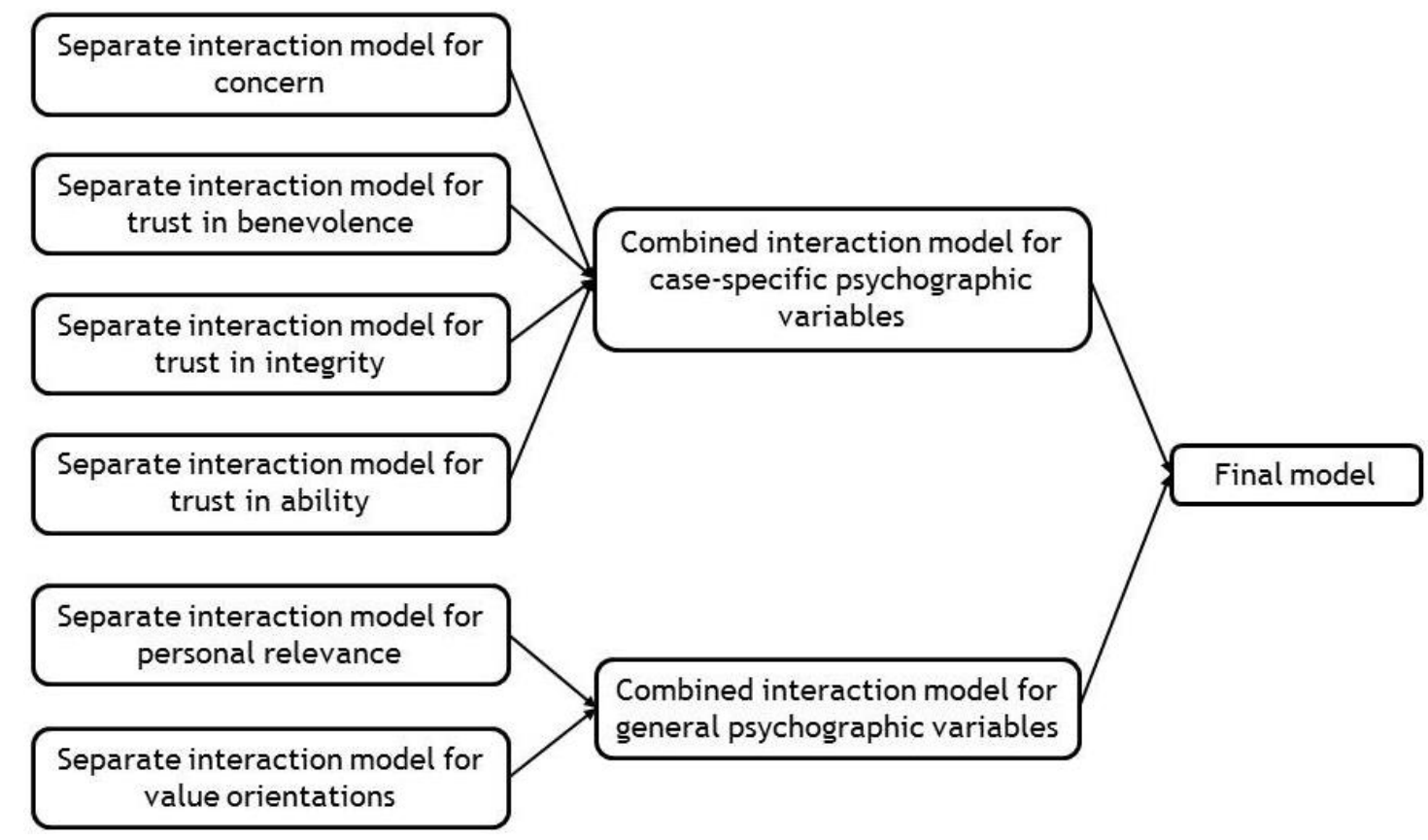

Figure 4.2: Model selection process

measure for the trade-off between model fit and model complexity (i.e. increased number of parameters). A lower BIC value indicates a better trade-off.

Next, the separate interaction models for concern, trust in ability, trust in benevolence and trust in integrity were combined into a larger interaction model for the case-specific psychographic characteristics (Figure 4.2), and the separate interaction models for personal relevance and the three value orientations were combined into a larger model for the general psychographic characteristics (Figure 4.2). The contribution of each interaction to these two combined interaction models was assessed using LR tests and BIC values. These two interaction models were then combined into one final model (Figure 4.2), where again, each interaction was assessed using LR tests and BIC values.

\section{Final model}

Interactions with significant and sizeable contributions to the separate, combined and final models were selected based on LR tests and BIC values, which resulted in a parsimonious final model. The stepwise procedure that was used to this end ensured that any masking effects due to possible collinearity of psychographics could be tracked. All psychographic characteristics that were used to estimate this final model were mean centred. As a result, each coefficient of the main effects (i.e. the sustainability issues) would hold for respondents with an average score on these psychographic characteristics, which enabled the comparison of the final model with the main effects model. 
Table 4.4: Age, gender and education level percentages in the survey sample compared to averages for the Netherlands (CBS, 2014, 2015)

\begin{tabular}{|c|c|c|c|}
\hline & & Percentage in the sample & Percentage in the Netherlands \\
\hline \multicolumn{4}{|l|}{ Age: } \\
\hline & $18-30$ & 11.2 & 23.4 \\
\hline _ & $31-40$ & 15.8 & 17.4 \\
\hline - & $41-50$ & 20.1 & 21.6 \\
\hline & $51-60$ & 24.9 & 20.4 \\
\hline & $61-70$ & 28.0 & 17.3 \\
\hline \multicolumn{4}{|c|}{ Gender: } \\
\hline - & Male & 51.7 & 49.5 \\
\hline - & Female & 48.3 & 50.5 \\
\hline \multicolumn{4}{|c|}{ Education level: } \\
\hline - & Low & 25.1 & 34.0 \\
\hline - & Medium & 46.2 & 41.0 \\
\hline - & High & 28.7 & 25.0 \\
\hline
\end{tabular}

\section{Results}

\subsection{Descriptive statistics}

In total, 561 respondents participated in the survey, which is more than the predetermined target of 400 completed surveys because the survey was not immediately closed after meeting this target. A total of 39 respondents indicated that they did not consume whitefish and, therefore, were excluded from the survey. A further 65 respondents did not complete the survey, resulting in 457 completed surveys. Table 4.4 displays the age, gender and education level distributions of the survey sample and compares these distributions to averages for the Netherlands. This Table shows that people aged 61-70 and people with a medium education level were overrepresented in the sample, whereas people aged 18-30 and people with a low education level were underrepresented. Overall, however, the survey sample is fairly representative of the Dutch population in terms of age, gender and education level.

\subsection{Main effects}

Table 4.5 shows the result from the conditional logit model as specified in Equation (2). This Table shows that people prefer the issue approach to overfishing over the issues fish welfare, product quality and worker safety. The parameter estimate for the issue local employment is not significant. The parameter estimate for the opt-out is negative, which means that people prefer a whitefish product without any labels over no whitefish product. 
Table 4.5: Results from the conditional logit model that was fitted to the survey data

\begin{tabular}{lcll}
\hline & Coefficient $^{2}$ & Standard error & P-value \\
\hline Opt-out & -0.913 & 0.084 & $<0.001$ \\
Worker safety & 0.350 & 0.051 & $<0.001$ \\
Product quality & 0.610 & 0.052 & $<0.001$ \\
Fish welfare & 0.696 & 0.052 & $<0.001$ \\
Local employment & 0.096 & 0.050 & 0.054 \\
Approach to overfishing & 1.052 & 0.053 & $<0.001$ \\
\hline
\end{tabular}

${ }^{1}$ Number of observations: 13,710, log likelihood: $-3817 \cdot 37$, McFadden's pseudo R²: 0.240

2 The coefficients indicate to what degree each of these issues contribute to the likelihood that a respondent will choose a product with labels for those issues

Table 4.6: Mean scores ${ }^{1}$ and standard deviations for the psychographic characteristics 'concern', 'trust in ability', 'trust in benevolence', 'trust in integrity', 'personal relevance', 'egoistic value orientation', 'altruistic value orientation' and 'biospheric value orientation'

\begin{tabular}{ccc}
\hline & Mean score & Standard deviation \\
\hline Concern: & -0.85 & \\
- Worker safety & -0.67 & 0.89 \\
- Product quality & -0.34 & 0.92 \\
- Fish welfare & -0.72 & 1.06 \\
- Local employment & -0.07 & 0.92 \\
- Approach to overfishing & & 1.11 \\
Trust in ability: & 0.69 & \\
- Worker safety & 0.46 & 0.83 \\
- Product quality & 0.58 & 0.81 \\
- Fish welfare & 0.37 & 0.88 \\
- Local employment & 0.74 & 0.81 \\
- Approach to overfishing & 0.57 & 0.89 \\
- Overall trust in ability & 0.56 & 0.63 \\
Trust in benevolence & 0.34 & 0.86 \\
Trust in integrity & & 0.84 \\
Personal relevance: & -0.05 & \\
- Worker safety & 0.51 & 0.98 \\
- Product quality & 0.21 & 0.71 \\
- Animal welfare & -0.47 & 1.00 \\
- Local employment & -0.03 & 0.93 \\
- Environment & 0.55 & 0.90 \\
Egoistic value orientation & 1.92 & 0.51 \\
Altruistic value orientation & 1.72 & 0.59 \\
Biospheric value orientation & 0.70 \\
\hline
\end{tabular}

${ }^{1}$ Concern, trust in ability, trust in benevolence, trust in integrity and personal relevance were scored on a 5-point scale ranging from a strong level of disagreement or unimportance (-2) to a strong level of agreement or importance (2). The egoistic, altruistic and biospheric value orientation were scored on a 5 -point scale that ranged from 'Opposed to my values' (-1), via 'Not important' (0) to 'Extremely important' (3) 


\subsection{Moderating effects of psychographic characteristics}

\subsubsection{Mean scores and standard deviations of psychographic characteristics}

Table 4.6 shows the mean scores and standard deviations for the psychographic characteristics, i.e. concern, trust in ability, trust in benevolence, trust in integrity, personal relevance, egoistic value orientation, altruistic value orientation and biospheric value orientation. The negative means for concern in Table 4.6 show that in general, respondents are not concerned about the current situation of the five sustainability issues of capture fisheries in the northeast Atlantic. However, the relatively large standard deviations indicate that there is considerable variability in concern. The positive means for all elements of trust show that, in general, respondents trust that fishing companies can achieve the improvements in the current situation of the sustainability issues that the labels represented (trust in ability), and that respondents trust the benevolence and the integrity of labels in general (Table 4.6). The positive means for personal relevance of product quality and animal welfare show that, in general, these issues are relevant to respondents, which means that they consider these issues in their purchase decisions, whereas they generally do not consider the other issues in their purchase decisions (Table 4.6). The scores for the value orientations in Table 4.6 show that respondents' values aligned more with the altruistic and the biospheric value orientation than with the egoistic value orientation.

\subsubsection{Model selection}

Table 4.7 shows the contributions of the different interactions to separate, combined and final interaction models, as indicated by their P-values and contribution to BIC $(\triangle \mathrm{BIC})$. An interaction was deleted from the subsequent interaction model (i.e. the combined or final model, as indicated by a '-' in Table 4.7) when the P-value for this interaction was not significant or when its contribution to BIC was negative.

The P-values for concern in Table 4.7 show that all interactions between concern and the sustainability issues significantly contributed to the separate interaction model for concern, the combined interaction model for case-specific psychographic characteristics and the final model. The changes in BIC for all interactions except product quality are positive, indicating that these interactions contributed to the separate, combined and final interaction models.

The P-values for trust in ability show that the interactions between trust in ability and all sustainability issues except local employment significantly contributed to the separate, combined and final interaction models (Table 4.7). The changes in BIC for the opt-out, worker safety, fish welfare and approach to overfishing are positive, indicating that these interactions for trust in ability contributed to the separate, combined and final interaction models. The P-values for trust in benevolence show that only the interaction between benevolence and the opt-out 
Table 4.7: P-value and contribution to Bayesian information criterion $(\triangle B I C)$ of each interaction in the separate, combined and final interaction models

\begin{tabular}{|c|c|c|c|c|c|c|}
\hline \multirow[t]{2}{*}{ Interaction } & \multicolumn{2}{|c|}{$\begin{array}{l}\text { Separate } \\
\text { interaction } \\
\text { models }\end{array}$} & \multicolumn{2}{|c|}{$\begin{array}{l}\text { Combined } \\
\text { interaction } \\
\text { models }\end{array}$} & \multicolumn{2}{|c|}{ Final model } \\
\hline & P-value & $\Delta \mathrm{BIC}$ & P-value & $\Delta \mathrm{BIC}$ & P-value & $\triangle \mathrm{BIC}$ \\
\hline \multicolumn{7}{|c|}{$\begin{array}{l}\text { Case-specific psychographic } \\
\text { characteristics }\end{array}$} \\
\hline Worker safety & $<0.001$ & 161.0 & $<0.001$ & 134.3 & $<0.001$ & 53.2 \\
\hline Product quality & $<0.001$ & 27.6 & $<0.001$ & 22.7 & $<0.001$ & -3.9 \\
\hline Fish welfare & $<0.001$ & 155.6 & $<0.001$ & 104.2 & $<0.001$ & 20.2 \\
\hline Local employment & $<0.001$ & 66.2 & $<0.001$ & 52.6 & $<0.001$ & 18.6 \\
\hline Approach to overfishing & $<0.001$ & 288.9 & $<0.001$ & 198.1 & $<0.001$ & 123.9 \\
\hline \multicolumn{7}{|c|}{ Trust in ability of sustainability issue $x$} \\
\hline Opt-out & $<0.001$ & 40.9 & $<0.001$ & 16.1 & $<0.001$ & 3.5 \\
\hline Worker safety & $<0.001$ & 21.2 & $<0.001$ & 6.5 & $<0.001$ & 3.3 \\
\hline Product quality & $<0.001$ & 2.6 & $<0.001$ & 7.2 & 0.019 & -4.0 \\
\hline Fish welfare & $<0.001$ & 52.4 & $<0.001$ & 31.0 & $<0.001$ & 6.2 \\
\hline Local employment & $<0.001$ & 1.9 & 0.017 & -3.8 & & - \\
\hline Approach to overfishing & $<0.001$ & 101.6 & $<0.001$ & 41.1 & $<0.001$ & 43.0 \\
\hline \multicolumn{7}{|l|}{ Trust in benevolence $x$} \\
\hline Opt-out & $<0.001$ & 8.2 & 0.001 & 1.9 & 0.014 & -3.5 \\
\hline Worker safety & $<0.001$ & 1.5 & 0.034 & -5.0 & - & - \\
\hline Product quality & 0.402 & -8.8 & - & - & - & - \\
\hline Fish welfare & 0.004 & -1.4 & - & - & - & - \\
\hline Local employment & 0.166 & -7.6 & - & - & - & - \\
\hline Approach to overfishing & 0.037 & -5.2 & - & - & - & - \\
\hline \multicolumn{7}{|l|}{ Trust in integrity $x$} \\
\hline Opt-out & 0.295 & -8.4 & - & - & - & - \\
\hline Worker safety & 0.003 & -0.5 & - & - & - & - \\
\hline Product quality & 0.190 & -7.8 & - & - & - & - \\
\hline Fish welfare & 0.005 & -1.7 & - & - & - & - \\
\hline Local employment & 0.002 & 0.0 & 0.039 & -5.3 & - & - \\
\hline Approach to overfishing & 0.171 & -7.7 & - & - & - & - \\
\hline \multicolumn{7}{|c|}{ General psychographic characteristics } \\
\hline \multicolumn{7}{|c|}{ Personal relevance of sustainability issue $\mathrm{x}$} \\
\hline Worker safety & $<0.001$ & 198.2 & $<0.001$ & 242.0 & $<0.001$ & 76.0 \\
\hline Product quality & $<0.001$ & 126.5 & $<0.001$ & 286.4 & $<0.001$ & 77.4 \\
\hline Fish welfare & $<0.001$ & 192.7 & $<0.001$ & 80.7 & $<0.001$ & 30.7 \\
\hline Local employment & $<0.001$ & 74.6 & $<0.001$ & 70.9 & $<0.001$ & 18.6 \\
\hline Approach to overfishing & $<0.001$ & 109.8 & $<0.001$ & 27.6 & 0.002 & 0.2 \\
\hline \multicolumn{7}{|l|}{ Egoistic value orientation $\mathrm{x}$} \\
\hline Opt-out & 0.141 & -0.7 & - & - & - & - \\
\hline Product quality & 0.105 & -5.3 & - & - & - & - \\
\hline \multicolumn{7}{|l|}{ Altruistic value orientation $\mathrm{x}$} \\
\hline Opt-out & $<0.001$ & 130.2 & $<0.001$ & 155.6 & $<0.001$ & 11.7 \\
\hline Worker safety & $<0.001$ & -6.8 & - & - & - & - \\
\hline Local employment & 0.073 & -9.4 & - & - & - & - \\
\hline \multicolumn{7}{|l|}{ Biospheric value orientation $\mathrm{x}$} \\
\hline Opt-out & 0.210 & 12.1 & - & - & - & - \\
\hline Fish welfare & $<0.001$ & 67.9 & $<0.001$ & 17.2 & $<0.001$ & 4.6 \\
\hline Approach to overfishing & $<0.001$ & 54.3 & $<0.001$ & 23.8 & 0.161 & -7.6 \\
\hline
\end{tabular}

${ }^{1} \mathrm{~A}$ '-' indicates that the P-value and $\triangle \mathrm{BIC}$ for an interaction are not given because this interaction was excluded based on its non-significant P-value or negative BIC value in the preceding interaction model 
contributed significantly to the separate, combined and final interaction models. However, the negative BIC value for this interaction shows that the increase in model fit does not compensate for the increase in model complexity. The P-values and changes in BIC for trust in integrity show that neither of the interactions between trust and the issues contributes to the final model.

The P-values and changes in BIC for personal relevance show that all interactions between personal relevance and the sustainability issues significantly contributed to the separate, combined and final interaction models (Table 4.7).

The hypothesised interactions for the egoistic value orientation with the opt-out and product quality did not significantly or sizeably contribute to the separate interaction model (Table 4.7). Only the interaction between the altruistic value orientation and the opt-out contributed significantly and sizeably to the separate, combined and final interaction models. Finally, of the hypothesised interactions of the biospheric value orientation with the opt-out, fish welfare and approach to overfishing, only the interaction with fish welfare contributed significantly and sizeably to the separate, combined and final models.

A comparison of the changes in BIC in the final model for all interactions shows that for the social sustainability issues, personal relevance contributed most to explaining preferences, whereas for the environmental sustainability issue approach to overfishing, concern contributed most to explaining preferences.

\subsubsection{Final conditional logit model}

Table 4.8 shows more detailed results for the final conditional logit model, which includes all interactions with significant $\mathrm{P}$-values and positive BIC values from Table 4.7. All coefficients in Table 4.8 are based on mean-centred psychographic characteristics, which means that the coefficients for the labels hold for respondents with an average score on the psychographic characteristics. As a consequence, the order of the coefficients for the issues in Table 4.8 is the same as the order of these coefficients in the main effects model (Table 4.5), i.e. approach to overfishing is preferred over, in order of importance, fish welfare, product quality, worker safety and local employment. The coefficients have become more extreme though, due to the improved fit of the model.

Table 4.8 shows that the coefficient for the opt-out is negative, indicating that, on average, respondents preferred any whitefish product over no whitefish product. The interaction between the opt-out and overall trust in ability indicates that respondents who trust that the improvements represented by the labels can be achieved, are more likely to choose a whitefish product than to not choose a whitefish product. The interactions between the opt-out and the altruistic value orientation indicates that respondents who are more altruistic are more likely to choose a whitefish product than to not choose a whitefish product. 
Table 4.8: Results for the final conditional logit model ${ }^{1}$ with all hypothesised and significant interactions ${ }^{2}$

\begin{tabular}{clll}
\hline & Coefficient & Standard error & P-value \\
\hline Opt-out x & -1.124 & 0.101 & $<0.001$ \\
Overall trust in ability & -0.551 & 0.110 & $<0.001$ \\
Altruistic value orientation & -0.584 & 0.113 & $<0.001$ \\
Worker safety x & 0.486 & 0.057 & $<0.001$ \\
Concern & 0.400 & 0.053 & $<0.001$ \\
Trust in ability & 0.184 & 0.054 & 0.01 \\
Personal relevance & 0.455 & 0.050 & $<0.001$ \\
Product quality x & 0.814 & 0.057 & $<0.001$ \\
Personal relevance & 0.692 & 0.062 & $<0.001$ \\
Fish welfare x & 0.961 & 0.060 & $<0.001$ \\
Concern & 0.245 & 0.048 & $<0.001$ \\
Trust in ability & 0.214 & 0.055 & $<0.001$ \\
Personal relevance & 0.348 & 0.055 & $<0.001$ \\
Biospheric value orientation & 0.247 & 0.074 & 0.001 \\
Local employment x & 0.193 & 0.055 & $<0.001$ \\
Concern & 0.258 & 0.052 & $<0.001$ \\
Personal relevance & 0.339 & 0.052 & $<0.001$ \\
Approach to overfishing x & 1.351 & 0.062 & $<0.001$ \\
Concern & 0.520 & 0.045 & $<0.001$ \\
Trust in ability & 0.380 & 0.051 & $<0.001$ \\
Personal relevance & 0.204 & 0.053 & $<0.001$ \\
\hline
\end{tabular}

${ }^{1}$ Number of observations: 13,710, log likelihood: -3301.61, McFadden's pseudo R²: 0.342

${ }^{2}$ All psychographic characteristics in the conditional logit model were mean centred so that the coefficients of the main effects indicate values for respondents with an average score on these psychographic characteristics

The positive coefficient for worker safety indicates that, on average, respondents have a preference for improved worker safety over current worker safety aboard fishing vessels. In addition, respondents with above average concern for worker safety have a stronger preference for this issue than respondents with below average concern for worker safety, as indicated by the positive coefficient for the interaction between concern for worker safety and worker safety. Respondents with above average trust in fishing companies' ability to improve the current situation for worker safety have a stronger preference for this issue than respondents with below average trust in ability. Finally, respondents with above average personal relevance for worker safety, i.e. respondents who commonly take worker safety into account in their purchasing decisions, have a stronger preference for this issue than respondents with below average personal relevance for worker safety. Coefficients for the interactions with worker safety show that personal relevance has the largest influence on preferences for worker safety.

The positive coefficient for product quality indicates that respondents have a preference for improved quality of whitefish products. Respondents with above average personal relevance for this issue have a stronger preference for product quality than respondents with below average personal relevance for this issue. 
The positive coefficient for fish welfare indicates that respondents have a preference for whitefish products that take fish welfare into consideration. This preference is stronger for respondents with above average concern for fish welfare, trust in fishing companies' ability to improve fish welfare, personal relevance (i.e. usually considering animal welfare in purchasing decisions) and biospheric value orientation. Coefficients for the interactions with fish welfare show that personal relevance has the largest influence on preferences for fish welfare.

The positive coefficient for local employment indicates that respondents have a preference for whitefish products that pay attention to local employment. This preference is stronger for respondents with above average concern for local employment and personal relevance (i.e. respondents who usually consider local employment in their purchasing decisions) than for respondents with below average concern and personal relevance. Coefficients for the interactions with local employment show that personal relevance has the largest influence on preferences for local employment.

Finally, the positive coefficient for approach to overfishing indicates that respondents have a preference for whitefish products with an improved approach to overfishing. This preference is stronger for respondents with above average concern for approach to overfishing, trust in fishing companies' ability to improve their approach to overfishing and personal relevance (i.e. respondents who usually consider the environment in their purchasing decisions) than respondents with below average concern, trust in ability and personal relevance (Table 4.8). Coefficients for the interactions with approach to overfishing show that concern has the largest influence on preferences for approach to overfishing.

\section{Discussion}

This study on consumer preferences for sustainability issues of whitefish from the northeast Atlantic showed that consumers prefer the environmental sustainability issue approach to overfishing over the social sustainability issues. Similarly, in a choice experiment on seafood restaurants with different sustainability labels, McClenachan et al. (2016) found that consumers had a higher willingness to pay for environmental sustainability than for social sustainability. The present study additionally showed that the social sustainability issue fish welfare is preferred over, in order, the social sustainability issues product quality, worker safety and local employment. These preferences indicate that in this case, consumers placed animal benefits over personal benefits, worker benefits and community benefits.

In contrast to consumers, cod and haddock fishing companies in the northeast Atlantic attach greatest importance to issues concerning the well-being of their employees (such as worker safety), some importance to issues concerning product 
quality and local employment, and no importance to fish welfare (Veldhuizen et al., 2015). Hence, results from the present study indicate that, based on consumer perspectives and therefore also based on companies' economic perspective, cod and haddock fishing companies might need to reconsider their prioritization of social sustainability issues and dedicate more attention to fish welfare.

Preferences for the sustainability issues were mainly explained by concern, trust in ability and personal relevance. The case-specific psychographic characteristic concern contributed most to explaining preferences for the environmental sustainability issue approach to overfishing, whereas the general psychographic characteristic personal relevance contributed most to explaining preferences for the social sustainability issues worker safety, product quality, fish welfare and local employment. The reason that these two types of sustainability issues are explained by different types of psychographic characteristics could be that consumers have been exposed to environmental sustainability (via MSC certification), but not to social sustainability issues in markets for fish products. As a result, people are likely to have formed opinions (e.g. concern) on overfishing that guide their behaviour, whereas people have not formed such opinions on social sustainability, which caused them to turn to predefined mindsets as expressed by, for example, personal relevance.

The case-specific psychographic characteristics trust in benevolence and trust in integrity did not contribute to explaining preferences for the sustainability issues, whereas trust in ability did. De Pelsmacker et al. (2005) and Thøgersen et al. (2010), on the other hand, found that trust influences consumer preferences for sustainability issues. These different findings with regard to the influence of trust on consumer preferences are likely explained by differences in the operationalization of this concept. In the present study, trust in benevolence and trust in integrity were determined for labels in general, while trust in ability was determined for the specific labels used in the survey, which could have influenced the finding that only trust in ability influences consumer preferences. On the other hand, De Pelsmacker et al. (2005) and Thøgersen et al. (2010) used the concept of trust without clarifying which aspect of trust (i.e. ability, benevolence and integrity; Mayer et al., 1995) this concept refers to. The finding that trust in ability contributed to explaining consumer preferences for sustainability issues, whereas trust in benevolence and trust in integrity did not, could indicate that it is relevant to distinguish between different aspects of trust.

The general psychographic characteristics egoistic value orientation, altruistic value orientation and biospheric value orientation did not contribute to explaining preferences for the sustainability issues to any (substantial) degree. In contrast, Van Dam and Van Trijp (2011) found that sustainability motives for purchasing sustainable products are for an important part explained by the biospheric value orientation, but not by the egoistic or altruistic value orientation. 
These authors, however, only included general psychographic characteristics in their study, which could explain why the biospheric value orientation was found to be of more influence in Van Dam and Van Trijp (2011) than in the present study. Barber et al. (2014) did include case-specific and general psychographic characteristics in their study and found that people with a positive and substantial willingness to pay for pro-environmental goods can be distinguished from people with a negative willingness to pay for such products based on their alignment with self-transcendence values (altruistic value orientation) versus self-enhancement values (egoistic value orientation). Such a dichotomy in attitudes towards sustainability based on value orientation was perhaps not identified in the present study because there was only a trade-off between sustainability issues and not between sustainability issues and product prices. When product prices would have been included, positive and negative attitudes towards sustainability had possibly been more pronounced.

The present study shows that consumers are interested in social sustainability of fish products at least to some degree. To approximate the degree of actual consumer interest, willingness to pay estimates are often used, even though willingness to pay estimates commonly overestimate actual consumer interest (Murphy et al., 2005). Since the price premium that consumers are currently paying for MSC certification of whitefish is already known from literature, results from the present study can be related to that price premium to determine the potential degree of consumer interest. The price premium for MSC certification (which is similar to the issue approach to overfishing in the present study) is approximately 10\% (Roheim et al., 2011, Sogn-Grundvåg et al., 2013), which means that it is likely relevant for fishing companies to explore their impact on fish welfare and other social sustainability issues in addition to their approach to overfishing.

There were two performance levels for the social sustainability issues in the survey, i.e. current situation for whitefish from the northeast Atlantic and an improvement to this current situation, as indicated by a label. Descriptions on the current situation were based on national statistics, reports and scientific literature. Descriptions on improvements to these situations were based on a 50\% improvement to the current situation or a substantial improvement to the current situation in case a quantitative description was not possible. The specific level of improvement that was chosen (i.e. 50\%) could have influenced the preferences that were identified in the present study. However, consumers in actual markets are commonly confronted with various labels rather than with the specific improvements they represent. The choice sets in the survey only displayed the labels and thus closely mimicked actual markets in that sense. Therefore, it is more likely that respondents in the survey focused on the labels rather than on the specific improvements to the current situation that these labels represented. As a result, it is not likely that the specific improvement level chosen influenced 
preferences for the sustainability issues as identified in the present study to any substantial degree.

\section{Conclusion}

This study on consumer preferences for social sustainability issues of whitefish from the northeast Atlantic showed that consumers prefer the environmental sustainability issue approach to overfishing over social sustainability issues. With regard to the social sustainability issues, this study showed that consumers have the strongest preference for fish welfare, indicating the pertinence of this issue for fishing companies. Consumers prefer this issue over the issues product quality, worker safety and local employment, which means that in this case, consumers place animal benefits over personal benefits, worker benefits and community benefits. The case-specific psychographic characteristic concern contributed most to explaining preferences for the environmental sustainability issue approach to overfishing, whereas personal relevance (a general psychographic characteristic) contributed most to explaining preferences for the social sustainability issues. This result is likely explained by the principal focus on MSC certification in markets for fish products, causing consumers to have formed opinions (e.g. concern) on overfishing, but not on social sustainability. Hence, introducing social sustainability issues of fish products could result in growing concern and consumer interest through increased exposure.

\section{Acknowledgements}

This research is supported by the project 'WhiteFish', a research project to the benefit of small and medium enterprise associations that is funded by the European Commission (286141) under the Seventh Framework Program (FP7). The authors would like to thank the research company for their assistance in performing the survey and all respondents for their participation in the survey. 




\section{Fish welfare in capture fisheries: a systematic review of injuries and mortality}

L.J.L. Veldhuizen, I.J.M. de Boer, P.B.M. Berentsen, E.A.M. Bokkers

Submitted 


\begin{abstract}
Concerns about the welfare of production animals have extended from farm animals to fish, but an overview of the impact of especially capture fisheries on fish welfare is lacking. This review provides a synthesis of 80 articles, which demonstrate that research interest in fish welfare in capture fisheries has increased over time and that research has focused more on trawls and hooks than on purse seines, gillnets, traps and particularly seines. In this review, we determined the occurrence of external injuries and mortality, and the influence of gear characteristics, fish characteristics and context variables on external injuries and mortality. Results show that scale, skin and fin injuries occur more frequently in trawls, purse seines, gillnets, traps and seines than in hooks, whereas hooking injuries occur in hooks only. Pressure injuries can occur in all gear types when deployed at greater depth. Furthermore, mortality is generally higher in trawls, purse seines and seines than in gillnets, hooks and traps. Mortality appears to increase with decreasing fish length, and differs across fish species. A greater capture depth and a longer fishing duration were associated with more external injuries and higher mortality, whereas a large change in water temperature, a longer duration of air exposure and a high density in the net were associated with higher mortality only. These aforementioned relations provide options to reduce injuries and mortality from commercial capture fisheries. Implementation of such options, however, would require analysis of potential trade-offs between welfare benefits, and ecological and economic consequences.
\end{abstract}




\section{Introduction}

Concerns about the welfare of production animals have extended from farm animals to fish in aquaculture and capture fisheries (Diggles et al., 2011, Huntingford et al., 2006). Huntingford et al. (2006) reviewed the scientific literature on fish welfare and identified welfare issues that arise in aquaculture, recreational fisheries and ornamental fish keeping, but they did not identify the welfare issues that arise in capture fisheries other than pointing out that "there is very little information on the welfare of fish in the context of commercial fisheries" (Huntingford et al., 2006: 362).

This limited information on fish welfare in commercial capture fisheries likely has two causes. First, for long, fish were generally believed to be unable to experience pain (Braithwaite and Boulcott, 2008). An animal is able to experience pain when it has the nervous system that enables it to detect noxious stimuli (i.e. nociception) and when it can consciously experience such stimuli (Ashley and Sneddon, 2008). Although studies have demonstrated the existence of nociception in several fish species (e.g. Ashley et al., 2006, 2007, Sneddon et al., 2003), there is still debate whether or not fish can consciously experience noxious stimuli. Chandroo et al. (2004b), Huntingford et al. (2006) and Braithwaite (2010), among others, advocate a focus on the welfare of individual fish based on the perspective that fish can consciously experience noxious stimuli, whereas Diggles et al. (2011), Rose et al. (2014) and Key (2014), among others, dismiss this perspective and advocate a focus on fish welfare from a population perspective, aimed at reducing mortality (which relates to fish welfare) due to fishing (Diggles et al., 2011, Rose et al., 2014). Despite the debate whether or not fish can consciously experience noxious stimuli, fish welfare is increasingly acknowledged to be an important issue (Arlinghaus et al., 2007, Braithwaite and Boulcott, 2008, Branson, 2008).

Second, information on fish welfare in capture fisheries might be limited because, contrary to fish in aquaculture, the welfare of fish in capture fisheries is directly affected by humans only during the fishes' final life stage. In capture fisheries, the welfare of fish is affected by the various fishing gear types used in the capture process, such as trawls, purse seines and traps (Metcalfe, 2009). Each of these gear types has its own modus operandi, for example in terms of the depths at which the gear type is deployed and the species that it targets. Consequently, the impact on fish welfare likely differs per gear type; compare e.g. a fish being caught by hook and line with a fish being caught by a trawl net (Metcalfe, 2009). Hence, an investigation into the impact of the capture process on fish welfare, should acknowledge these differences in gear types.

Animal welfare can be considered from three overlapping approaches, i.e. the function-based approach, the nature-based approach and the feelings-based 
approach (Fraser, 2008, Fraser et al., 1997). The function-based approach prescribes that an animal should be in good health, with its biological systems functioning well and not being forced to respond beyond its capacity. The naturebased approach prescribes that an animal is able to lead a natural life and express its natural behaviour. The feelings-based approach prescribes that an animal should feel well, be free from negative experiences and have access to positive experiences. Of these three approaches, the function-based approach provides direct and relatively easy measured information on welfare (Diggles et al., 2011, Huntingford et al., 2006), which is most useful at this early stage in the research on fish welfare in capture fisheries. Two function-based indicators that are relatively easy measured in both field and laboratory settings are external injuries and mortality, where an increase in injuries or mortality can be interpreted as a deterioration of fish welfare. External injuries are the visible effects of the capture process on the fish, whereas mortality is the ultimate consequence resulting from the severity of this capture process.

The objective of this study was to conduct a systematic literature review to determine what is known about the effects of the capture process in capture fisheries on fish welfare. This review is based on the function-based approach to fish welfare and focuses on external injuries and mortality in teleost (ray-finned) fish species caught in commercial fisheries. Although every fish species has its own species-specific characteristics, external injuries and mortality can be assessed across species.

\section{Methods}

The systematic literature review on fish welfare in capture fisheries started with the development of a search strategy that was subsequently applied to the literature. Next, the information that was extracted from each relevant article in the literature search was synthesized in relation to this review's objective (Brunton et al., 2012, European Food Safety Authority, 2010).

\subsection{Development and application of a search strategy}

The first step in developing a search strategy for this review was to determine relevant search terms based on key concepts in the research objective, i.e. capture fisheries and fish welfare. Potential search terms relating to capture fisheries were based on the different gear types used in capture fisheries (Nédélec and Prado, 1990). Since not all these gear types are used in the commercial capture of teleost fish, only trawl nets, hook and line (hereafter referred to as hooks), surrounding nets (hereafter referred to as purse seines), gillnets and entangling nets (hereafter referred to as gillnets), traps, and seine nets were included (see Appendix 5.1 for a description of these gear types and their subtypes). Potential search terms relating to fish welfare were identified based on two earlier reviews on fish welfare (Ashley, 2007, Huntingford et al., 2006). The efficacy of each potential 
search term was determined by comparing results based on all search terms with results based on all search terms except one. In case the exclusion of a search term resulted in the exclusion of a relevant article, the search term was retained because this meant that the search term resulted in an additionally relevant result. Searches to determine search terms were performed in October 2015 and resulting search terms are shown in Appendix 5.2.

Next, exclusion criteria were defined that were used to determine relevant exclusion terms. These exclusion criteria were based on the objective of this review and subsequent delineations. An article was excluded when it did not focus on teleost fish, capture fisheries, fish welfare, relevant gear types, external injuries or mortality, or when it lacked empirical or experimental data. Such exclusion criteria could not be used directly to exclude irrelevant articles, but rather, were used to define specific exclusion terms. The efficacy of each exclusion term was assessed by adding the exclusion term to the confirmed search terms and determining whether this exclusion term excluded (relevant) results or not. In case relevant or zero results were excluded, an exclusion term was not retained. In addition to these specific exclusion terms, additional exclusion terms were defined to ensure that only peer-reviewed scientific articles and reviews (thus excluding e.g. conference proceedings) in English would be included. Searches to determine exclusion terms were performed in October and November 2015 and the resulting exclusion terms are shown in Appendix 5.2.

Finally, the search with all final search and exclusion terms was performed on 7 January 2016 and resulted in 677 articles. The titles, abstracts and full texts of these articles were screened using the aforementioned exclusion criteria (Brunton et al., 2012), which resulted in a final list of 80 peer-reviewed scientific articles.

\subsection{Synthesizing information}

For each article, basic information on data collection, species, capture process and capture site was recorded in Excel. Moreover, empirical results, experimental results, results from data analysis, relevant conclusions, limitations and generalizability were recorded for each article. The synthesis of this information focused on the occurrence of injuries and mortality per gear type, and on the influence of explanatory variables on injuries and mortality.

Since terminology for external injuries was not used consistently across the articles reviewed, these injuries were classified into five broad categories, i.e. scale, skin, fin, pressure and hooking injuries. Scale injuries are injuries such as scale damage and scale loss, skin injuries are injuries such as cuts and tissue loss, fin injuries are injuries such as fin erosion and fin loss, pressure injuries are injuries arising from large changes in depth such as stomach eversion and exophthalmia (i.e. bulging eyes), and hooking injuries are injuries from hooks specified by their location, i.e. hooking in the mouth, deep-hooking (hook is 
swallowed) and foul-hooking (hooking outside the mouth). The injury rates (i.e. percentages of injuries) that were reported for the injury categories in the relevant articles were summarized in ranges per species. Similarly, mortality rates (i.e. percentages of fish that died) resulting from the capture process prior to slaughter (i.e. escaping from or trapping by the gear, surfacing or slipping, landing or discarding) were summarized in ranges per species for escaped, slipped (intentionally released prior to landing), discarded and landed fish (mortality of landed fish was recorded prior to slaughter).

Variables that were commonly used to explain injuries and mortality in the articles reviewed were classified into gear characteristics, fish characteristics and context variables. Gear characteristics that were considered are gear subtype, size, material and modification, and selectivity device. Fish characteristics that were considered are fish length and species. Context variables that were considered are change in water temperature (due to higher temperatures of surface water), capture depth, fishing duration, duration of air exposure, density in the net, species composition in the net and landing procedure. Relations between these explanatory variables, and injuries and mortality are presented in the Results section if findings on such relations were reported in the articles reviewed.

\section{Results}

In total, 80 relevant articles were identified (Appendix 5.3) that focused on the welfare of approximately 134 fish species, with cod, herring and sablefish among the main species (see Appendix 5.4 for a complete overview including scientific names). Eight of these articles included results on injuries, 49 articles included results on mortality and 23 included results on injuries and mortality.

Table 5.1 shows that the number of articles on fish welfare in capture fisheries has increased over time and that fish welfare in the northeast Atlantic, the world's third most important fishing area in terms of volumes landed (FAO, 2014c), received most research interest. Only eight articles investigated fish welfare in the four other most important fishing areas e.g. the northwest, western central and southeast Pacific, and the eastern Indian ocean. Fish welfare in various other fishing areas, such as the western Indian ocean and the eastern central Atlantic was not investigated at all. In terms of gear types used, Table 5.1 shows that trawls and hooks received most research interest, whereas purse seines, gillnets, traps and particularly seines received considerably less research interest.

\subsection{Injuries}

The ranges of the injury rates in Table 5.2 are based on a limited number of articles, which means that these ranges should be used with care when comparisons are made between injury categories or gear types. Still, Table 5.2 shows that for hooks, injury ranges were not reported for scale or fin injuries, 
Table 5.1: year of publication, fishing location and gear type of the 80 articles that were included in the review

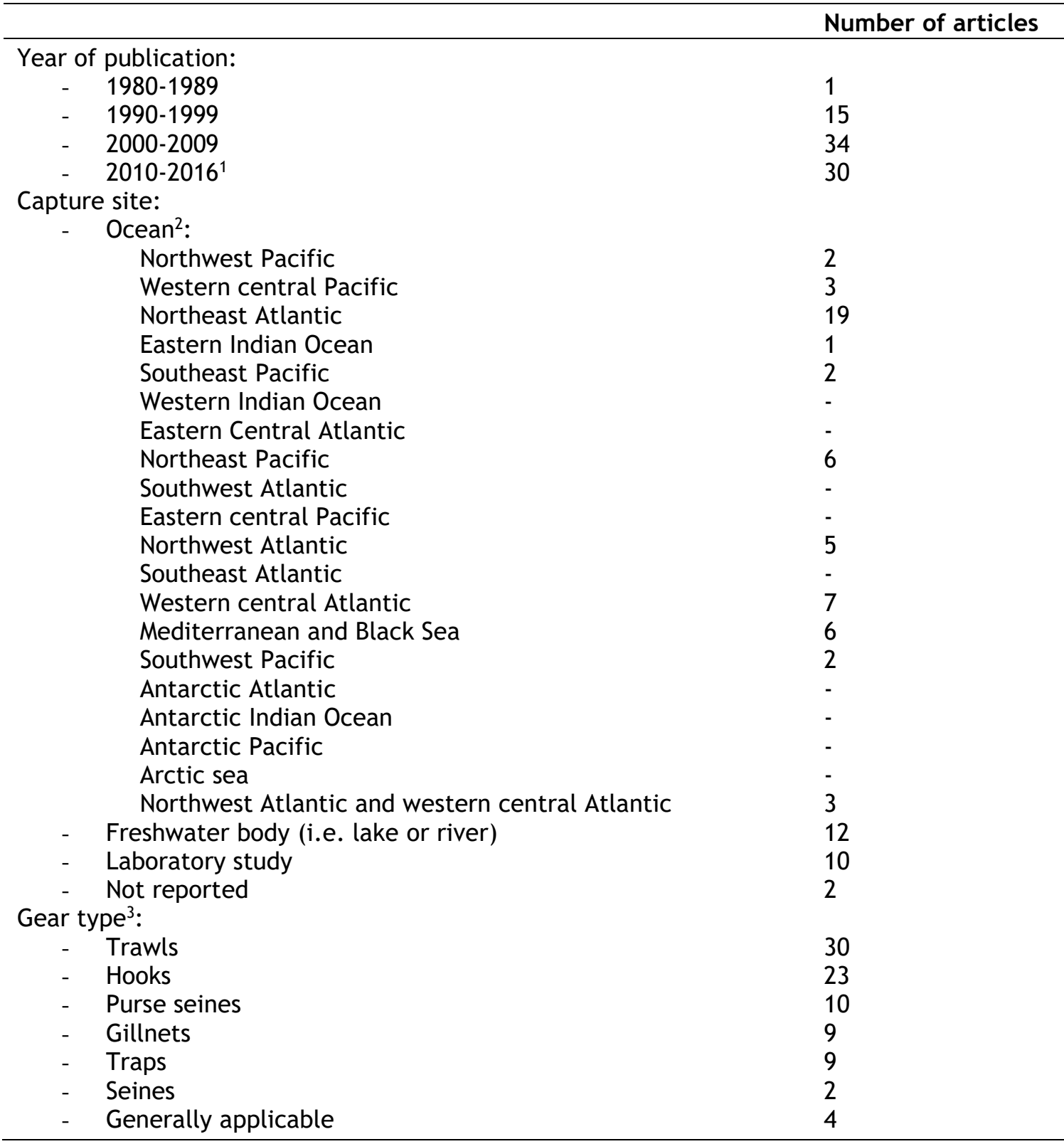

${ }^{1}$ Publications were retrieved on 7 January 2016

${ }^{2}$ Based on FAO classification of fishing areas, ordered from largest to smallest volume landed (CWP, 2015)

${ }_{3}^{3}$ Double counting occurred because several articles included results on multiple gear types

likely because hooks do not involve abrasion with the net or other fish like, for example, trawls. Injury ranges for purse seines were not reported for pressure injuries, even though in the articles reviewed purse seining occurred up to depths of 220 meter (Raby et al., 2015). Injury ranges for gillnets and traps were reported for a limited number of injury categories because only four articles reported injury rates for these gear types. For seines, injury ranges are not reported in Table 5.2 because no article reported these for seines. 
Table 5.2: injury ranges per injury category (i.e. scale, skin, fin, pressure and hooking injuries) reported for trawls, hooks, purse seines, gillnets and traps based on the articles reviewed

\begin{tabular}{|c|c|c|c|}
\hline Gear type & Injury category & $\begin{array}{l}\text { Injury } \\
\text { range (\%) }\end{array}$ & $\begin{array}{l}\text { References for the lower and upper } \\
\text { boundaries of the injury range }\end{array}$ \\
\hline \multirow[t]{4}{*}{ Trawls } & Scale injuries & $27-100$ & Suuronen et al., 1996b - Digre et al., 2010 \\
\hline & Skin injuries & $0-92$ & Bottari et al., 2003 \\
\hline & Fin injuries & $6-59$ & Düzbastilar et al., 2015 \\
\hline & Pressure injuries & $0-88$ & Bottari et al., 2003 \\
\hline \multirow[t]{6}{*}{ Hooks } & Skin injuries & $0-17$ & Mapleston et al., 2008 \\
\hline & Pressure injuries & $0-94$ & $\begin{array}{l}\text { Drumhiller et al., 2014, Pribyl et al., } 2011 \text { - } \\
\text { Pribyl et al., } 2011\end{array}$ \\
\hline & Hooking injuries: & & \\
\hline & - Deep-hooking & $0-30$ & Orsi et al., 1993 - Willis and Millar, 2001 \\
\hline & $\begin{array}{l}\text { - Mouth- } \\
\text { hooking }\end{array}$ & $61-97$ & Orsi et al., 1993 - Stachura et al., 2012 \\
\hline & - Foul-hooking & $1-39$ & Stachura et al., 2012 - Orsi et al., 1993 \\
\hline \multirow[t]{2}{*}{ Purse seines } & Scale injuries & $13-68$ & Marcalo et al., 2010 - Candy et al., 1996 \\
\hline & Skin injuries & & Mitchell et al., 2002 \\
\hline \multirow[t]{2}{*}{ Gillnets } & Scale injuries & $2-61$ & Purbayanto et al., 2001 \\
\hline & Fin injuries & $8-39$ & Purbayanto et al., 2001 \\
\hline Traps & Pressure injuries & 4 & Rudershausen et al., 2008 \\
\hline
\end{tabular}

Table 5.3 shows that the majority of relations between explanatory variables and injuries were identified for trawls and hooks, which is in line with the larger number of articles on these gear types included in this review. Across gear types, Table 5.3 shows that greater capture depth and longer fishing duration result in more injuries. In addition, gear modification and fish species influence injuries in several gear types, though their influence depends on the gear modification and on the fish species considered. Finally, fish length also influences injuries, though its influence is variable. Results on the relation between injuries and all gear characteristics, fish characteristics and context variables in Table 5.3 are presented in more detail and per gear type in Sections 3.1.1-3.1.4, and synthesized and interpreted across gear types in the Discussion.

\subsubsection{Explanatory variables for injuries in trawls}

A gear characteristic that explains scale, skin and pressure injuries in haddock (but not cod) is gear modification, with more such injuries in conventional trawl nets than in trawl nets that were modified (i.e. knots further apart with a $90^{\circ}$ shift in direction) to improve catch quality by reducing movement of the codend (Digre et al., 2010).

A fish characteristic that explains injuries from trawls is fish length, with more scale and skin injuries in larger than in smaller cod (Suuronen et al., 2005). Such a relation between fish length, and scale and skin injuries in cod, however, was not identified in other studies (Ingólfsson and Jørgensen, 2006, Suuronen et al., 
Table 5.3: relations identified between injuries and gear characteristics, fish characteristics and context variables ${ }^{1}$ in trawls, hooks, purse seines and traps $^{2}$. A ' \pm ' indicates a relation for categorical variables, '+' indicates a positive relation for continuous variables, '-' indicates a negative relation for continuous variables, 'o' indicates no relation for certain fish species and 'n.a.' indicates that such a relation is not applicable

\begin{tabular}{|c|c|c|c|c|}
\hline & Trawls & Hooks & Purse seines & Traps \\
\hline \multicolumn{5}{|l|}{ Gear characteristics: } \\
\hline Gear subtype & &, \pm 0 & & \\
\hline Gear modification &, \pm 0 &, \pm 0 & & \\
\hline Gear size & &,+ 0 & & \\
\hline \multicolumn{5}{|l|}{ Fish characteristics: } \\
\hline Fish length &,+ 0 &,,-+ 0 & - & \\
\hline Fish species & \pm & \pm & & \\
\hline \multicolumn{5}{|l|}{ Context variables: } \\
\hline Change in water temperature & & & &,+ 0 \\
\hline Capture depth & + &,+ 0 & & + \\
\hline Fishing duration & + & & &,+ 0 \\
\hline Density in the net &,+- & n.a. & & \\
\hline Species composition in the net & \pm & n.a. & & \\
\hline Landing procedure & & & \pm & \\
\hline $\begin{array}{l}{ }^{1} \text { Only those gear characteristics, } \\
\text { for which a relation with injuries } \\
{ }^{2} \text { Only trawls, hooks, purse seines } \\
\text { explanatory variables and injuri } \\
\text { reviewed }\end{array}$ & $\begin{array}{l}\text { aracterist } \\
\text { entified in } \\
\text { raps are } \\
\text { s identifi }\end{array}$ & $\begin{array}{l}\text { context v } \\
\text { ticles revi } \\
\text { d in this ? } \\
\text { gillnets }\end{array}$ & $\begin{array}{l}\text { bles are include } \\
d \\
\text { e because no rel } \\
\text { seines based o }\end{array}$ & $\begin{array}{l}\text { this Tabl } \\
\text { n betweel } \\
\text { ne article }\end{array}$ \\
\hline
\end{tabular}

1996b) or in hoki (Jones, 1993). Fish species also explains injuries from trawls, with more scale, skin and fin injuries in cod than in whiting, sole and plaice (Depestele et al., 2014), and with more scale and pressure injuries in haddock than in cod (Digre et al., 2010).

Context variables that explain injuries from trawls are capture depth, fishing duration, density in the net and species composition in the net. Greater capture depth and longer fishing duration resulted in more skin and pressure injuries in red mullet, greater forkbeard, European hake and blue whiting (Bottari et al., 2003). A higher density in the net due to a higher catch weight resulted in more pressure injuries in cod, haddock (Digre et al., 2010) and blue whiting (Bottari et al., 2003), in more skin injuries in blue whiting (Bottari et al., 2003), but in less scale injuries in haddock (Digre et al., 2010). Species composition in the net explains skin injuries in red mullet, greater forkbeard, European hake and blue whiting, with more such injuries when crustaceans were present in the net, likely due to their chitinous-calcareous structure (Bottari et al., 2003).

\subsubsection{Explanatory variables for injuries in hooks}

Hook type is a gear characteristic that explains hooking injuries, i.e. deephooking, hooking in the mouth and foul-hooking. Deep-hooking was higher on J- 
style hooks than on circle hooks in several species including swordfish, escolar and red emperor (Kerstetter and Graves, 2006a, Mapleston et al., 2008). In contrast, hooking in the mouth was higher on circle hooks than on J-style hooks in yellowfin tuna (Falterman and Graves, 2002) and chinook salmon (Orsi et al., 1993), in line with circle hooks' purpose to decrease deep-hooking and increase hooking in the mouth. Foul-hooking was higher on J-style hooks than on circle hooks in chinook salmon (Orsi et al., 1993), but the reverse was true for white marlin (Kerstetter and Graves, 2006b). A relation between hook type and hooking injuries was not identified in several other species, including white marlin, crimson snapper and albacore (Kerstetter and Graves, 2006a, Mapleston et al., 2008). Hook size explains skin injuries in coral trout, saddletail snapper and crimson snapper (but not trevallies), with more such injuries on larger hooks than on smaller hooks (Mapleston et al., 2008). Hook modification explains hooking injuries, though its influence on hooking injuries depends on the hook and its modification considered. Deep-hooking of snapper was higher on conventional 16R hooks than on 16R hooks that were modified with an appendage to reduce deep-hooking (Willis and Millar, 2001). In contrast, deep-hooking was higher on offset circle hooks that were modified to increase catch than on nonoffset circle hooks for swordfish, but not for billfish, blue marlin or tuna (Rice et al., 2012). Finally, hook modification also explains skin injuries, with more such injuries on modified, offset circle hooks than on non-offset circle hooks in several species including coral trout, saddletail snapper and red emperor (Mapleston et al., 2008).

With regard to fish characteristics, fish length explains skin injuries, with more such injuries in smaller than in larger individuals of several species including cod (Pálsson Ó et al., 2003), red emperor and trevallies, but not coral trout (Mapleston et al., 2008). Species explains pressure injuries, with the type of pressure injury and its occurrence differing between species, e.g. minimal pressure injuries in yellowtail and quillback rockfish (Pribyl et al., 2011).

Greater capture depth, a context variable, resulted in more skin injuries in cod (Pálsson Ó et al., 2003). In addition, greater capture depth resulted in more pressure injuries in several species including scamp, red snapper and black rockfish (Drumhiller et al., 2014, McLennan et al., 2014, Pribyl et al., 2011, Stephen and Harris, 2010), but not in pearl perch (Campbell et al., 2014).

\subsubsection{Explanatory variables for injuries in purse seines}

In the literature reviewed, injuries from purse seines were not explained by gear characteristics. Fish length, a fish characteristic, explains scale and skin injuries, with more such injuries in smaller than in larger coho salmon (Raby et al., 2015). With regard to context variables, landing procedure explains scale injuries, with a higher degree of scale loss in chinook salmon landed on-board than in chinook salmon landed from the purse seine using a dip net (Candy et al., 1996). 


\subsubsection{Explanatory variables for injuries in traps}

Injuries from traps were not explained by gear or fish characteristics in the literature reviewed. Change in water temperature is a context variable that explains scale injuries and skin injuries, with more such injuries in largemouth bass and northern pike at larger than at smaller changes in temperature due to higher temperatures of surface water (Colotelo et al., 2013). A larger change in water temperature also resulted in more fin injuries in largemouth bass, but not in northern pike (Colotelo et al., 2013). Fishing duration is another context variable that explains fin injuries, with more such injuries in largemouth and northern pike after longer trap set times (Colotelo et al., 2013). Longer fishing duration also resulted in more scale and skin injuries in largemouth bass, but not in northern pike (Colotelo et al., 2013). Finally, capture depth explains pressure injuries, with more pressure injuries in black sea bass caught from greater depths (Rudershausen et al., 2008).

\subsection{Mortality}

Table 5.4 shows that mortality of escaped, discarded and landed fish in trawls ranges from $0-100 \%$, depending on field conditions or on the experimental setup. The same holds for hooks, except that none of the articles included in this review focused on fish escaping from hooks. Although the mortality ranges for purse seines in Table 5.4 are based on a limited number of articles, mortality seems higher for slipped than for escaped or discarded fish. Mortality ranges for gillnets, traps and seines seem higher for discarded than for landed fish.

Table 5.5 shows that the majority of relations between explanatory variables and mortality of escaped, slipped, discarded and landed fish was identified in trawls, though a relatively large number of relations was also identified in the other gear types except seines. Across gear types, Table 5.5 shows that smaller fish length, larger change in water temperature, greater capture depth, longer fishing duration and longer duration of air exposure were associated with higher mortality. Results on the relation between all explanatory variables in Table 5.5 and mortality are presented in more detail in Sections 3.2.1-3.2.6, and synthesized and interpreted across gear types in the Discussion.

\subsubsection{Explanatory variables for mortality in trawls}

Gear characteristics that explain mortality from trawls are gear subtype, gear modification and selectivity device. Mortality of plaice was higher after capture by beam rather than otter trawl (Van Beek et al., 1990). With regard to gear modification, mortality of haddock (but not cod) was higher after capture by conventional rather than modified trawl net that was designed to improve catch quality by reducing movement of the codend (Digre et al., 2010). The influence of selectivity device on mortality of escaped fish is variable. Mortality of herring was higher after escape via codend meshes than after escape via sorting grid (Suuronen et al., 1996c), in line with the sorting grid's purpose of reducing 
Table 5.4: mortality ranges for escaped, slipped, discarded and landed fish in trawls, hooks, purse seines, gillnets, traps and seines based on the articles reviewed

\begin{tabular}{|c|c|c|c|}
\hline $\begin{array}{l}\text { Gear } \\
\text { type }\end{array}$ & $\begin{array}{l}\text { Mortality } \\
\text { category }\end{array}$ & $\begin{array}{l}\text { Mortality } \\
\text { range (\%) }\end{array}$ & $\begin{array}{l}\text { References for the lower and upper boundaries of the } \\
\text { mortality range }\end{array}$ \\
\hline \multirow[t]{3}{*}{ Trawls } & Escaped & $0-100$ & $\begin{array}{l}\text { Suuronen et al., 2005, Suuronen et al., 1996a, Davis, 2007, } \\
\text { Düzbastilar et al., 2010, Ingólfsson et al., 2007, Olla et al., } \\
\text { 1997, Olla et al., 1998, Davis and Olla, 2001, Davis et al., } \\
2001 \text { - Davis and Ottmar, 2006, Düzbastilar et al., 2010, Olla } \\
\text { et al., 1997, Suuronen et al., 1996b, Davis et al., 2001 }\end{array}$ \\
\hline & Discarded & $0-100$ & $\begin{array}{l}\text { Davis, 2007, Olla et al., 1997, Olla et al., 1998, Davis and } \\
\text { Olla, 2001, Davis et al., 2001 - Jurvelius et al., 2000, } \\
\text { Ragonese and Morara, 2012, Davis, 2007, Depestele et al., } \\
\text { 2014, Yergey et al., 2012, Olla et al., 1997, Davis et al., } 2001\end{array}$ \\
\hline & Landed & $0-100$ & $\begin{array}{l}\text { Davis, 2007, Lambooij et al., 2012, Olla et al., 1997, Olla et } \\
\text { al., 1998, Davis and Olla, 2001, Davis et al., } 2001 \text { - Davis, } \\
\text { 2007, Olla et al., 1997, Davis et al., } 2001\end{array}$ \\
\hline \multirow[t]{2}{*}{ Hooks } & Discarded & $0-100$ & $\begin{array}{l}\text { Drumhiller et al., 2014, Milliken et al., 2009, Wilson Jr and } \\
\text { Burns, 1996, Davis and Olla, 2001, Davis et al., } 2001 \text { - Wilson } \\
\text { Jr and Burns, 1996, Stachura et al., 2012, Stephen and } \\
\text { Harris, 2010, Davis et al., } 2001\end{array}$ \\
\hline & Landed & $0-100$ & $\begin{array}{l}\text { Humborstad et al., 2016, Davis and Olla, 2001, Davis et al., } \\
2001 \text { - Falterman and Graves, 2002, Kerstetter and Graves, } \\
\text { 2006, Davis et al., } 2001\end{array}$ \\
\hline \multirow{4}{*}{$\begin{array}{l}\text { Purse } \\
\text { seines }\end{array}$} & Escaped & $0-82$ & Misund and Beltestad, 2000 \\
\hline & Slipped & $4-100$ & $\begin{array}{l}\text { Lockwood et al., } 1983 \text { - Misund and Beltestad, 1995, Huse } \\
\text { and Vold, } 2010\end{array}$ \\
\hline & Discarded & $23-47$ & Candy et al., 1996 - Raby et al., 2015 \\
\hline & Landed & $0-52$ & Marçalo et al., 2008 - Tenningen et al., 2012 \\
\hline \multirow[t]{2}{*}{ Gillnets } & Discarded & 7-95 & $\begin{array}{l}\text { Broadhurst et al., 2009, Vander Haegen et al., } 2004 \text { - Smith } \\
\text { and Scharf, } 2011\end{array}$ \\
\hline & Landed & $0-70$ & Broadhurst et al., 2009 \\
\hline \multirow[t]{3}{*}{ Traps } & Escaped & $2-13$ & Rudershausen et al., 2008 - Lundin et al., 2012 \\
\hline & Discarded & $2-100$ & Stewart, 2008 - Gisbert and López, 2008 \\
\hline & Landed & $0-35$ & Humborstad et al., 2016 - Dieterman et al., 2000 \\
\hline \multirow[t]{2}{*}{ Seines } & Discarded & $10-72$ & Broadhurst et al., 2008 \\
\hline & Landed & 0 & Broadhurst et al., 2008 \\
\hline
\end{tabular}

escapee mortality. In escape via codend meshes, mortality of red mullet was higher after escape via diamond meshes rather than square meshes (Düzbastilar et al., 2015, Düzbastilar et al., 2010a), in line with square meshes' purpose of reducing escapee mortality. No influence of selectivity devices aimed at reducing escapee mortality was identified, however, on escapee mortality of haddock (Ingólfsson et al., 2007), herring (Suuronen et al., 1996a), brown comber (Düzbastilar et al., 2010b) or cod (Suuronen et al., 2005).

A fish characteristic that explains mortality from trawls is fish length, with higher mortality in smaller than in larger individuals of several species including herring, sole and brown comber (Depestele et al., 2014, Düzbastilar et al., 2015, Düzbastilar et al., 2010a, Düzbastilar et al., 2010b, Hyvärinen et al., 2008, 
Table 5.5: relations identified between mortality and gear characteristics, fish characteristics and context variables. $A$ ' \pm ' indicates a relation for categorical variables, '+' indicates a positive relation for continuous variables, '-' indicates a negative relation for continuous variables, 'o' indicates no relation and ' $n$.a.' indicates that such a relation is not applicable

\begin{tabular}{|c|c|c|c|c|c|c|}
\hline & Trawls & Hooks & Purse seines & Gillnets & Traps & Seines \\
\hline \multicolumn{7}{|l|}{ Gear characteristics: } \\
\hline Gear subtype & \pm & \pm & & \pm & & \\
\hline Gear modification &, \pm 0 &, \pm 0 & & \pm & & \\
\hline Selectivity device &, \pm 0 & &, \pm 0 & & & \\
\hline Gear material & & & & \pm & & \\
\hline Fish characteristics: & & & & & & \\
\hline Fish length &,- 0 &,- 0 &,- 0 &,- 0 &,-+ &,- 0 \\
\hline Fish species & \pm & \pm & & \pm & \pm & \pm \\
\hline \multicolumn{7}{|l|}{ Context variables: } \\
\hline Change in water temperature &,+ 0 & + & + &,+ 0 &,+ 0 & \\
\hline Capture depth & + &,+ 0 & & + & + & \\
\hline Fishing duration &,+ 0 & + & + & + & & \\
\hline Duration of air exposure & + & & & &,+ 0 & \\
\hline Density in the net &,+ 0 & n.a. &,+ 0 & &,+ 0 & \\
\hline Species composition in the net & & n.a. & \pm & & & \\
\hline Landing procedure & \pm & \pm & & & & \\
\hline
\end{tabular}

Ingólfsson et al., 2007, Richards et al., 1995, Suuronen et al., 1996a, Suuronen et al., 1996c). Such a relation between fish length and mortality, however, was not identified in another study on brown comber (Düzbastilar et al., 2010a) or in cod (Suuronen et al., 2005). Species is another fish characteristic that explains mortality from trawls, with higher mortality of walleye pollock than of sablefish (Olla et al., 1997), coho salmon, and particularly rock sole and Pacific halibut (Davis, 2007). Mortality after trawling is also higher in haddock than in cod (Digre et al., 2010), and in landlocked salmon than in pike-perch or brown trout (Jurvelius et al., 2000).

Context variables that explain mortality from trawls are capture depth, change in water temperature, fishing duration, density in the net, duration of air exposure and landing procedure. Greater capture depth resulted in higher mortality of haddock (Ingólfsson et al., 2007), pike-perch (Jurvelius et al., 2000), sole (Depestele et al., 2014) and halibut (Richards et al., 1995). A larger change in water temperature due to higher temperatures of surface water resulted in higher mortality of several species including cod, plaice and sablefish (Davis and Olla, 2001, Davis et al., 2001, Hyvärinen et al., 2008, Olla et al., 1998, Suuronen et al., 2005, Van Beek et al., 1990). Changes in water temperature likely also explain the higher mortality of pike-perch after longer chilling in on-board water tanks (Hyvärinen et al., 2008). No relation between change in water temperature and mortality was identified in brown trout (Turunen et al., 1994), pike-perch, rainbow trout or landlocked salmon (Jurvelius et al., 2000). Longer fishing 
duration resulted in higher mortality of several species including yellowtail flounder, sole and coho salmon (Barkley and Cadrin, 2012, Davis, 2007, Van Beek et al., 1990), but not of pike-perch (Hyvärinen et al., 2008, Jurvelius et al., 2000), rainbow trout or landlocked salmon (Jurvelius et al., 2000). Higher density in the net due to a higher catch weight resulted in higher mortality of Pacific halibut (Richards et al., 1995), sole (Depestele et al., 2014) and cod (Suuronen et al., 2005), but not herring (Suuronen et al., 1996a). Longer duration of air exposure resulted in higher mortality of discarded hoki (Jones, 1993), Pacific halibut (Davis, 2007, Richards et al., 1995) and yellowtail flounder (Barkley and Cadrin, 2012). With regard to landing procedure, mortality of discarded brown trout was higher when fish were landed on deck rather than in the water (Turunen et al., 1994).

\subsubsection{Explanatory variables for mortality in hooks}

The gear characteristic hook type explains mortality from hooks, with higher mortality of chinook salmon (Orsi et al., 1993), yellowfin tuna (Falterman and Graves, 2002), white marlin (Kerstetter and Graves, 2006b) and swordfish (Kerstetter and Graves, 2008) on J-style hooks than on circle hooks. Hook modification also explains mortality from hooks, with higher mortality on modified, offset circle hooks than on non-offset circle hooks for blue marlin and swordfish, but not for tuna (Rice et al., 2012).

With regard to fish characteristics, fish length explains mortality from hooks, with higher mortality in smaller than in larger individuals of vermillion snapper (Stephen and Harris, 2010) and cod (Milliken et al., 1999, Pálsson Ó et al., 2003), but not of several other species including red porgy, pink snapper and yellowfin tuna (Kerstetter and Graves, 2006a, McLennan et al., 2014, Stachura et al., 2012, Stephen and Harris, 2010). Mortality from hooks is also explained by fish species, with higher mortality of wahoo, gempylids and sailfish than of yellowfin tuna, albacore, bigeye tuna, oilfishes and dolphinfish (Falterman and Graves, 2002).

Context variables that explain mortality from hooks are change in water temperature, capture depth, fishing duration and landing procedure. A larger change in water temperature resulted in higher mortality of pacific halibut (Davis and Olla, 2001), sablefish (Davis et al., 2001) and cod (Milliken et al., 2009). Greater capture depth resulted in higher mortality of several species including red snapper, cod and scamp (Drumhiller et al., 2014, Milliken et al., 2009, Pálsson Ó et al., 2003, Stachura et al., 2012, Wilson Jr and Burns, 1996), but not pink snapper (McLennan et al., 2014). Longer fishing duration resulted in higher mortality of yellowfin tuna and swordfish (Kerstetter and Graves, 2006a). Finally, mortality is explained by landing procedure, with higher mortality of discarded cod after mechanical than after careful hook removal (Milliken et al., 1999, Milliken et al., 2009). 


\subsubsection{Explanatory variables for mortality in purse seines}

In mackerel, mortality was higher after purse seining and escape via a sorting grid (a selectivity device) than for controls that did not go through this procedure, though this was not the case for saithe, which experienced no mortality after either treatment (Misund and Beltestad, 2000).

With regard to fish characteristics, mortality was higher among smaller herring (Tenningen et al., 2012) and sardine (Marçalo et al., 2010). No relation between fish length and mortality was identified in chinook salmon (Candy et al., 1996).

Context variables that explain mortality from purse seines are change in water temperature, fishing duration, density in the net and species composition in the net. A larger change in water temperature resulted in higher mortality of sardine (Marçalo et al., 2010, 2008). Longer fishing duration resulted in higher mortality of chinook salmon (Candy et al., 1996), mackerel (Lockwood et al., 1983), sardine (Marçalo et al., 2010) and herring (Tenningen et al., 2012). Higher density in the net resulted in higher mortality of mackerel (Huse and Vold, 2010, Lockwood et al., 1983), sardine (Marçalo et al., 2010) and herring (Tenningen et al., 2012), but not chinook salmon (Candy et al., 1996). Higher density in the net could also explain the higher mortality of herring and South American pilchard after purse seining and net burst (Misund and Beltestad, 1995) or slipping (Mitchell et al., 2002) rather than after purse seining alone, likely due to the high density in the net prior to net burst or slipping. With regard to species composition in the net, mortality of sardine was lower when only sardine were caught than when other species were caught as well (Marçalo et al., 2008).

\subsubsection{Explanatory variables for mortality in gillnets}

Gear subtype explains mortality from gillnets, with higher mortality of Atlantic sturgeon after capture by set gillnet rather than drift gillnet (Stein et al., 2004). Mortality of chinook salmon was higher after capture by conventional rather than modified gillnet with smaller mesh size (Vander Haegen et al., 2004). With regard to gear material, mortality of paddlefish was higher after capture by monofilament rather than multifilament gillnet (Bettoli and Scholten, 2006).

Fish length explains mortality from gillnets, with higher mortality in smaller than in larger individuals of black sole (Broadhurst et al., 2009), Japanese whiting (Purbayanto et al., 2001) and southern flounder (Smith and Scharf, 2011). No relation between fish length and mortality was identified in paddlefish (Bettoli and Scholten, 2006), black bream, surf bream, large-tooth flounder or dusky flathead (Broadhurst et al., 2009). Species also explains mortality from gillnets, with higher mortality of surf bream, largetooth flounder and dusky flathead than of black bream, black sole and yellowfin leather jacket (Broadhurst et al., 2009). 
Context variables that explain mortality from gillnets are fishing duration, capture depth and change in water temperature. Longer fishing duration resulted in higher mortality of paddlefish (Bettoli and Scholten, 2006) and coho salmon (Buchanan et al., 2002). Greater capture depth resulted in higher mortality of Black Sea turbot (Basaran and Samsun, 2004). A larger change in water temperature resulted in higher mortality of paddlefish (Bettoli and Scholten, 2006), black bream and large-tooth flounder, but not dusky flathead or surf bream (Broadhurst et al., 2009).

\subsubsection{Explanatory variables for mortality in traps}

Mortality from traps is not explained by gear characteristics, possibly due to the passive and non-intrusive nature of this gear.

Fish length explains mortality from traps, with higher mortality in smaller than in larger pink snapper (Stewart, 2008), though the reverse is true for escaped herring (Lundin et al., 2012). Fish species also explains mortality from traps, with higher mortality of grey mullets than of ironfishes, common rudd and bleak (Gisbert and López, 2008).

Context variables that explain mortality from traps are capture depth, change in water temperature, density in the trap and duration of air exposure. Greater capture depth resulted in higher mortality of pink snapper (Stewart, 2008), walleye, lake trout (MacMillan and Roth, 2012) and black sea bass (Rudershausen et al., 2008). A larger change in water temperature resulted in higher mortality of walleye and lake trout (MacMillan and Roth, 2012), but not paddlefish (Dieterman et al., 2000). Higher density in the trap resulted in higher mortality of black sea bass (Rudershausen et al., 2008), but not pink snapper (Stewart, 2008). Longer duration of air exposure resulted in higher mortality of several discarded species including thinlip mullet, eastern mosquitofish and flathead grey mullet (Gisbert and López, 2008), whereas deck time (which involves air exposure) did not explain mortality of black sea bass (Rudershausen et al., 2008).

\subsubsection{Explanatory variables for mortality in seines}

Thus far, mortality from (beach) seines has only been explained by variables relating to fish characteristics. Mortality was higher in smaller than in larger individuals of surf bream, but not blue salmon catfish (Broadhurst et al., 2008). Species also explains mortality in beach seines, with higher mortality of common silver belly than surf bream and sand whiting (Broadhurst et al., 2008).

\section{Discussion}

This review has shown that the gear types used in commercial capture fisheries can result in scale, skin, fin and pressure injuries, and that the occurrence of these injuries depends on gear type. Scale, skin and fin injuries are caused mainly by 
contact with the net (Davis and Ottmar, 2006, Gregory, 1998), with other fish (Davis and Ottmar, 2006) or with species with hard body parts such as crustaceans (Bottari et al., 2003, Suuronen and Erickson, 2010). Hence, such injuries occur more frequently in trawls, purse seines, gillnets and seines than in hooks (Gregory, 1998) and possibly also traps. Hooks, however, inevitably result in hooking injuries, with deep-hooking resulting in higher mortality than hooking in the mouth (Campbell et al., 2014, McLennan et al., 2014). Pressure injuries commonly occur in fish caught at depths of 25-30 m or more (Gregory, 1998, Humborstad and Mangor-Jensen, 2013). At greater depth, the swimbladders of fish with closed swimbladders overinflate when these fish are surfaced, which commonly results in pressure injuries such as bulging eyes or protrusion of the gut via the mouth or anus (Gregory, 1998). In cod, however, overinflation, and therefore pressure injuries, can be prevented when internal swimbladder puncture occurs (Humborstad and Mangor-Jensen, 2013). Depending on the depth at which the gear type is deployed, all gear types (unless operated near the surface like e.g. drifting gillnets or small purse seines) can result in pressure injuries.

Mortality of escaped, slipped, discarded and landed fish generally ranges from o$100 \%$. Mortality of escaped and slipped fish is likely caused by contact with the net (and resulting scale, skin and fin injuries) and high densities in the net prior to escaping or slipping. Although discarded and landed fish are largely subjected to the same process, landed fish are slaughtered, whereas discarded fish are exposed to air and subsequently returned to the water where these fish are vulnerable to predation (Drumhiller et al., 2014, Olla et al., 1997). Mortality of fish landed by trawls, purse seines and seines is higher than mortality of fish landed by gillnets (Benoît et al., 2010), hooks (Benoît et al., 2010, Davis and Olla, 2001) or traps (Rudershausen et al., 2014). This higher mortality for trawls, purse seines, seines and gillnets is likely explained by the higher occurrence of scale, skin and fin injuries in these gear types as compared to hooks and traps, commonly resulting in higher mortality (e.g. Depestele et al., 2014, Olsen et al., 2012, Smith and Scharf, 2011). The higher mortality for trawls and seines than for gillnets is additionally explained by the active fishing of trawls and seines as compared to the passive fishing of gillnets. Movement and turbulence of a trawl can cause the codend to twist, adding to the compression that the fish already experience due to the density in the codend (Gregory, 1998).

Results on the influence of gear characteristics on injuries and mortality cannot be compared across gear types because these characteristics are gear-specific. Results on the influence of fish characteristics and context variables on injuries and mortality, however, can be compared across gear types. Such a comparison shows that fish length and species, capture depth, and fishing duration explain both injuries and mortality across gear types, whereas change in water temperature, duration of air exposure, density in the net and landing procedure 
explain only mortality across gear types. Despite the large number of teleost fish species and differences between these species, results on these fish characteristics and context variables were commonly identified in multiple species and gear types, making it likely that these results hold more widely.

Fish length explains both injuries and mortality, though this relation was only clear-cut for mortality, which is higher among smaller than among larger fish of a considerable number of species in all gear types, except traps. The higher mortality among smaller fish could be explained by their poorer swimming ability and endurance as compared to larger fish (Suuronen and Erickson, 2010), which disables them to avoid contact with the trawl, purse seine or seine net (Olla et al., 1997). In gillnets, differences in captured condition between smaller and larger fish likely explain size differences in mortality since smaller fish are more likely to be gilled (Purbayanto et al., 2001) or wedged, whereas larger fish are more likely to be pocketed (Purbayanto et al., 2001) or snagged. The reason for the higher mortality of smaller rather than larger fish caught by hooks, however, remains unclear. Species is another fish characteristic that explains injuries and mortality in several gear types. Differences between species in, for example, morphology and endurance likely contribute to differences in injuries and mortality between species. In addition, differences in mortality between species are possibly also explained by the negative relation between fish length and mortality, since species with higher mortality are generally smaller (Broadhurst et al., 2008, Davis, 2007, Digre et al., 2010, Gisbert and López, 2008, Jurvelius et al., 2000).

The context variable capture depth explains both injuries and mortality because greater capture depth results in pressure injuries (e.g. Bottari et al., 2003, McLennan et al., 2014, Rudershausen et al., 2008), a common cause of mortality (Campbell et al., 2014). Longer fishing duration also results in more injuries and mortality, likely because this context variable aggravates the influence of other variables such as density in the net, species composition in the net, fish length and gear (sub-)type on injuries and mortality. For example, mortality of mackerel as a result of the density in a purse seine increased with fishing duration (Lockwood et al., 1983).

The context variable change in water temperature explains mortality. A larger change in water temperature can expose fish to thermoclines, i.e. changes in water temperature that exceed fish' tolerance limits (Olla et al., 1998). Air exposure, a context variable that affects landed and discarded fish, causes mortality through asphyxiation, which, for example in cod, occurs after 30-120 minutes (Lambooij et al., 2012, Olsen et al., 2013). Asphyxiation occurs earlier when fish are exposed to air temperatures above their body temperature and later when fish are exposed to air temperatures below their body temperature (Davis and Schreck, 2005, Kestin et al., 1991). The duration of air exposure depends on gear type. In hooks, fish are landed and slaughtered individually, whereas in the 
other gear types, fish are landed all at once and the time of slaughter subsequently depends on catch size. Asphyxiation not only results from air exposure, but can also result from higher densities in the net, which disable fish to move their gills for breathing (Gregory, 1998). In addition, asphyxiation of discarded and landed fish can result from the landing procedure used when fish are landed in air.

Several knowledge gaps can be identified from this review in terms of the gear types and explanatory variables included. The most important gear types in terms of catch volumes landed worldwide are, in order, trawls, purse seines and seines, gillnets, hooks and traps (Watson et al., 2006). The majority of research on fish welfare, however, has focused on trawls and hooks. As a result, there is less knowledge on the impact of purse seines, gillnets, traps and seines on the welfare of a substantial amount ( $\sim 45 \%)$ of fish caught worldwide (Watson et al., 2006). Although a variety of gear characteristics, fish characteristics and context variables have been included in this review, results on these explanatory variables only focused on a limited number of gear types. As a result, more research is needed on the relation between external (and internal) injuries, and virtually all explanatory variables included in this review, except capture depth and fishing duration. Moreover, more research is needed on the relation between mortality and most gear characteristics, species composition in the net and various landing procedures. In addition to the variables considered in this review, research is needed to determine the influence of other variables, such as fish' reproductive cycle, fish morphology, changes in salinity (Broadhurst et al., 2009), light intensity (i.e. visibility) and towing speeds (Olla et al., 1997) on injuries and mortality.

Finally, this literature review gives rise to several recommendations for fishers and policy-makers to reduce the impact of gear, fish and context choices on fish welfare. The choice for gear type based on concerns for fish welfare, however, involves a trade-off between injury types, injury levels, mortality levels, and ecological and economic consequences such as by-catch rates and fuel costs. There are, however, improvement options available within gear types, such as using circle hooks rather than J-style hooks to reduce deep-hooking and resulting mortality. The use of a selectivity device could reduce mortality of escaped fish, though its effectiveness in reducing mortality seems to differ between gear types and species. Given that mortality is negatively related to fish length in all gear types (except traps), continued size selectivity contributes to improving fish welfare from capture fisheries. With regard to context variables, mortality can be reduced by catching fish at lower surface water temperatures, though variations in surface water temperature are likely limited within a fishing season. Mortality can also be reduced by reducing capture depth, though most fish species are only found at specific depths. In addition, mortality can be reduced by decreasing fishing duration, duration of air exposure (e.g. by landing fish in water tanks 
rather than in air on deck) and density in the net (for example by reducing catch weight), but these improvement options might have economic consequences (e.g. catch reduction, cost increase, quality improvement) that would require further analysis.

\section{Conclusion}

This review has shown that research interest in fish welfare in capture fisheries has increased over time and that research on this topic has focused more on trawls and hooks than on purse seines, gillnets, traps and particularly seines. Synthesis of the articles reviewed shows that scale, skin and fin injuries occur more frequently in trawls, purse seines, gillnets, traps and seines than in hooks, whereas hooking injuries occur in hooks only. Pressure injuries can occur in all gear types included in this review, though its occurrence depends on the depth at which gear types are deployed. Furthermore, mortality is generally higher in trawls, purse seines and seines than in gillnets, hooks and traps. Besides gear type and corresponding gear characteristics, fish characteristics and context variables influence injuries and mortality from capture fisheries as well. Mortality appears to increase with decreasing fish length, and differs across species. A greater capture depth and a longer fishing duration were associated with more external injuries and higher mortality, whereas a large change in water temperature, a longer duration of air exposure and a high density in the net were associated with higher mortality only.

\section{Acknowledgements}

This research is supported by the project 'WhiteFish', a research project to the benefit of small and medium enterprise associations that is funded by the European Commission (286141) under the Seventh Framework Program (FP7). The authors would like to thank Leo Nagelkerke for providing valuable feedback on this manuscript. 



\section{Appendix 5.1}

All gear type descriptions were based on Nédélec and Prado (1990). All figures were taken from Nédélec and Prado (1990).

\section{Trawls}

Trawls are towed nets that are cone-shaped with a large collection bag at the end (codend). The two main types of trawls are demersal beam trawl (Figure A1) and pelagic or demersal otter trawls (Figure A2), operated individually or in pairs.

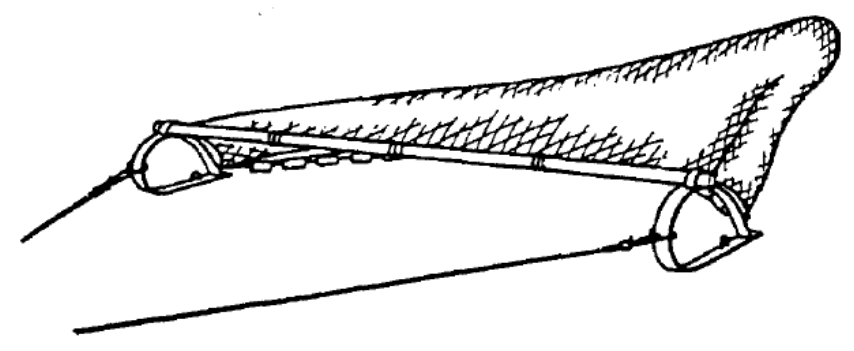

Figure A1: beam trawl

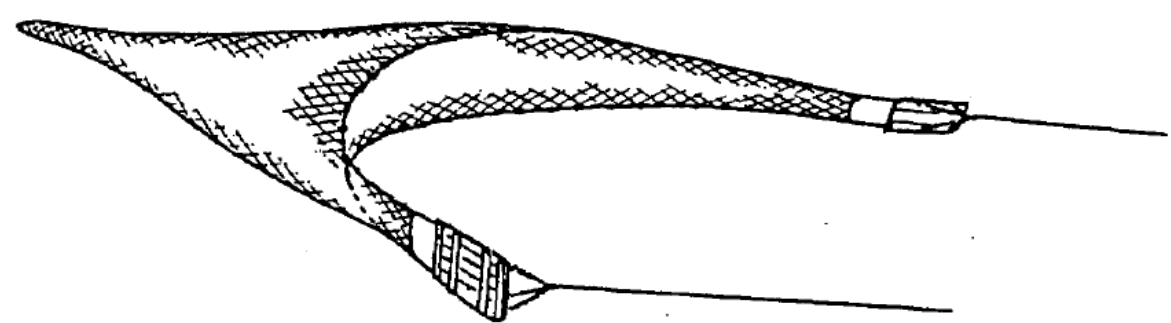

Figure A2: otter trawl

\section{Hooks}

Hooks are baited with artificial or natural bait to attract and capture fish. A hook on a single line (either electronically or manually operated) is called a handline, whereas multiple hooks on single or multiple lines are called (set or drifting) longlines (Figure A3).

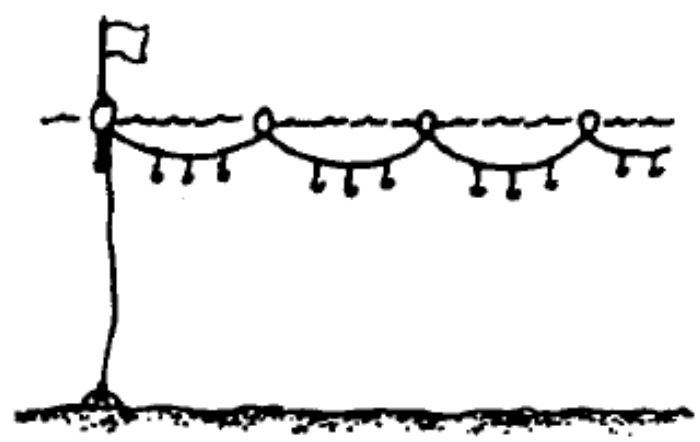

Figure A3: (set) longline 


\section{Purse seines}

Purse seines surround a school of fish with a wall of netting that is subsequently closed at the bottom and drawn up (pursed) to the surface (Figure A4).

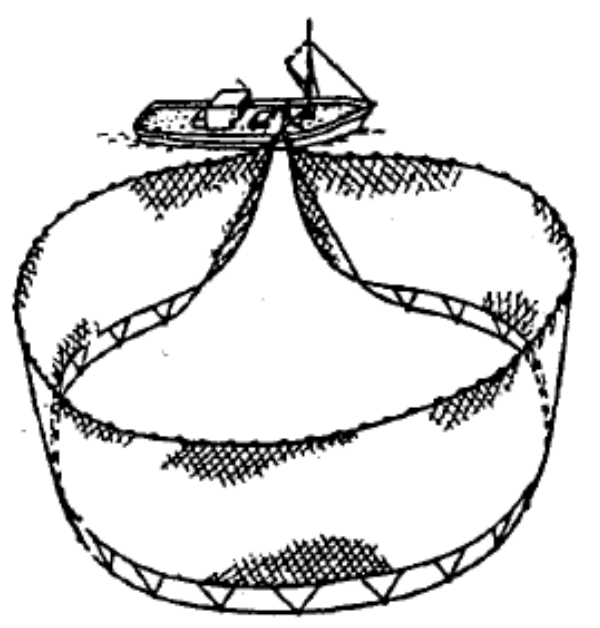

Figure A4: purse seine

\section{Gillnets}

Gillnets (Figure A5) capture fish through snagging (caught by the mouth or head), gilling (caught by the gills), wedging (caught by a larger part of the body) entangling (caught by protruding body parts such as teeth or spines), or pocketing (caught in a pocket of netting, occurs only in trammel nets). These nets can be deployed at the bottom (set gillnets), near the surface (drifting gillnets), on stakes in coastal waters (fixed gillnets) or in multiple rows of nets (trammel nets).

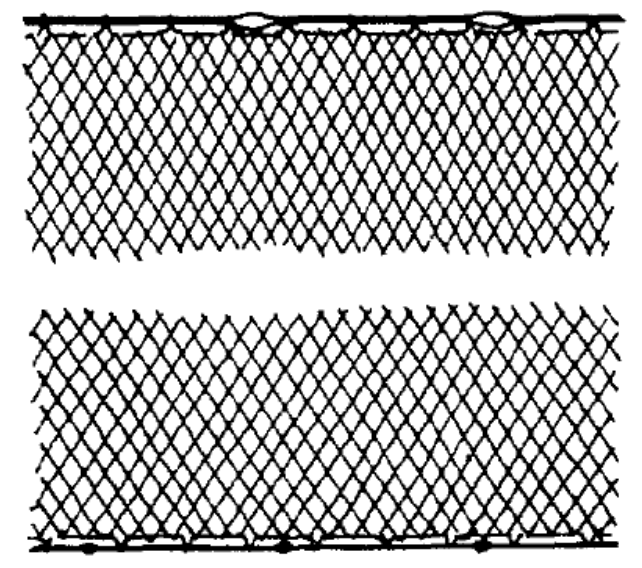

Figure A5: gillnet

\section{Traps}

Traps are a gear type that the fish enter voluntarily but cannot escape. Subtypes of traps are e.g. pots (Figure A6) and fyke nets (Figure A7). 


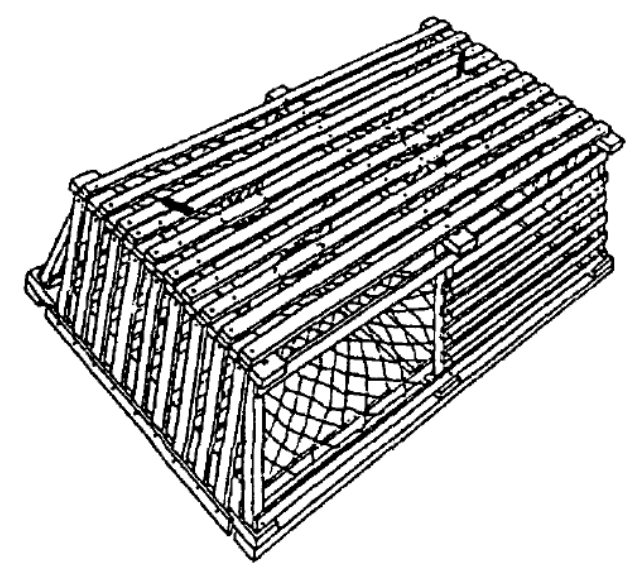

Figure A6: pot

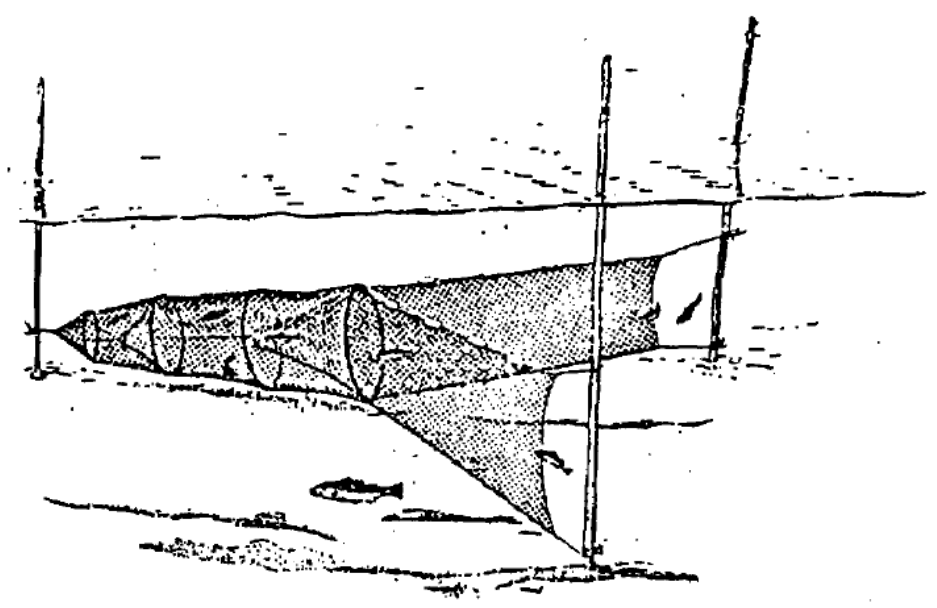

Figure A7: fyke net

\section{Seines}

Seines are towed nets that surround an area of water with a very long net with or without a bag at the centre (Figure A8). Two types of seines are boat seines and beach seines.

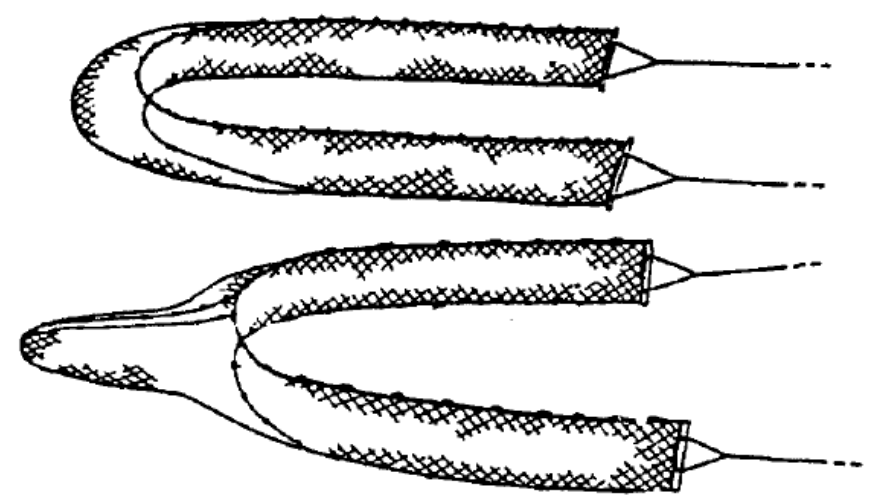

Figure A8: seine nets 


\section{Appendix 5.2}

Final search string:

((((TITLE-ABS-KEY (injur* OR mortality OR exhaust* OR "physical damage" OR "scale loss" OR abrasion OR asphyxia*) AND TITLE-ABS-KEY (fisheries OR fishing OR sein* OR trawl* OR "trammel net") AND NOT TITLE-ABS-KEY (whale OR lobster OR mollusc OR cetacean OR krill OR clam OR urchin OR seal OR seabird OR population OR recruitment OR growth OR exploitation OR "natural mortality" OR oil OR "sea lice" OR worker OR occupation* OR farm* OR patient OR trophic OR virus OR medic* OR viral OR pond OR accident* OR genetic OR infectious OR closure OR nitrogen OR genotype OR "marine protected area" OR octopus OR phenotype OR toxi* OR *economic OR reared OR diet* OR hatching OR shrimp OR decision OR overfish* OR immun* OR feed OR aquarium OR tournament OR rearing OR "risk assessment" OR "ghost fishing" OR hatched OR real-time OR ornamental OR crocodile OR derelict OR "fish aggregating device") AND NOT TITLE (shark OR turtle OR stock OR managing OR fishermen OR fisher OR angl* OR environment OR biology OR disease OR conservation OR "climate change" OR crab OR habitat OR infect* OR ecosystem OR gen* OR seasonal OR bacteria OR benthic OR cage OR clos* OR "sport fishing" OR vulnerable OR egg OR coral OR acid* OR effort OR distribut* OR exposed OR "fisheries management" OR *cultured OR fauna OR hatch* OR quota OR captive OR risk OR tagged) AND NOT KEY (health OR catch-and-release OR shark OR turtle OR fishermen OR fisher OR bacteria OR habitat OR drug OR recreational OR pheno* OR clos* OR benthic OR crab OR suscept* OR egg OR feed* OR quota OR fauna))))) AND (LIMIT-TO (DOCTYPE, "ar") OR LIMIT-TO (DOCTYPE, "re")) AND (LIMIT-TO (LANGUAGE, "English")) 
110 | Chapter 5

\section{Appendix 5.3}

Overview of the main information that was extracted from the 80 articles that were included in this review

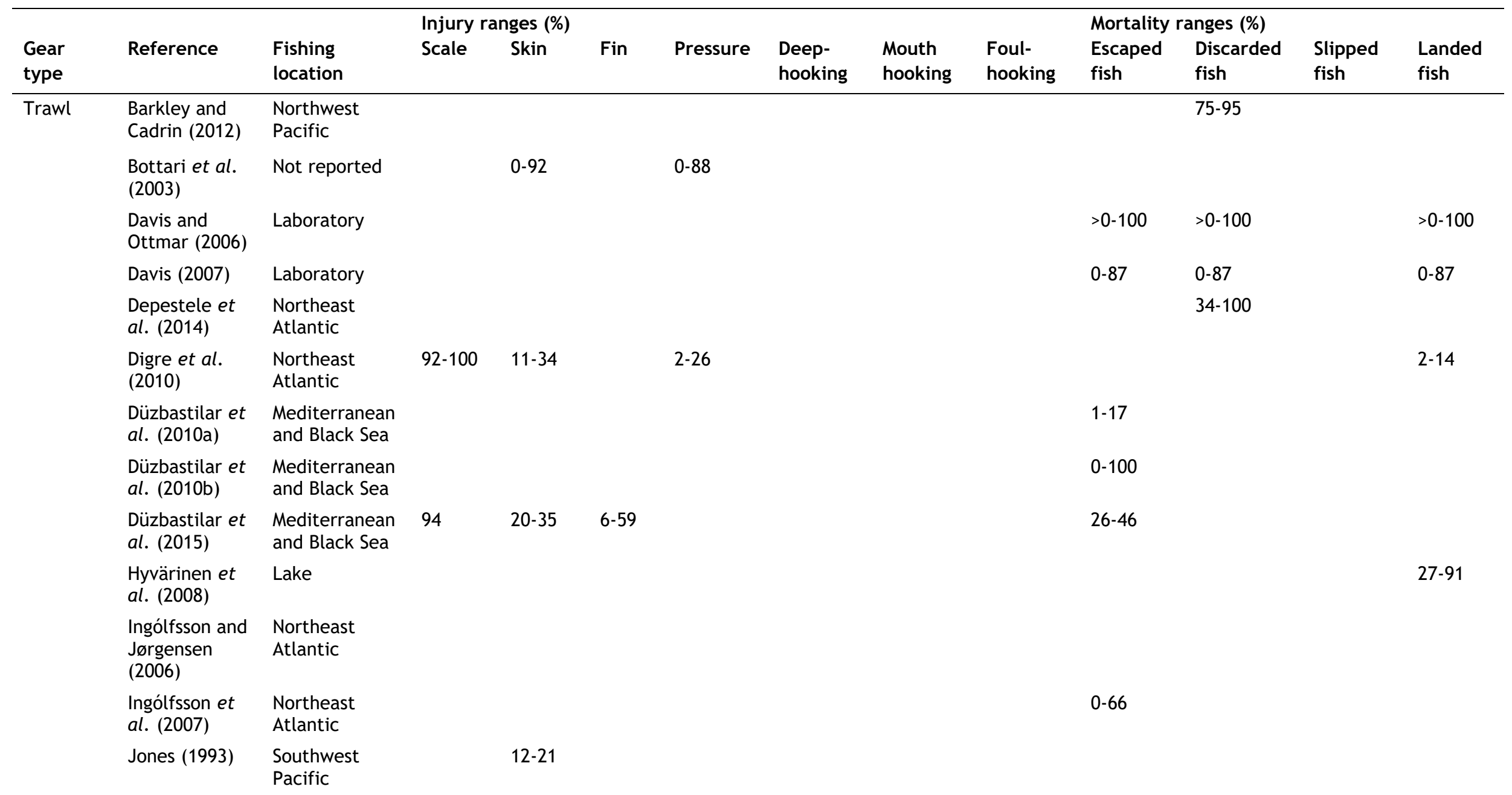


Appendices | 111

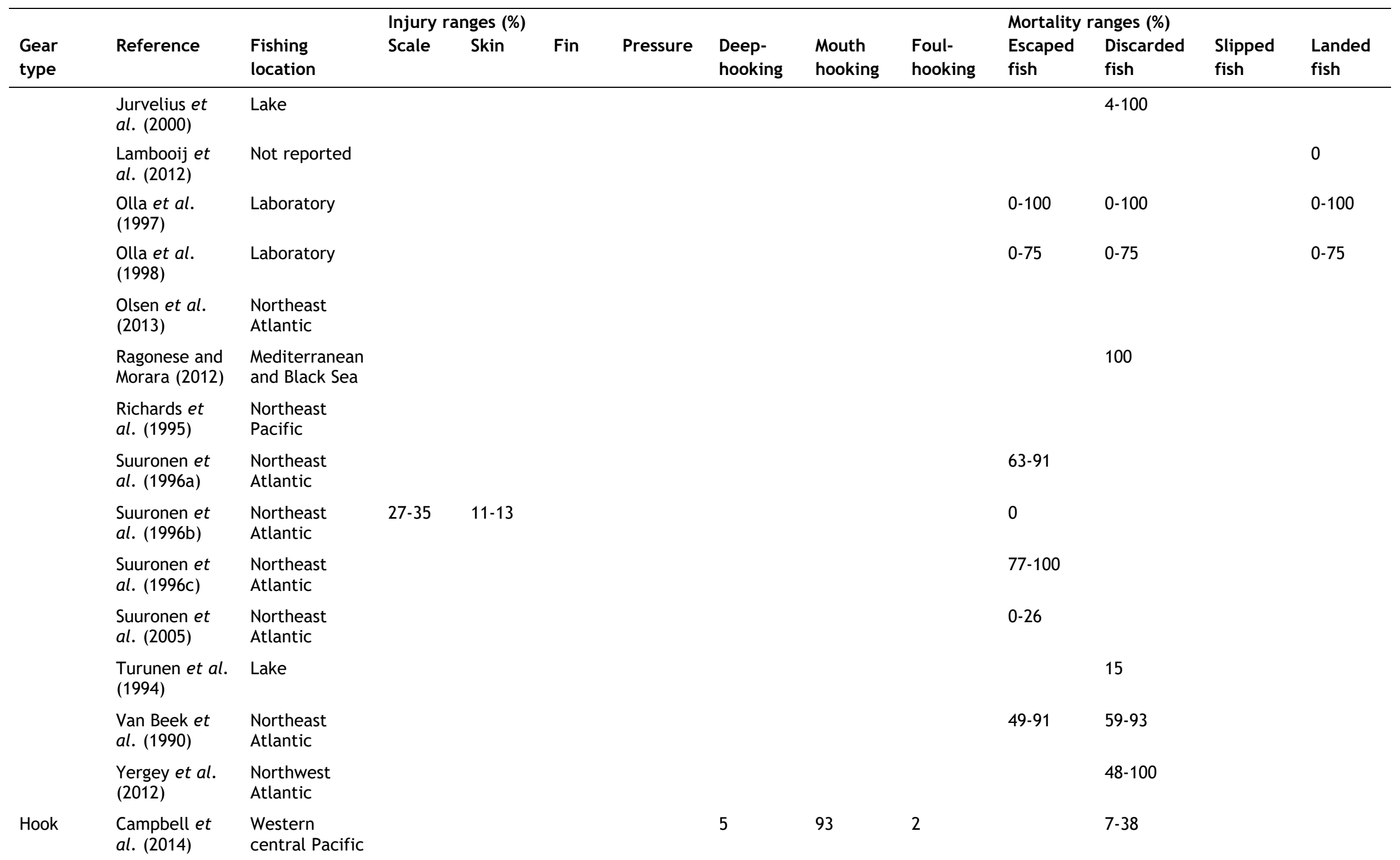


112 | Chapter 5

\begin{tabular}{|c|c|c|c|c|c|c|c|c|c|c|c|c|c|}
\hline \multirow[b]{2}{*}{$\begin{array}{l}\text { Gear } \\
\text { type }\end{array}$} & \multirow[b]{2}{*}{ Reference } & \multirow[b]{2}{*}{$\begin{array}{l}\text { Fishing } \\
\text { location }\end{array}$} & \multicolumn{3}{|c|}{ Injury ranges (\%) } & \multirow[b]{2}{*}{ Pressure } & \multirow[b]{2}{*}{$\begin{array}{l}\text { Deep- } \\
\text { hooking }\end{array}$} & \multirow[b]{2}{*}{$\begin{array}{l}\text { Mouth } \\
\text { hooking }\end{array}$} & \multirow[b]{2}{*}{$\begin{array}{l}\text { Foul- } \\
\text { hooking }\end{array}$} & \multicolumn{2}{|c|}{ Mortality ranges (\%) } & \multirow[b]{2}{*}{$\begin{array}{l}\text { Slipped } \\
\text { fish }\end{array}$} & \multirow[b]{2}{*}{$\begin{array}{l}\text { Landec } \\
\text { fish }\end{array}$} \\
\hline & & & Scale & Skin & Fin & & & & & $\begin{array}{l}\text { Escaped } \\
\text { fish }\end{array}$ & $\begin{array}{l}\text { Discarded } \\
\text { fish }\end{array}$ & & \\
\hline & $\begin{array}{l}\text { Drumhiller et } \\
\text { al. (2014) }\end{array}$ & $\begin{array}{l}\text { Western } \\
\text { Central } \\
\text { Atlantic }\end{array}$ & & & & 0 & & & & & $0-83$ & & \\
\hline & $\begin{array}{l}\text { Falterman } \\
\text { and Graves } \\
(2002)\end{array}$ & $\begin{array}{l}\text { Western } \\
\text { central } \\
\text { Atlantic }\end{array}$ & & & & & $3-9$ & $65-95$ & $2-11$ & & & & $0-100$ \\
\hline & $\begin{array}{l}\text { Kerstetter } \\
\text { and Graves } \\
(2006 a)\end{array}$ & $\begin{array}{l}\text { Northwest } \\
\text { Atlantic, } \\
\text { western } \\
\text { central } \\
\text { Atlantic }\end{array}$ & & & & & & & & & & & $14-100$ \\
\hline & $\begin{array}{l}\text { Kerstetter } \\
\text { and Graves } \\
\text { (2006b) }\end{array}$ & $\begin{array}{l}\text { Western } \\
\text { Central } \\
\text { Atlantic, } \\
\text { northwest } \\
\text { Atlantic }\end{array}$ & & & & & $11-22$ & $78-89$ & & & 37 & & 35 \\
\hline & $\begin{array}{l}\text { Kerstetter } \\
\text { and Graves } \\
(2008)\end{array}$ & $\begin{array}{l}\text { Western } \\
\text { Central } \\
\text { Atlantic }\end{array}$ & & & & & 6 & 71 & 24 & & 12 & & 31 \\
\hline & $\begin{array}{l}\text { Mapleston et } \\
\text { al. (2008) }\end{array}$ & $\begin{array}{l}\text { Western } \\
\text { central Pacific }\end{array}$ & & $0-17$ & & & $2-10$ & $85-92$ & $4-10$ & & & & \\
\hline & $\begin{array}{l}\text { McLennan et } \\
\text { al. (2014) }\end{array}$ & $\begin{array}{l}\text { Western } \\
\text { central Pacific }\end{array}$ & & & & 77 & & & & & 12 & & \\
\hline & $\begin{array}{l}\text { Milliken et al. } \\
\text { (1999) }\end{array}$ & $\begin{array}{l}\text { Northwest } \\
\text { Atlantic }\end{array}$ & & & & & & & & & $60-69$ & & \\
\hline & $\begin{array}{l}\text { Milliken et al. } \\
\text { (2009) }\end{array}$ & $\begin{array}{l}\text { Northwest } \\
\text { Atlantic }\end{array}$ & & & & & & & & & $0-69$ & & \\
\hline & $\begin{array}{l}\text { Orsi et al. } \\
(1993)\end{array}$ & $\begin{array}{l}\text { Northeast } \\
\text { Pacific }\end{array}$ & & & & & 0 & $61-79$ & $21-39$ & & & & $12-25$ \\
\hline & $\begin{array}{l}\text { Pálsson Ó et } \\
\text { al. (2003) }\end{array}$ & $\begin{array}{l}\text { Northeast } \\
\text { Atlantic }\end{array}$ & & & & & & & & & $32-54$ & & \\
\hline & $\begin{array}{l}\text { Pribyl et al. } \\
\text { (2011) }\end{array}$ & $\begin{array}{l}\text { Northeast } \\
\text { Pacific }\end{array}$ & & & & $0-94$ & & & & & & & \\
\hline
\end{tabular}


Appendices | 113

\begin{tabular}{|c|c|c|c|c|c|c|c|c|c|c|c|c|c|}
\hline \multirow[b]{2}{*}{$\begin{array}{l}\text { Gear } \\
\text { type }\end{array}$} & \multirow[b]{2}{*}{ Reference } & \multirow[b]{2}{*}{$\begin{array}{l}\text { Fishing } \\
\text { location }\end{array}$} & \multicolumn{5}{|c|}{ Injury ranges (\%) } & \multirow[b]{2}{*}{$\begin{array}{l}\text { Mouth } \\
\text { hooking }\end{array}$} & \multirow[b]{2}{*}{$\begin{array}{l}\text { Foul- } \\
\text { hooking }\end{array}$} & \multicolumn{3}{|c|}{ Mortality ranges (\%) } & \multirow[b]{2}{*}{$\begin{array}{l}\text { Landec } \\
\text { fish }\end{array}$} \\
\hline & & & Scale & Skin & Fin & Pressure & $\begin{array}{l}\text { Deep- } \\
\text { hooking }\end{array}$ & & & $\begin{array}{l}\text { Escaped } \\
\text { fish }\end{array}$ & $\begin{array}{l}\text { Discarded } \\
\text { fish }\end{array}$ & $\begin{array}{l}\text { Slipped } \\
\text { fish }\end{array}$ & \\
\hline & $\begin{array}{l}\text { Rice et al. } \\
(2012)\end{array}$ & $\begin{array}{l}\text { Northwest } \\
\text { Atlantic, } \\
\text { western } \\
\text { central } \\
\text { Atlantic }\end{array}$ & & & & & & & & & & & \\
\hline & $\begin{array}{l}\text { Stachura et } \\
\text { al. (2012) }\end{array}$ & $\begin{array}{l}\text { Northeast } \\
\text { Pacific }\end{array}$ & & & & & 2 & 97 & 1 & & $4-100$ & & \\
\hline & $\begin{array}{l}\text { Stephen and } \\
\text { Harris (2010) }\end{array}$ & $\begin{array}{l}\text { Western } \\
\text { central } \\
\text { Atlantic }\end{array}$ & & & & & & & & & $48-100$ & & \\
\hline & $\begin{array}{l}\text { Willis and } \\
\text { Millar (2001) }\end{array}$ & $\begin{array}{l}\text { Southeast } \\
\text { Pacific }\end{array}$ & & & & & $2-30$ & $70-98$ & & & & & \\
\hline & $\begin{array}{l}\text { Wilson Jr and } \\
\text { Burns (1996) }\end{array}$ & $\begin{array}{l}\text { Western } \\
\text { central } \\
\text { Atlantic }\end{array}$ & & & & 14 & 19 & 81 & & & $0-100$ & & \\
\hline \multirow[t]{8}{*}{$\begin{array}{l}\text { Purse } \\
\text { seine }\end{array}$} & $\begin{array}{l}\text { Candy et al. } \\
\text { (1996) }\end{array}$ & $\begin{array}{l}\text { Northeast } \\
\text { Pacific }\end{array}$ & 68 & & & & & & & & 23 & & \\
\hline & $\begin{array}{l}\text { Huse and Vold } \\
(2010)\end{array}$ & $\begin{array}{l}\text { Northeast } \\
\text { Atlantic }\end{array}$ & & & & & & & & & & $28-100$ & \\
\hline & $\begin{array}{l}\text { Lockwood et } \\
\text { al. (1983) }\end{array}$ & $\begin{array}{l}\text { Northeast } \\
\text { Atlantic }\end{array}$ & & & & & & & & & & $4-99$ & \\
\hline & $\begin{array}{l}\text { Marçalo et al. } \\
(2008)\end{array}$ & $\begin{array}{l}\text { Northeast } \\
\text { Atlantic }\end{array}$ & & & & & & & & & & & $0-8$ \\
\hline & $\begin{array}{l}\text { Marçalo et al. } \\
\text { (2010) }\end{array}$ & $\begin{array}{l}\text { Mediterranean } \\
\text { and Black Sea }\end{array}$ & 13 & & & & & & & & & 36 & \\
\hline & $\begin{array}{l}\text { Misund and } \\
\text { Beltestad } \\
\text { (1995) }\end{array}$ & $\begin{array}{l}\text { Northeast } \\
\text { Atlantic }\end{array}$ & & & & & & & & & & $95-100$ & \\
\hline & $\begin{array}{l}\text { Misund and } \\
\text { Beltestad } \\
(2000)\end{array}$ & $\begin{array}{l}\text { Northeast } \\
\text { Atlantic }\end{array}$ & & & & & & & & $0-82$ & & & \\
\hline & $\begin{array}{l}\text { Mitchell et al. } \\
(2002)\end{array}$ & $\begin{array}{l}\text { Eastern Indian } \\
\text { ocean }\end{array}$ & & 8 & & & & & & & & 38 & \\
\hline
\end{tabular}


114 | Chapter 5

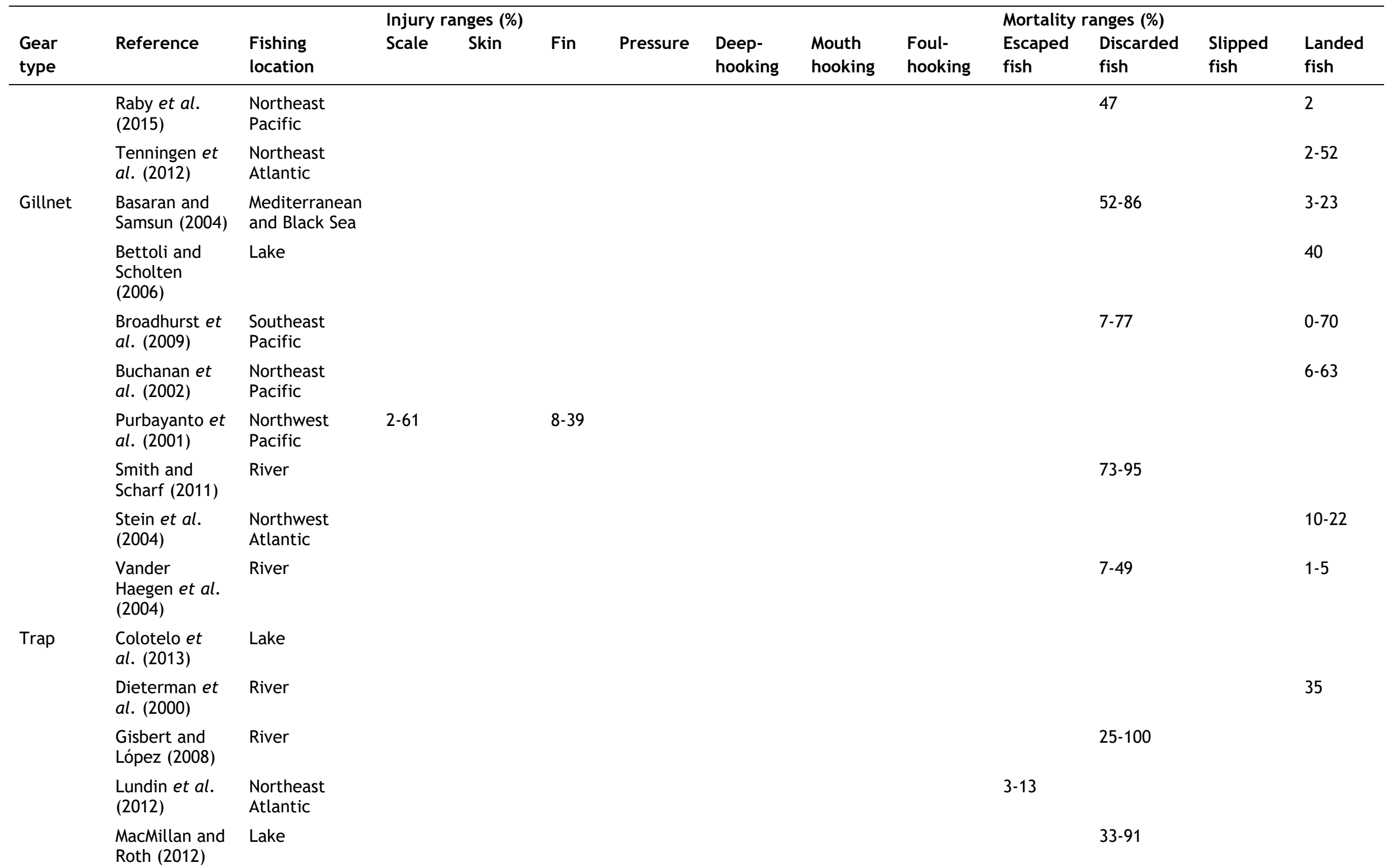


Appendices | 115

\begin{tabular}{|c|c|c|c|c|c|c|c|c|c|c|c|c|c|}
\hline \multirow[b]{2}{*}{$\begin{array}{l}\text { Gear } \\
\text { type }\end{array}$} & \multirow[b]{2}{*}{ Reference } & \multirow[b]{2}{*}{$\begin{array}{l}\text { Fishing } \\
\text { location }\end{array}$} & \multicolumn{3}{|c|}{ Injury ranges (\%) } & \multirow[b]{2}{*}{ Pressure } & \multirow[b]{2}{*}{$\begin{array}{l}\text { Deep- } \\
\text { hooking }\end{array}$} & \multirow[b]{2}{*}{$\begin{array}{l}\text { Mouth } \\
\text { hooking }\end{array}$} & \multirow[b]{2}{*}{$\begin{array}{l}\text { Foul- } \\
\text { hooking }\end{array}$} & \multicolumn{2}{|c|}{ Mortality ranges (\%) } & \multirow[b]{2}{*}{$\begin{array}{l}\text { Slipped } \\
\text { fish }\end{array}$} & \multirow[b]{2}{*}{$\begin{array}{l}\text { Landed } \\
\text { fish }\end{array}$} \\
\hline & & & Scale & Skin & Fin & & & & & $\begin{array}{l}\text { Escaped } \\
\text { fish }\end{array}$ & $\begin{array}{l}\text { Discarded } \\
\text { fish }\end{array}$ & & \\
\hline & $\begin{array}{l}\text { Rudershausen } \\
\text { et al. (2008) }\end{array}$ & $\begin{array}{l}\text { Western } \\
\text { central } \\
\text { Atlantic }\end{array}$ & & & & 4 & & & & $2-4$ & & & \\
\hline & $\begin{array}{l}\text { Stewart } \\
(2008)\end{array}$ & $\begin{array}{l}\text { Southwest } \\
\text { Pacific }\end{array}$ & & & & & & & & & $2-55$ & & \\
\hline Seine & $\begin{array}{l}\text { Broadhurst et } \\
\text { al. (2008) }\end{array}$ & River & & & & & & & & & $10-72$ & & 0 \\
\hline \multirow[t]{4}{*}{ General } & $\begin{array}{l}\text { Davis and } \\
\text { Schreck } \\
\text { (2005) }\end{array}$ & Laboratory & & & & & & & & $0-100$ & $0-100$ & $0-100$ & $0-100$ \\
\hline & $\begin{array}{l}\text { Humborstad } \\
\text { and Mangor- } \\
\text { Jensen (2013) }\end{array}$ & Laboratory & & & & & & & & & $3-10$ & & \\
\hline & $\begin{array}{l}\text { Kestin et al. } \\
\text { (1991) }\end{array}$ & Laboratory & & & & & & & & & & & 100 \\
\hline & $\begin{array}{l}\text { Olsen et al. } \\
\text { (2012) }\end{array}$ & Laboratory & & & & & & & & $19-43$ & $19-43$ & $19-43$ & \\
\hline \multirow[t]{2}{*}{$\begin{array}{l}\text { Hook, } \\
\text { trawl }\end{array}$} & $\begin{array}{l}\text { Davis and Olla } \\
\text { (2001) }\end{array}$ & Laboratory & & & & & & & & $0-78$ & $0-78$ & $0-78$ & 0 \\
\hline & $\begin{array}{l}\text { Davis et al. } \\
\text { (2001) }\end{array}$ & Laboratory & & & & & & & & $0-100$ & $0-100$ & $0-100$ & 0 \\
\hline \multirow[t]{2}{*}{$\begin{array}{l}\text { Hook, } \\
\text { trap }\end{array}$} & $\begin{array}{l}\text { Humborstad } \\
\text { et al. (2016) }\end{array}$ & $\begin{array}{l}\text { Northeast } \\
\text { Atlantic }\end{array}$ & & & & & & & & & $9-79$ & & \\
\hline & $\begin{array}{l}\text { Rudershausen } \\
\text { et al. (2014) }\end{array}$ & $\begin{array}{l}\text { Western } \\
\text { central } \\
\text { Atlantic }\end{array}$ & & & & & & & & & $9-84$ & & \\
\hline $\begin{array}{l}\text { Gillnet, } \\
\text { hook, } \\
\text { trawl, } \\
\text { seine }\end{array}$ & $\begin{array}{l}\text { Benoît et al. } \\
(2010)\end{array}$ & $\begin{array}{l}\text { Northwest } \\
\text { Atlantic }\end{array}$ & & & & & & & & & & & \\
\hline
\end{tabular}




\section{Appendix 5.4}

Overview of all species with their scientific names from the 80 articles that were included in this review

\begin{tabular}{|c|c|c|}
\hline Reference & Species & Scientific names \\
\hline Barkley and Cadrin (2012) & Yellowtail flounder & Limanda ferruginea \\
\hline Basaran and Samsun (2004) & Black Sea turbot & Psetta maxima maeotica \\
\hline \multirow[t]{12}{*}{ Benoît et al. (2010) } & American plaice & Hippoglossoides platessoides \\
\hline & Atlantic cod & Gadus morhua \\
\hline & Atlantic halibut & Hippoglossus hippoglossus \\
\hline & Eelpouts & $\begin{array}{l}\text { Lycodes lavalaei, Lycodes vahlii, } \\
\text { Zoarces americanus }\end{array}$ \\
\hline & Greenland cod & Gadus ogac \\
\hline & Sculpins & Myoxocephalus \\
\hline & & octodecemspinosus, \\
\hline & & $\begin{array}{l}\text { Myoxocephalus scorpius, } \\
\text { Hemitripterus americanus }\end{array}$ \\
\hline & White hake & Urophycis tenuis \\
\hline & Winter flounder & Pseudopleuronectes americanus \\
\hline & Witch flounder & Glyptocephalus cynoglossus \\
\hline & Wolffishes & Anarhichas lupus (mainly) \\
\hline Bettoli and Scholten (2006) & Paddlefish & Polyodon spathula \\
\hline \multirow[t]{4}{*}{ Bottari et al. (2003) } & Blue whiting & Micromesisitius poutassou \\
\hline & European hake & Merluccius merluccius \\
\hline & Greater forkbeard & Phycis blennioides \\
\hline & Red mullet & Mullus barbatus \\
\hline \multirow[t]{13}{*}{ Broadhurst et al. (2008) } & Blue salmon catfish & Neoarius graeffei \\
\hline & Castelnau's herring & Herklotsichthys castelnaui \\
\hline & Common silver belly & Gerres subfasciatus \\
\hline & Common toadfish & Tetractenos hamiltoni \\
\hline & Dusky flathead & Platycephalus fuscus \\
\hline & Eastern Sea Garfish & Hyporhamphus australis \\
\hline & Flat-tail mullet & Liza argentea \\
\hline & Flathead grey mullet & Mugil cephalus \\
\hline & Goldlined seabream & Rhabdosargus sarba \\
\hline & Old wife & Enoplosus armatus \\
\hline & Sand whiting & Sillago ciliata \\
\hline & Surf bream & Acanthopagrus australis \\
\hline & Trevallies & Caranx sp. \\
\hline \multirow[t]{10}{*}{ Broadhurst et al. (2009) } & Black sole & Synaptura nigra \\
\hline & Common silver belly & Gerres subfasciatus \\
\hline & Dusky flathead & Platycephalus fuscus \\
\hline & Estuary perch & Macquaria colonorum \\
\hline & Goldlined seabream & Rhabdosargus sarba \\
\hline & Largetooth flounder & Pseudorhombus arsius \\
\hline & Parore & Girella tricuspidata \\
\hline & Sand whiting & Sillago ciliata \\
\hline & Surf bream & Acanthopagrus australis \\
\hline & Yellowfin leather jacket & Meuschenia trachylepis \\
\hline Buchanan et al. (2002) & Coho salmon & Oncorhynchus kisutch \\
\hline Campbell et al. (2014) & Pearl perch & Glaucosoma scapulare \\
\hline Candy et al. (1996) & Chinook salmon & Oncorhynchus tshawytscha \\
\hline \multirow[t]{3}{*}{ Colotelo et al. (2013) } & Bluegill & Lepomis macrochirus \\
\hline & Largemouth bass & Micropterus salmoides \\
\hline & Northern pike & Esox Lucius \\
\hline Davis (2007) & Coho salmon & Oncorhynchus kisutch \\
\hline
\end{tabular}




\begin{tabular}{|c|c|c|}
\hline Reference & Species & Scientific names \\
\hline & Northern rock sole & Lepidopsetta polyxystra \\
\hline & Pacific halibut & Hippoglossus stenolepis \\
\hline & Walleye pollock & Theragra chalcogramma \\
\hline Davis and Olla (2001) & Pacific halibut & Hippoglossus stenolepis \\
\hline \multirow[t]{4}{*}{ Davis and Ottmar (2006) } & Northern rock sole & Lepidopsetta polyxystra \\
\hline & Pacific halibut & Hippoglossus stenolepis \\
\hline & Sablefish & Anoplopoma fimbria \\
\hline & Walleye pollock & Theragra chalcogramma \\
\hline Davis and Schreck (2005) & Pacific halibut & Hippoglossus stenolepis \\
\hline Davis et al. (2001) & Sablefish & Anoplopoma fimbria \\
\hline \multirow[t]{5}{*}{ Depestele et al. (2014) } & Cod & Gadus morhua \\
\hline & European plaice & Pleuronectes platessa \\
\hline & Poutings & Trisopterus sp. \\
\hline & Sole & Solea solea \\
\hline & Whiting & Merlangius merlangus \\
\hline Dieterman et al. (2000) & Paddlefish & Polyodon spathula \\
\hline \multirow[t]{2}{*}{ Digre et al. (2010) } & Cod & Gadus morhua \\
\hline & Haddock & Melanogrammus aeglefinus \\
\hline \multirow[t]{7}{*}{ Drumhiller et al. (2014) } & Red snapper & Lutjanus campechanus \\
\hline & Annular seabream & Diplodus annularis \\
\hline & Blotched picarel & Spicara maena \\
\hline & Brown comber & Serranus hepatus \\
\hline & Red mullet & Mullus barbatus \\
\hline & Scaldfish & Arnoglossus laterna \\
\hline & Common pandora & Pagellus erythrinus \\
\hline Düzbastilar et al. (2010b) & Brown comber & Serranus hepatus \\
\hline Düzbastilar et al. (2015) & Red mullet & Mullus barbatus \\
\hline \multirow[t]{9}{*}{ Falterman and Graves (2002) } & Albacore & Thunnus alalunga \\
\hline & Bigeye tuna & Thunnus obesus \\
\hline & Dolphin fish & Coryphaena hippurus \\
\hline & Gempylids & Alepisaurus spp. \\
\hline & Longbill spearfish & Tetrapturus pfluegeri \\
\hline & Oilfishes & Ruvettus sp. \\
\hline & Sailfish & Istiophorus platypterus \\
\hline & Wahoo & Acanthocybium solandri \\
\hline & Yellowfin tuna & Thunnus albacares \\
\hline \multirow[t]{10}{*}{ Gisbert and López (2008) } & Big-scale sand smelt & Atherina boyeri \\
\hline & Common bleak & Alburnus alburnus \\
\hline & Common goby & Pomatoschistus microps \\
\hline & Common rudd & Scardinius erythrophthalmus \\
\hline & Eastern mosquitofish & Gambusia holbrooki \\
\hline & Flathead grey mullet & Mugil cephalus \\
\hline & Golden grey mullet & Liza aurata \\
\hline & Ironfishes & Carassius sp. \\
\hline & Spanish toothcarp & Aphanius iberus \\
\hline & Thinlip mullet & Liza ramada \\
\hline $\begin{array}{l}\text { Humborstad and Mangor- } \\
\text { Jensen (2013) }\end{array}$ & Cod & Gadus morhua \\
\hline Humborstad et al. (2016) & Cod & Gadus morhua \\
\hline Huse and Vold (2010) & Mackerel & Scomber scombrus \\
\hline Hyvärinen et al. (2008) & Pike-perch & Sander lucioperca \\
\hline \multirow{3}{*}{$\begin{array}{l}\text { Ingólfsson and Jørgensen } \\
\text { (2006) }\end{array}$} & Cod & Gadus morhua \\
\hline & Haddock & Melanogrammus aeglefinus \\
\hline & Saithe & Pollachius virens \\
\hline \multirow[t]{3}{*}{ Ingólfsson et al. (2007) } & Cod & Gadus morhua \\
\hline & Haddock & Melanogrammus aeglefinus \\
\hline & Saithe & Pollachius virens \\
\hline Jones (1993) & Hoki & Macruronus novaezelandiae \\
\hline
\end{tabular}




\begin{tabular}{|c|c|c|}
\hline Reference & Species & Scientific names \\
\hline \multirow[t]{3}{*}{ Jurvelius et al. (2000) } & Brown trout & Salmo trutta \\
\hline & Landlocked salmon & Salmo salar m. sebago \\
\hline & Pike-perch & Sander lucioperca \\
\hline \multirow[t]{11}{*}{ Kerstetter and Graves (2006a) } & Albacore & Thunnus alalunga \\
\hline & Bigeye tuna & Thunnus obesus \\
\hline & Escolar & Lepidocybium flavobrunneum \\
\hline & Great barracuda & Sphyraena barracuda \\
\hline & Lancetfishes & Alepisaurus spp. \\
\hline & Oilfish & Ruvettus pretiosus \\
\hline & Sailfish & Istiophorus platypterus \\
\hline & Snake mackerel & Gempylus serpens \\
\hline & Swordfish & Xiphias gladius \\
\hline & White marlin & Tetrapturus albidus \\
\hline & Yellowfin tuna & Thunnus albacares \\
\hline Kerstetter and Graves (2006b) & White marlin & Tetrapturus albidus \\
\hline Kerstetter and Graves (2008) & Sailfish & Istiophorus platypterus \\
\hline Kestin et al. (1991) & Rainbow trout & Oncorhynchus mykiss \\
\hline \multirow[t]{2}{*}{ Lambooij et al. (2012) } & Cod & Gadus morhua \\
\hline & Haddock & Melanogrammus aeglefinus \\
\hline Lockwood et al. (1983) & Mackerel & Scomber scombrus \\
\hline Lundin et al. (2012) & Herring & Clupea harengus \\
\hline \multirow[t]{2}{*}{ MacMillan and Roth (2012) } & Lake trout & Salvelinus namaycush \\
\hline & Walleye & Sander vitreus \\
\hline \multirow[t]{8}{*}{ Mapleston et al. (2008) } & Blackbloth emperor & Lethrinus semicinctus \\
\hline & Blue spotted rock cod & Cephalopholis cyanostigma \\
\hline & Coral trout & Plectropomus leopardus \\
\hline & Crimson snapper & Lutjanus campechanus \\
\hline & Red emperor & Lutjanus sebae \\
\hline & Redthroat emperor & Lethrinus miniatus \\
\hline & Saddletail snapper & Lutjanus malabaricus \\
\hline & Trevallies & Carangidae \\
\hline \multirow[t]{3}{*}{ Marçalo et al. (2008) } & Chub mackerel & Scomber japonicus \\
\hline & Jack mackerel & Trachurus picturatus \\
\hline & Sardine & Sardina pilchardus \\
\hline Marçalo et al. (2010) & Sardine & Sardina pilchardus \\
\hline McLennan et al. (2014) & Pink snapper & Pagrus auratus \\
\hline Milliken et al. (1999) & Cod & Gadus morhua \\
\hline Milliken et al. (2009) & Cod & Gadus morhua \\
\hline Misund and Beltestad (1995) & Herring & Clupea harengas \\
\hline \multirow[t]{3}{*}{ Misund and Beltestad (2000) } & Horse mackerel & Trachurus trachurus \\
\hline & Mackerel & Scomber scombrus \\
\hline & Saithe & Pollachius virens \\
\hline Mitchell et al. (2002) & South American pilchard & Sardinops sagax \\
\hline \multirow[t]{2}{*}{ Olla et al. (1997) } & Sablefish & Anoplopoma fimbria \\
\hline & Walleye pollock & Theragra chalcogramma \\
\hline Olla et al. (1998) & Sablefish & Anoplopoma fimbria \\
\hline Olsen et al. (2012) & Herring & Clupea harengus \\
\hline Olsen et al. (2013) & Cod & Gadus morhua \\
\hline Orsi et al. (1993) & Chinook salmon & Oncorhynchus tshawytscha \\
\hline Pálsson Ó et al. (2003) & Cod & Gadus morhua \\
\hline \multirow[t]{6}{*}{ Pribyl et al. (2011) } & Black rockfish & Sebastes melanops \\
\hline & Blue rockfish & Sebastes mystinus \\
\hline & Canary rockfish & Sebastes pinniger \\
\hline & Quillback rockfish & Sebastes maliger \\
\hline & Yelloweye rockfish & Sebastes ruberrimus \\
\hline & Yellowtail rockfish & Sebastes ruberrimus \\
\hline Purbayanto et al. (2001) & Japanese whiting & Sillago japonica \\
\hline Raby et al. (2015) & Coho salmon & Oncorhynchus kisutch \\
\hline
\end{tabular}




\begin{tabular}{|c|c|c|}
\hline Reference & Species & Scientific names \\
\hline Ragonese and Morara (2012) & Blunthead puffer & Sphoeroides pachygaster \\
\hline \multirow[t]{4}{*}{ Rice et al. (2012) } & Billfishes & Istiophorus platypterus (mainly) \\
\hline & Blue marlin & Makaira nigricans \\
\hline & Bigeye tuna & Thunnus obesus \\
\hline & Swordfish & Xiphias gladius \\
\hline Richards et al. (1995) & Pacific halibut & Hippoglossus stenolepis \\
\hline Rudershausen et al. (2008) & Black sea bass & Centropristis striata \\
\hline Rudershausen et al. (2014) & Black sea bass & Centropristis striata \\
\hline Smith and Scharf (2011) & Southern flounder & Paralichthys lethostigma \\
\hline Stachura et al. (2012) & Sablefish & Anoplopoma fimbria \\
\hline Stein et al. (2004) & Atlantic sturgeon & Acipenser oxyrinchus \\
\hline \multirow[t]{17}{*}{ Stephen and Harris (2010) } & Bank sea bass & Centropristis ocyurus \\
\hline & Black sea bass & Centropristis striata \\
\hline & Gag & Mycteroperca microlepis \\
\hline & Gray triggerfish & Balistes capriscus \\
\hline & Greater amberjack & Seriola dumerili \\
\hline & Red grouper & Epinephelus morio \\
\hline & Red porgy & Pagrus pagrus \\
\hline & Red snapper & Lutjanus campechanus \\
\hline & Sand perch & Diplectrum formosum \\
\hline & Sand tilefish & Malacanthus plumeri \\
\hline & Scamp & Mycteroperca phenax \\
\hline & Snowy grouper & Epinephelus niveatus \\
\hline & Tomtate & Haemulon aurolineatum \\
\hline & Vermilion snapper & Rhomboplites aurorubens \\
\hline & White grunt & Haemulon plumeiri \\
\hline & Yellow fin grouper & Mycteroperca venenosa \\
\hline & Yellowtail snapper & Ocyurus chrysurus \\
\hline Stewart (2008) & Snapper & Pagrus auratus \\
\hline Suuronen et al. (1996a) & Herring & Clupea harengus \\
\hline Suuronen et al. (1996b) & Cod & Gadus morhua \\
\hline Suuronen et al. (1996c) & Herring & Clupea harengus \\
\hline Suuronen et al. (2005) & Cod & Gadus morhua \\
\hline Tenningen et al. (2012) & Herring & Clupea harengus \\
\hline Turunen et al. (1994) & Brown trout & Salmo trutta \\
\hline \multirow[t]{2}{*}{ Van Beek et al. (1990) } & Plaice & Pleuronectes platessa \\
\hline & 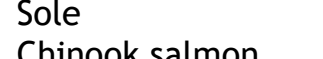 & Solea solea \\
\hline Vander Haegen et al. (2004) & $\begin{array}{l}\text { Chinook salmon } \\
\text { Snanner }\end{array}$ & Oncorhynchus tschawytscha \\
\hline \multirow{3}{*}{ Wilson Jr and Burns (1996) } & $\begin{array}{l}\text { Snapper } \\
\text { Gag }\end{array}$ & $\begin{array}{l}\text { Pagrus auratus (Sparidae) } \\
\text { Mycteroperca microlepis }\end{array}$ \\
\hline & Red grouper & Epinephelus morio \\
\hline & Scamp & Mycteroperca phenax \\
\hline Yergey et al. (2012) & Summer flounder & Paralichthys dentatus \\
\hline
\end{tabular}





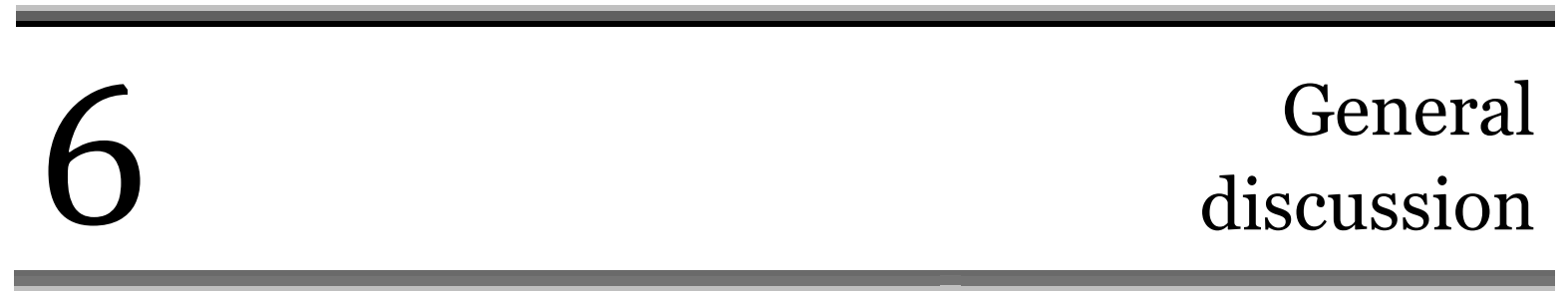




\section{Introduction}

Declining profitability of fisheries and excess capacity in the fleet (World Bank and FAO, 2009) likely resulted in increased competition among fishing companies. Companies faced with increasing competition can try to gain a competitive advantage by differentiating their products, e.g. by marketing new product attributes that consumers are interested in (Chamberlin, 1933). In recent years, consumers have displayed increasing interest in products with attributes relating to sustainability such as organic or Fairtrade products (Andorfer and Liebe, 2012, Tully and Winer, 2014). This makes it likely that consumers are also interested in sustainability of fish.

Sustainability is generally composed of environmental, economic, and social sustainability (Jeswani et al., 2010, Kloepffer, 2008). Environmental sustainability of capture fisheries has attracted considerable scientific attention (e.g. Pelletier et al., 2007, Seves et al., 2016, Ziegler et al., 2003) and consumers are interested in environmental sustainability of fish (Roheim et al., 2011, SognGrundvåg et al., 2013). Although consumers could be considerably interested in social sustainability of fish as well (Tully and Winer, 2014), this topic has received little research interest (e.g. Glaser and Diele, 2004, Van Holt et al., 2016). The overall objective of this thesis, therefore, was to understand social sustainability of capture fisheries.

Social sustainability can be understood by applying the framework for social sustainability assessment, which consists of stakeholder consultation and issue selection, indicator development and quantification, and interpretation, to the case considered (Meul et al., 2008, Mollenhorst and De Boer, 2004, Van Calker et al., 2005). In Chapter 2, stakeholders were consulted to identify social sustainability issues for cod and haddock fisheries in the northeast Atlantic, the case considered in this thesis. In Chapter 3, indicators were defined to measure the state of the important issues identified in Chapter 2 and rubrics (i.e. categories that articulate levels of performance) were developed to interpret information from these indicators. These indicators and rubrics were subsequently used to assess social sustainability of a Norwegian trawler to determine whether their application provides valuable information. To determine whether outcomes from such a social sustainability assessment can potentially be used for product differentiation, consumer interest in social sustainability issues of whitefish from the northeast Atlantic was studied in Chapter 4. This chapter demonstrated that fish welfare is the most important social sustainability issue for consumers. Given the lack of overview of the knowledge on this issue, the literature on fish welfare in capture fisheries was reviewed in Chapter 5. This chapter specifically focused on the impact of the capture process on injuries and mortality, two important function-based indicators for welfare that can be assessed in both field and laboratory settings. 
The outline of this general discussion is as follows. Section 2 discusses the practice of social sustainability assessment based on results presented in this thesis. Section 3 discusses how fishing companies can use consumer interest in social sustainability (and in specific issues such as fish welfare) to their advantage. In Section 4, a number of recommendations are provided for the fishing sector, researchers, certification organizations and policy-makers. Finally, in Section 5 , the main conclusions of this thesis are provided.

\section{Performing social sustainability assessment}

In Chapters 2 and 3, the framework for social sustainability assessment of animal husbandry systems (e.g. Meul et al., 2008, Mollenhorst and De Boer, 2004, Van Calker et al., 2005) was applied to cod and haddock fisheries in the northeast Atlantic. In Section 2.1, this methodological approach will be discussed in more detail. In Section 2.2, potential extensions of social sustainability assessment at the company level are discussed.

\subsection{Methodological approach}

Social sustainability assessment starts with stakeholder identification and consultation (Bell and Morse, 1999). In this step, it is crucial that all stakeholder groups are identified and consulted (or at least invited for consultation) to ensure that a complete view on social sustainability issues can be obtained. Omission of stakeholder groups can result in the omission of issues, which will ultimately result in a biased assessment. Exclusion of the fish welfare organization in Chapter 2, for example, could have resulted in omission of the issue fish welfare, while it appeared to be the most important social sustainability issue for consumers in Chapter 4.

Inclusion of a heterogeneous group of stakeholders inevitably leads to a plethora of perspectives on social sustainability issues, as was demonstrated in Chapter 2, where, for example, fishing companies and policy-makers had different perspectives on the importance of companies' contribution to the local community. The approach to dealing with such differences depends on the purpose of social sustainability issue selection and assessment. If the purpose is assessment of a company, a value chain, or a sector, all stakeholder perspectives on social sustainability issues have to be included (Chapter 3). If the purpose is product differentiation in order to retain or increase a certain market share or profit, then consumer perspectives on social sustainability issues (Chapter 4) will be most important.

Given that various indicators can be used in social sustainability assessment, it is important to use indicator criteria such as those used in Chapter 3 to select the best available indicator. The inclusion of multiple indicators for certain issues is recommended to ensure that all relevant aspects of each issue are assessed. The 
issue worker safety, for example, is best assessed by the occurrence of accidents and their severity, and by preventive measures (Chapter 3 ).

Interpretation of indicator values was enabled by rubrics in Chapter 3. Such rubrics (and other performance reference points such as benchmarks) involve value judgments and hence introduce ambiguity to the social sustainability assessment. It is important, therefore, to not only provide such tools for interpretation, but also to be transparent on their scoring system and on the choices that were made in defining scoring levels (e.g. 1-10 scales or acceptableunacceptable dichotomies) (De Olde et al., 2016).

\subsection{Extension of social sustainability assessment at the company level}

Chapters 2 and 3 focused on social sustainability assessment at the level of the fishing company. A fishing company, however, is part of a larger value chain that includes, among others, suppliers, processing companies, distributors and retailers. Hence, the final fish product is not only affected by social sustainability performance of the fishing company, but also by the performance of all other companies in the value chain. For example, part of the fish that was caught and frozen by the Norwegian trawler assessed in Chapter 3 was subsequently shipped to China for processing and returned to Europe where a Swedish sales organization distributed the fish product to retailers. To be able to account for the different social impacts along the fish product's value chain, the next step for fishing companies in the northeast Atlantic (and other companies in the value chain) would be to perform social sustainability assessment at the level of the value chain using social life cycle assessment (S-LCA) (Benoît-Norris et al., 2011).

S-LCA is a method that can be used to assess the social impacts of a product along its value chain. This method starts with the definition of the assessment's goal and scope, which involves the definition of a functional unit for the product studied and the identification of relevant activities, processes and stakeholders. The next phase in S-LCA is data inventory, where generic and site-specific data are collected to determine indicator values for social sustainability issues. These indicator values are subsequently related to stakeholder categories (i.e. workers, local community, national and global society, consumers, and value chain actors) in the impact assessment phase. Finally in the interpretation phase, significant issues (i.e. key concerns) are identified, the assessment's quality is evaluated, and conclusions and recommendations are provided (UNEP/SETAC, 2009).

Similar to Chapter 2, the issues that are central to S-LCA have been identified based on stakeholder (and expert) consultation (Benoit-Norris et al., 2011). Assessment of these issues focuses on the most important issues, which are identified based on generic data in the data inventory phase (UNEP/SETAC, 2009). In the impact assessment phase of S-LCA, performance reference points 
(which are similar to the rubrics in Chapter 3) can be used to interpret indicator data (UNEP/SETAC, 2009). Alternatively, indicator data can be aggregated and interpreted using impact pathways (Weidema, 2006, 2009, 2016). Such impact pathways outline the impact of specific indicator values on end-points such as human well-being. One problem with impact pathways in S-LCA, however, is that models have to be developed to link indicator values to generic impacts, which commonly involve a substantial degree of uncertainty (Jørgensen et al., 2010). Another problem with impact pathways is that an issue can have only a small effect on the end-point, even if the issue in itself is considered highly important (Jørgensen et al., 2010). This latter problem involves conflicting views from utilitarian versus deontological ethics.

Chapters 2 and 3 exclusively focused on the social dimension of sustainability because prior to this thesis, very little was known about social sustainability of capture fisheries (Glaser and Diele, 2004, Utne, 2007). Trade-offs and synergies commonly exist, however, between social, economic and environmental sustainability (Hahn et al., 2010). Reducing fishing duration to improve fish welfare (as recommended in Chapter 5), for example, likely reduces economic sustainability (i.e. revenues and thus profitability), resulting in a trade-off between social and economic sustainability. In contrast, the recommendation from Chapter 5 for continued size selectivity could result in less discards of undersized fish, which is an improvement in both social and environmental sustainability that could also benefit economic sustainability. To identify such trade-offs and synergies, full sustainability assessment, using for example life cycle sustainability assessment (LCSA) (Finkbeiner et al., 2010) or the G4 sustainability reporting guidelines from the global reporting initiative (GRI, 2015), would be the next step.

LCSA integrates the social, economic and environmental dimensions of sustainability into one assessment by combining the methodologies of S-LCA, life cycle costing and environmental life cycle assessment (Finkbeiner et al., 2010). Given that it includes S-LCA, LCSA is the logical next step after S-LCA. The G4 guidelines provide sustainability issues and accompanying indicators that companies and organizations can use to prepare their sustainability report. G4, like the approach used in this thesis, is based on stakeholder involvement. Important issues are identified using materiality analysis (GRI, 2015), i.e. by considering both internal and external factors such as the company's overall mission and societal expectations. Given that it focuses on the company (GRI, 2015), G4 is the logical next step for sustainability assessment at the company level. 


\section{Utilizing consumer interest in social sustainability}

The understanding of social sustainability from Chapters 2 and 3 was used in Chapters 4 and 5 to investigate how fishing companies can use the outcomes from a social sustainability assessment to their advantage. These latter chapters were based on a consumer perspective because this thesis was written in the context of the Whitefish project that ultimately aimed to gain a competitive advantage through product differentiation on sustainability attributes. Product differentiation entails alteration of a product attribute (or multiple attributes) as compared to the attributes of competitors' products. Successful product differentiation on, for example, social sustainability ensures that consumers become less sensitive to other product attributes such as price (Sharp and Dawes, 2001).

Product differentiation based on information that a fishing company provides itself is hardly feasible in national or international markets (as opposed to local markets). Such information is commonly lost in the value chain (Karlsen et al., 2011), unless a specific traceability system has been put in place as, for example, for the marine stewardship council (commonly known as MSC) (MSC, 2015a). External certification, therefore, is a more promising option for fishing companies to differentiate their products based on social sustainability. A label for social sustainability of whitefish from the northeast Atlantic is currently lacking (Fairtrade International and FLOCERT, 2015). Various labels, however, promote local origin or environmental sustainability and could extend their focus by including social sustainability issues as well. The advantage of extending existing labels is that no new labels are introduced that add to the existing confusion over labels (Parkes et al., 2010).

A marketing company for MSC-certified skipjack and yellowfin tuna recently launched social guidelines for its fisheries (Pacifical, 2016), which provides an example of how existing labels can be extended to include social sustainability. These guidelines primarily focus on the welfare of the people working in these fisheries and are based on international labour standards (Pacifical, 2016). Given that these guidelines seem voluntary, however, their implementation may be limited. If such guidelines are enforced more strongly and more widely, for example by the MSC itself, they could contribute to promoting worker rights and welfare in various countries.

Information on sustainability is often provided for one specific issue (e.g. dolphin-safe tuna) or for a sustainability dimension in general (e.g. Fairtrade for social sustainability). Chapter 4 showed that Dutch consumers are most interested in the social sustainability issue fish welfare (though the environmental sustainability issue approach to overfishing was most important overall), making this a relevant issue for certification. In addition, fish welfare could become more important in the coming years, in line with increasing 
importance of farm animal welfare since the 1990s (Issanchou, 1996, Verbeke and Viaene, 1999). Currently, there is no legislation on fish welfare in capture fisheries, while in contrast, there is legislation on the welfare of animals kept for farming purposes, including fish in aquaculture (Council of the European Union, 1998). In the absence of legislation, inclusion of fish welfare in certification schemes could contribute to improving fish welfare. The recommendations from Chapter 5 provide starting points for introducing fish welfare in legislation or certification schemes, which could focus, for example, on technical measures such as selectivity devices and water tanks to limit air exposure of fish after landing onboard.

Rather than including one issue in certification schemes, the social sustainability dimension as a whole can be incorporated in such schemes. The issues that were identified in Chapter 2, however, cannot be used for inclusion in certification schemes with a global focus such as MSC. These issues hold specifically for the northeast Atlantic and can thus only be incorporated in certification schemes for fisheries in this specific region such as Iceland responsible fisheries. These issues could be relevant for certification schemes with a global focus, however, when such schemes develop fishery-specific minimum requirements for social sustainability (e.g. no child labour in regions where child labour is prevalent and local employment where the existence of local communities is threatened). The approach to issue selection that was used in Chapter 2 can be used to identify social sustainability issues that are relevant for capture fisheries in regions other than the northeast Atlantic or to identify issues with global significance.

When it comes to providing information on social sustainability at an aggregated level, certification schemes often use scoring systems that consist of multiple indicators and performance reference points. The MSC, for example, uses three principles and various indicators for each of these principles in its certification. A fishery qualifies for certification when it achieves a score of at least 60/100 for each indicator and an average higher than 80/100 for each principle (MSC, 2015b). This certification scheme could be extended to include the social dimension of sustainability as well by including principles for social sustainability such as proper working conditions and minimising impact on fish welfare. The approach to defining indicators and rubrics that was used in Chapter 3 provides a starting point for defining such principles based on indicators and different levels of desirability.

\section{Recommendations}

A number of recommendations for fishing companies, researchers, current certification schemes and policy-makers follow from this thesis. 
Fishing companies in the northeast Atlantic can use the indicators and accompanying rubrics from Chapter 3 to perform social sustainability assessment of their company. These indicators are relatively easy to use because one of their criteria was simplicity. Results from such a company-specific social sustainability assessment can be used for product differentiation, but can also result in gains outside the market. An example of such a gain is the increased worker satisfaction that could result from an improvement in working conditions.

For all fishing companies, one likely area for improvement is fish welfare. The Norwegian trawler in Chapter 3 performed less well on this issue than on other issues such as worker safety. Given that there is no legislation on fish welfare and given the results from Chapter 5 (e.g. commercial fishing can result in 100\% mortality prior to slaughter), other fishing companies are likely not performing well on this issue either. Low performance for fish welfare, combined with consumer interest in this issue (Chapter 4) are a potential risk for fishing companies. When fishing companies' performance on fish welfare is below consumers' expectations, consumers will likely punish these companies harder than that they would reward them for improved performance (Moosmayer, 2012), especially when expectations of performance are high (Trudel and Cotte, 2009). Fishing companies should, therefore, consider the implementation of improvement options for fish welfare as, for example, suggested in Chapter 5 .

The framework for social sustainability assessment that was used in this thesis can be used by researchers to assess social sustainability of other fisheries or production systems. In addition, fisheries researchers could work with fishing companies to prioritize the knowledge gaps that were identified in Chapter 5 and to study the consequences of implementing the improvement options from that chapter on, for example, catch rates, fuel use and working conditions.

Current certification schemes for fish from capture fisheries primarily focus on environmental sustainability and local origin. Given that sustainability consists of three dimensions, certification organizations could consider including other aspects of sustainability as well. Such an extension of current certification schemes, however, likely increases the complexity and costs of certification, and, therefore, increases the risk of excluding small-scale fishing companies (Hadjimichael and Hegland, 2016). Such exclusion could, in part, be alleviated by providing financial support to small-scale fishing companies to enable them to apply for certification as well.

Finally, no legislation exists on fish welfare in capture fisheries, as opposed to fish welfare in aquaculture. Policy-makers should, therefore, consider introducing legislation on fish welfare in capture fisheries. One major obstacle to introducing such legislation, however, is the ongoing scientific debate on sentience in fish (e.g. Braithwaite, 2010, Diggles et al., 2011, Huntingford et al., 2006, Rose et al., 
2014). Possibly, researchers can draw up a common research agenda to address the main questions in this debate (Cooke, 2016). Irrespective of the scientific debate, however, fish welfare can become an issue of public and political debate, which could give rise to legislation on fish welfare in capture fisheries based on the precautionary principle.

\section{Conclusion}

This thesis is the first study to apply the framework for social sustainability assessment of animal husbandry systems to capture fisheries. Results from the case of capture fisheries in the northeast Atlantic show that this application leads to an understanding of social sustainability that companies can use to their advantage. Specifically, this application showed that stakeholder perspectives on social sustainability issues vary, demonstrating the importance of consulting a heterogeneous group of stakeholders. The stakeholder consultation showed that issues relating to working conditions, terms of employment, employees' job fulfilment, companies' contribution to the local community, food safety and product quality, and fish welfare are relevant for fisheries in the northeast Atlantic. Application of indicators and rubrics that were developed for the most important issues demonstrated that such indicators and rubrics provide insight into social sustainability that companies can use, for example, for product differentiation. Consumer interest, which is essential for product differentiation, was highest for approach to overfishing, followed by fish welfare, product quality, worker safety and local employment. Consumer interest in these social sustainability issues differs from the prioritization given by fishing companies to worker safety over product quality, local employment and particularly fish welfare, which illustrates that fishing companies need to start paying attention to fish welfare. Fishing companies that want to pay attention to fish welfare can improve their performance for this issue by improving size selectivity, by fishing at lower water temperatures, by decreasing capture depth, fishing duration, duration of air exposure and density in the net (e.g. by lowering catch per haul of the net), and by changing landing procedures (i.e. to prevent that fish are exposed to air). 


\section{References}

Aghazadeh, S.M. (2007) Re-examining the training side of productivity improvement: Evidence from service sector. International Journal of Productivity and Performance Management 56, 744-757.

Åhman, H. (2013) Social sustainability - Society at the intersection of development and maintenance. Local Environment 18, 1153-1166.

Alexandratos, N. and Bruinsma, J. (2012) World agriculture towards 2030/2050: The 2012 revision. FAO, Rome.

Andorfer, V.A. and Liebe, U. (2012) Research on fair trade consumption - A review. Journal of Business Ethics 106, 415-435.

Arlinghaus, R., Cooke, S.J., Schwab, A. and Cowx, I.G. (2007) Fish welfare: A challenge to the feelings-based approach, with implications for recreational fishing. Fish and Fisheries 8, 57-71.

Ashley, P.J. (2007) Fish welfare: Current issues in aquaculture. Applied Animal Behaviour Science 104, 199-235.

Ashley, P.J. and Sneddon, L.U. (2008) Pain and fear in fish. In: Fish welfare, (Ed. E.J. Branson), Blackwell Publishing, Oxford, pp. 49-77.

Ashley, P.J., Sneddon, L.U. and McCrohan, C.R. (2006) Properties of corneal receptors in a teleost fish. Neuroscience Letters 410, 165-168.

Ashley, P.J., Sneddon, L.U. and McCrohan, C.R. (2007) Nociception in fish: Stimulusresponse properties of receptors on the head of trout Oncorhynchus mykiss. Brain Research 1166, 47-54.

Auger, P., Burke, P., Devinney, T.M. and Louviere, J.J. (2003) What will consumers pay for social product features? Journal of Business Ethics 42, 281-304.

Barber, N.A., Bishop, M. and Gruen, T. (2014) Who pays more (or less) for proenvironmental consumer goods? Using the auction method to assess actual willingness-to-pay. Journal of Environmental Psychology 40, 218-227.

Barkley, A.S. and Cadrin, S.X. (2012) Discard mortality estimation of yellowtail flounder using reflex action mortality predictors. Transactions of the American Fisheries Society 141, 638-644.

Barnes-Mauthe, M., Oleson, K.L.L. and Zafindrasilivonona, B. (2013) The total economic value of small-scale fisheries with a characterization of post-landing trends: An application in Madagascar with global relevance. Fisheries Research 147, 175-185.

Basaran, F. and Samsun, N. (2004) Survival rates of black sea turbot (Psetta maxima maeotica, L. 1758) broodstock captured by gill nets from different depths and their adaptation culture conditions. Aquaculture International 12, 321-331.

Bavinck, M. and Monnereau, I. (2007) Assessing the social costs of capture fisheries: An exploratory study. Social Science Information 46, 135-152. 
Bell, S. and Morse, S. (1999) Sustainability indicators - Measuring the immeasurable? Earthscan Publications Limited, London.

Ben-Akiva, M. and Lerman, S.R. (1985) Discrete choice analysis: Theory and application to travel demand. The MIT Press, Cambridge.

Béné, C., Barange, M., Subasinghe, R., Pinstrup-Andersen, P., Merino, G., Hemre, G.-I. and Williams, M. (2015) Feeding 9 billion by 2050 - Putting fish back on the menu. Food Security 7, 261-274.

Benoit-Norris, C., Vickery-Niederman, G., Valdivia, S., Franze, J., Traverso, M., Ciroth, A. and Mazijn, B. (2011) Introducing the UNEP/SETAC methodological sheets for subcategories of social LCA. International Journal of Life Cycle Assessment 16, 682690.

Benoît, H.P., Hurlbut, T. and Chassé, J. (2010) Assessing the factors influencing discard mortality of demersal fishes using a semi-quantitative indicator of survival potential. Fisheries Research 106, 436-447.

Bettoli, P.W. and Scholten, G.D. (2006) Bycatch rates and initial mortality of paddlefish in a commercial gillnet fishery. Fisheries Research 77, 343-347.

Boström, M. (2012) A missing pillar? Challenges in theorizing and practicing social sustainability: Introduction to the special issue. Sustainability: Science, Practice, and Policy 8, 3-14.

Bottari, T., Greco, S. and Panebianco, A. (2003) Trawling lesions: Incidence in some fish species and preliminary statistical evaluations. Veterinary Research Communications 27, 285-288.

Braithwaite, V.A. (2010) Do fish feel pain? Oxford University Press, Oxford.

Braithwaite, V.A. and Boulcott, P. (2007) Pain perception, aversion and fear in fish. Diseases of Aquatic Organisms 75, 131-138.

Braithwaite, V.A. and Boulcott, P. (2008) Can fish suffer? In: Fish welfare, (Ed. E.J. Branson), Blackwell Publishing, Oxford, pp. 78-92.

Branson, E.J. (2008) Fish welfare. Blackwell Publishing, Oxford.

Broadhurst, M.K., Millar, R.B. and Brand, C.P. (2009) Mitigating discard mortality from dusky flathead platycephalus fuscus gillnets. Diseases of Aquatic Organisms 85, 157166.

Broadhurst, M.K., Millar, R.B., Brand, C.P. and Uhlmann, S.S. (2008) Mortality of discards from southeastern Australian beach seines and gillnets. Diseases of Aquatic Organisms 80, 51-61.

Broom, D.M. (2010) Animal welfare: An aspect of care, sustainability, and food quality required by the public. Journal of Veterinary Medical Education 37, 83-88.

Brundtland, G.H. (1987) Our common future. University Press, Oxford.

Brunton, G., Stansfield, C. and Thomas, J. (2012) Finding relevant studies. In: An introduction to systematic reviews, (Eds. D. Gough, S. Oliver, J. Thomas), Sage Publications, London, pp. 107-134.

Buchanan, S., Farrell, A.P., Fraser, J., Gallaugher, P., Joy, R. and Routledge, R. (2002) Reducing gill-net mortality of incidentally caught coho salmon. North American Journal of Fisheries Management 22, 1270-1275. 
Caffey, R.H., Kazmierczak, R.F. and Avault, J.W. (2000) Developing consensus indicators of sustainability for southeastern United States aquaculture. LSU Agricultural Center, Baton Rouge.

Campbell, M.J., McLennan, M.F. and Sumpton, W.D. (2014) Short-term survival of discarded pearl perch (Glaucosoma scapulare Ramsay, 1881) caught by hook-andline in Queensland, Australia. Fisheries Research 151, 206-212.

Candy, J.R., Carter, E.W., Quinn, T.P. and Riddell, B.E. (1996) Adult chinook salmon behavior and survival after catch and release from purse-seine vessels in Johnstone Strait, British Columbia. North American Journal of Fisheries Management 16, 521529.

CBS (2014) Inkomen, arbeidsdeelname, opleidingsniveau, vermogen en sociale samenhang naar regio. Tabel 4: Personen van 18 jaar of ouder (exclusief studerenden) naar hoogst behaalde opleidingsniveau naar Waddengebied, provincie, COROP en gemeente, september 2011 [in Dutch], accessible via: http://www.cbs.nl/nl-NL/menu/themas/dossiers/nederlandregionaal/cijfers/incidenteel/maatwerk/2014-arbeid-inkomensbron-vermogenopleiding-sociale-samenhang-mw.htm, accessed on: 24 February 2016.

CBS (2015) Bevolking; geslacht, leeftijd en burgerlijke staat, 1 januari [in Dutch], accessible via:

http://statline.cbs.nl/StatWeb/publication/?DM=SLNL\&PA=7461BEV\&D1=0\&D2= $1-2 \& \mathrm{D}_{3}=\mathrm{O}-$

$100 \& \mathrm{D} 4=0 \% 2 \mathrm{c} 10 \% 2 \mathrm{c} 20 \% 2 \mathrm{c} 30 \% 2 \mathrm{c} 40 \% 2 \mathrm{c} 50 \% 2 \mathrm{cl} \& \mathrm{HDR}=\mathrm{T} \% 2 \mathrm{cG} 3 \& \mathrm{STB}=\mathrm{G} 1 \% 2 \mathrm{cG} 2 \&$ VW=T, accessed on: 24 February 2016.

Ceriola, L., Accadia, P., Mannini, P., Massa, F., Milone, N. and Ungaro, N. (2008) A bioeconomic indicators suite for the appraisal of the demersal trawl fishery in the Southern Adriatic Sea (Central Mediterranean). Fisheries Research 92, 255-267.

Chamberlin, E. (1933) The theory of monopolistic competition. Harvard University Press, Cambridge.

Chandroo, K.P., Duncan, I.J.H. and Moccia, R.D. (2004a) Can fish suffer? Perspectives on sentience, pain, fear and stress. Applied Animal Behaviour Science 86, 225-250.

Chandroo, K.P., Yue, S. and Moccia, R.D. (2004b) An evaluation of current perspectives on consciousness and pain in fishes. Fish and Fisheries 5, 281-295.

Christian, C., Ainley, D., Bailey, M., Dayton, P., Hocevar, J., LeVine, M., Nikoloyuk, J., Nouvian, C., Velarde, E., Werner, R., et al. (2013) A review of formal objections to Marine Stewardship Council fisheries certifications. Biological Conservation 161, 1017.

Chu, C. (2009) Thirty years later: The global growth of ITQs and their influence on stock status in marine fisheries. Fish and Fisheries 10, 217-230.

Codex Alimentarius Commission (2009) Codex Alimentarius: Food hygiene, basic texts. WHO and FAO, Rome.

Coglan, L. and Pascoe, S. (2015) Corporate-cooperative management of fisheries: A potential alternative governance structure for low value small fisheries? Marine Policy 57, 27-35. 
Colotelo, A.H., Cooke, S.J., Blouin-Demers, G., Murchie, K.J., Haxton, T. and Smokorowski, K.E. (2013) Influence of water temperature and net tending frequency on the condition of fish bycatch in a small-scale inland commercial fyke net fishery. Journal for Nature Conservation 21, 217-224.

Cooke, S.J. (2016) Spinning our wheels and deepening the divide: Call for an evidencebased approach to the fish pain debate. Animal Sentience 72.

Côté, I.M., Mosqueira, I. and Reynolds, J.D. (2001) Effects of marine reserve characteristics on the protection of fish populations: A meta-analysis. Journal of Fish Biology 59, 178-189.

Council of the European Union (1998) Council Directive 98/58/EC of 20 July 1998 concerning the protection of animals kept for farming purposes

CWP (2015) Section H: Fishing areas for statistical purposes. In: Handbook of Fishery Statistical Standards. (Ed. CWP), FAO, Rome.

Davis, M.W. (2007) Simulated fishing experiments for predicting delayed mortality rates using reflex impairment in restrained fish. ICES Journal of Marine Science 64, 15351542.

Davis, M.W. and Olla, B.L. (2001) Stress and delayed mortality induced in Pacific halibut by exposure to hooking, net towing, elevated seawater temperature and air: Implications for management of bycatch. North American Journal of Fisheries Management 21, 725-732.

Davis, M.W., Olla, B.L. and Schreck, C.B. (2001) Stress induced by hooking, net towing, elevated sea water temperature and air in sablefish: Lack of concordance between mortality and physiological measures of stress. Journal of Fish Biology 58, 1-15.

Davis, M.W. and Ottmar, M.L. (2006) Wounding and reflex impairment may be predictors for mortality in discarded or escaped fish. Fisheries Research 82, 1-6.

Davis, M.W. and Schreck, C.B. (2005) Responses by pacific halibut to air exposure: Lack of correspondence among plasma constituents and mortality. Transactions of the American Fisheries Society 134, 991-998.

De Bekker-Grob, E.W., Donkers, B., Jonker, M.F. and Stolk, E.A. (2015) Sample size requirements for discrete-choice experiments in healthcare: A practical guide. The Patient - Patient-Centered Outcomes Research 8, 373-384.

De Groot, J.I.M. and Steg, L. (2008) Value orientations to explain beliefs related to environmental significant behavior: How to measure egoistic, altruistic, and biospheric value orientations. Environment and Behavior 40, 330-354.

De Groot, J.I.M. and Steg, L. (2010) Relationships between value orientations, selfdetermined motivational types and pro-environmental behavioural intentions. Journal of Environmental Psychology 30, 368-378.

De Olde, E.M., Oudshoorn, F.W., Sørensen, C.A.G., Bokkers, E.A.M. and De Boer, I.J.M. (2016) Assessing sustainability at farm-level: Lessons learned from a comparison of tools in practice. Ecological Indicators 66, 391-404.

De Pelsmacker, P. and Janssens, W. (2007) A model for fair trade buying behaviour: The role of perceived quantity and quality of information and of product-specific attitudes. Journal of Business Ethics 75, 361-380. 
De Pelsmacker, P., Janssens, W., Sterckx, E. and Mielants, C. (2005) Consumer preferences for the marketing of ethically labelled coffee. International Marketing Review 22, 512-530.

Depestele, J., Desender, M., Benoît, H.P., Polet, H. and Vincx, M. (2014) Short-term survival of discarded target fish and non-target invertebrate species in the "eurocutter" beam trawl fishery of the southern North Sea. Fisheries Research 154, 82-92.

Dieterman, D.J., Baird, M.S. and Galat, D.L. (2000) Mortality of paddlefish in hoop nets in the lower Missouri River, Missouri. North American Journal of Fisheries Management 20, 226-230.

Diggles, B.K., Cooke, S.J., Rose, J.D. and Sawynok, W. (2011) Ecology and welfare of aquatic animals in wild capture fisheries. Reviews in Fish Biology and Fisheries 21, 739-765.

Digre, H., Hansen, U.J. and Erikson, U. (2010) Effect of trawling with traditional and 'T9o' trawl codends on fish size and on different quality parameters of cod Gadus morhua and haddock Melanogrammus aeglefinus. Fisheries Science 76, 549-559.

Drumhiller, K.L., Johnson, M.W., Diamond, S.L., Reese Robillard, M.M. and Stunz, G.W. (2014) Venting or rapid recompression increase survival and improve recovery of red snapper with barotrauma. Marine and Coastal Fisheries 6, 190-199.

Düzbastilar, F.O., Laleli, T., Özgül, A. and Metin, G. (2015) Determining the severity of skin injuries of red mullet, Mullus barbatus (Actinopterygii: Perciformes: Mullidae), inflicted during escape from trawl codend. Acta Ichthyologica et Piscatoria 45, 75-83.

Düzbastilar, F.O., Özbilgin, H., Aydin, C., Metin, G., Ulaş, A., Lök, A. and Metin, C. (2010a) Mortalities of fish escaping from square and diamond mesh codends in the Aegean Sea. Fisheries Research 106, 386-392.

Düzbastilar, F.O., Özgül, A., Aydin, I., Gül, B. and Soykan, O. (2010b) A preliminary study on the survival of brown comber, Serranus hepatus (Actinopterygii, Perciformes, Serranidae), escaping from the codend of a bottom trawl. Acta Ichthyologica et Piscatoria 40, 27-36.

Ellingsen, H. and Aanondsen, S.A. (2006) Environmental impacts of wild caught cod and farmed salmon - A comparison with chicken. International Journal of Life Cycle Assessment 11, 60-65.

Emanuelsson, A., Ziegler, F., Pihl, L., Sköld, M. and Sonesson, U. (2014) Accounting for overfishing in life cycle assessment: New impact categories for biotic resource use. International Journal of Life Cycle Assessment 19, 1156-1168.

Epperly, S.P., Watson, J.W., Foster, D.G. and Shah, A.K. (2012) Anatomical hooking location and condition of animals captured with pelagic longlines: The grand banks experiments 2002-2003. Bulletin of Marine Science 88, 513-527.

European Food Safety Authority (2010) Application of systematic review methodology to food and feed safety assessments to support decision making. EFSA Journal 8, 16371726.

Evans, L., Cherrett, N. and Pemsl, D. (2011) Assessing the impact of fisheries comanagement interventions in developing countries: A meta-analysis. Journal of Environmental Management 92, 1938-1949.

Fairtrade International and FLOCERT (2015) Monitoring the scope and benefits of Fairtrade. Fairtrade International, Bonn. 
Falterman, B. and Graves, J.E. (2002) A preliminary comparison of the relative mortality and hooking efficiency of circle and straight shank ("J") hooks used in the pelagic longline industry. American Fisheries Society Symposium 2002, 80-87.

FAO (1997) Fisheries management. Technical guidelines for responsible fisheries, (Ed. FAO), FAO, Rome.

FAO (1999) Indicators for sustainable development of marine capture fisheries. Technical guidelines for responsible fisheries, (Ed. FAO), FAO, Rome.

FAO (2008) Major fishing areas: Atlantic, Northeast (major fishing area 27), accessible via: http://www.fao.org/fishery/area/Area27/en, accessed on: 13 June 2016.

FAO (2010) World fisheries production, by capture and aquaculture, by country, accessible via: ftp://ftp.fao.org/fi/stat/summary/summ_10/a-oa.pdf, accessed on: 21 September 2015.

FAO (2011) Food balance sheets.Yearbook of Fishery Statistics - Summary Tables, accessible via: ftp://ftp.fao.org/FI/STAT/summary/FBS_bycontinent.pdf, accessed on: 12 February 2015.

FAO (2012) The state of world fisheries and aquaculture. FAO, Rome.

FAO (2014a) SAFA guidelines. FAO, Rome.

FAO (2014b) The State of World Fisheries and Aquaculture: Opportunities and challenges. FAO, Rome.

FAO (2014c) World capture production.Yearbook of Fishery Statistics - Summary tables, accessible via: ftp://ftp.fao.org/FI/STAT/summary/a1a.pdf, accessed on: 24 May 2016.

FAO (2014d) World fisheries production, by capture and aquaculture, by country, accessible via: ftp://ftp.fao.org/FI/STAT/summary/a-oa.pdf, accessed on: 12 February 2015.

FAO, ILO and IMO (1975) Code of safety for fishermen and fishing vessels. IMO, London.

Finkbeiner, M., Schau, E.M., Lehmann, A. and Traverso, M. (2010) Towards life cycle sustainability assessment. Sustainability 2, 3309-3322.

Fraser, D. (2008) Understanding animal welfare: The science in its cultural context. Wiley-Blackwell, Hoboken.

Fraser, D., Weary, D.M., Pajor, E.A. and Milligan, B.N. (1997) A scientific conception of animal welfare that reflects ethical concerns. Animal Welfare 6, 187-205.

Freeman, R.E. (1984) Strategic management: A stakeholder approach. Pitman, Boston.

Galhardo, L. and Oliveira, R.F. (2009) Psychological stress and welfare in fish. Annual Review of Biomedical Sciences 11, 1-20.

Giannakourou, M.C., Koutsoumanis, K., Nychas, G.J.E. and Taoukis, P.S. (2005) Field evaluation of the application of time temperature integrators for monitoring fish quality in the chill chain. International Journal of Food Microbiology 102, 323-336.

Gisbert, E. and López, M.A. (2008) Impact of glass eel fishery on by-catch fish species: A quantitative assessment. Hydrobiologia 602, 87-98. 
Glaser, M. and Diele, K. (2004) Asymmetric outcomes: Assessing central aspects of the biological, economic and social sustainability of a mangrove crab fishery, Ucides cordatus (Ocypodidae), in North Brazil. Ecological Economics 49, 361-373.

Glass, J.R., Kruse, G.H. and Miller, S.A. (2015) Socioeconomic considerations of the commercial weathervane scallop fishery off Alaska using SWOT analysis. Ocean and Coastal Management 105, 154-165.

Good, J.W., Weber, J.W. and Charland, J.W. (1999) Protecting estuaries and coastal wetlands through state coastal zone management programs. Coastal Management 27, 139-186.

Goodrich, H. (1997) Understanding rubrics. Educational Leadership 54, 14-17.

Gracia, A., Loureiro, M.L. and Nayga, R.M. (2011) Valuing an EU animal welfare label using experimental auctions. Agricultural Economics 42, 669-677.

Gregory, N.G. (1998) Fish. In: Animal welfare and meat science, (Ed. N.G. Gregory), CABI Publishing, Oxon, pp. 195-212.

GRI (2015) GRI G4 guidelines part 1: Reporting principles and standards. Global Reporting Initiative, Amsterdam.

Guyader, O., Berthou, P., Koutsikopoulos, C., Alban, F., Demanèche, S., Gaspar, M.B., Eschbaum, R., Fahy, E., Tully, O., Reynal, L., et al. (2013) Small scale fisheries in Europe: A comparative analysis based on a selection of case studies. Fisheries Research 140, 1-13.

Hadjimichael, M. and Hegland, T.J. (2016) Really sustainable? Inherent risks of ecolabeling in fisheries. Fisheries Research 174, 129-135.

Hafner, J.C. and Hafner, P.M. (2003) Quantitative analysis of the rubric as an assessment tool: An empirical study of student peer-group rating. International Journal of Science Education 25, 1509-1528.

Hahn, T., Figge, F., Pinkse, J. and Preuss, L. (2010) Editorial trade-offs in corporate sustainability: You can't have your cake and eat it. Business Strategy and the Environment 19, 217-229.

Hair, J.F., Black, W.C., Babin, B.J., Anderson, R.E. and Tatham, R.L. (2006) Multivariate data analysis, 6th edition. Pearson Education, Inc., Upper Saddle River.

Häni, F., Braga, F., Stämpfli, A., Keller, T., Fischer, M. and Porsche, H. (2003) RISE, a tool for holistic sustainability assessment at the farm level. International Food and Agribusiness Management Review 6, 78-90.

Hattula, T., Luoma, T., Kostiainen, R., Poutanen, J., Kallio, M. and Suuronen, P. (1995) Effects of catching method on different quality parameters of Baltic herring (Clupea harengus L.). Fisheries Research 23, 209-221.

Hensher, D.A., Rose, J.M. and Green, W.H. (2005) Applied choice analysis: A primer. Cambridge University Press, Cambridge.

Hisamune, S., Amagai, K., Kimura, N. and Kishida, K. (2006) A study of factors relating to work accidents among seamen. Industrial Health 44, 144-149.

Hornborg, S., Svensson, M., Nilsson, P. and Ziegler, F. (2013) By-catch impacts in fisheries: Utilizing the iucn red list categories for enhanced product level assessment in seafood LCAS. Environmental Management 52, 1239-1248. 
HSE (2014) Health and safety in agriculture in Great Britain, 2014, accessible via: http://www.hse.gov.uk/Statistics/industry/agriculture/agriculture.pdf, accessed on: 22 May 2015.

Humborstad, O.B., Breen, M., Davis, M.W., Løkkeborg, S., Mangor-Jensen, A., Midling, K.T. and Olsen, R.E. (2016) Survival and recovery of longline- and pot-caught cod (Gadus morhua) for use in capture-based aquaculture (CBA). Fisheries Research 174, 103-108.

Humborstad, O.B. and Mangor-Jensen, A. (2013) Buoyancy adjustment after swimbladder puncture in cod Gadus morhua: An experimental study on the effect of rapid decompression in capture-based aquaculture. Marine Biology Research 9, 383393 .

Huntingford, F.A., Adams, C., Braithwaite, V.A., Kadri, S., Pottinger, T.G., Sandøe, P. and Turnbull, J.F. (2006) Current issues in fish welfare. Journal of Fish Biology 68, 332372.

Huse, I. and Vold, A. (2010) Mortality of mackerel (Scomber scombrus L.) after pursing and slipping from a purse seine. Fisheries Research 106, 54-59.

Hutchins, M.J. and Sutherland, J.W. (2008) An exploration of measures of social sustainability and their application to supply chain decisions. Journal of Cleaner Production 16, 1688-1698.

Hyvärinen, P., Leppäniemi, V., Johansson, K., Korhonen, P. and Suuronen, P. (2008) Stress and survival of small pike-perch Sander lucioperca (L.) after trawling and chilling. Journal of Fish Biology 72, 2677-2688.

ICES (2016) ICES statistical areas, accessible via: http://geo.ices.dk/download.php?dataset=ices_ref:ices_areas, accessed on: 26 August 2016.

ILO (2010) Ergonomic checkpoints: Practical and easy-to-implement solutions for improving safety, health and working conditions. International Labour Office, Geneva.

Ingólfsson, O.A. and Jørgensen, T. (2006) Escapement of gadoid fish beneath a commercial bottom trawl: Relevance to the overall trawl selectivity. Fisheries Research 79, 303-312.

Ingólfsson, O.A., Soldal, A.V., Huse, I. and Breen, M. (2007) Escape mortality of cod, saithe, and haddock in a Barents Sea trawl fishery. ICES Journal of Marine Science $64,1836-1844$.

ISO (2006a) ISO 14040. Environmental management - Life cycle assessment Principles and framework. .

ISO (2006b) ISO 14044. Environmental management - Life cycle assessment Requirements and management.

ISO (2010) ISO 2600o. Guidance on social responsibility. Geneva.

Issanchou, S. (1996) Consumer expectations and perceptions of meat and meat product quality. Meat Science 43, 5-19.

Jacquet, J., Pauly, D., Ainley, D., Holt, S., Dayton, P. and Jackson, J. (2010) Seafood stewardship in crisis. Nature 467, 28-29. 
Janssen, M. and Hamm, U. (2012) Product labelling in the market for organic food: Consumer preferences and willingness-to-pay for different organic certification logos. Food Quality and Preference 25, 9-22.

Jeswani, H.K., Azapagic, A., Schepelmann, P. and Ritthoff, M. (2010) Options for broadening and deepening the LCA approaches. Journal of Cleaner Production 18, 120-127.

Jones, J.B. (1993) Net damage injuries to New Zealand Hoki, Macruronus novaezelandiae. New Zealand Journal of Marine and Freshwater Research 27, 23-30.

Jonsson, A. and Svingby, G. (2007) The use of scoring rubrics: Reliability, validity and educational consequences. Educational Research Review 2, 130-144.

Jørgensen, A., Lai, L.C.H. and Hauschild, M.Z. (2010) Assessing the validity of impact pathways for child labour and well-being in social life cycle assessment. International Journal of Life Cycle Assessment 15, 5-16.

Jurvelius, J., Riikonen, R., Marjomäki, T.J. and Lilja, J. (2000) Mortality of pike-perch (Stizostedion lucioperca), brown trout (Salmo trutta) and landlocked salmon (Salmo salar m. sebago) caught as by-catch in pelagic trawling in a Finnish lake. Fisheries Research 45, 291-296.

Kaimmer, S.M. and Trumble, R.J. (1998) Injury, condition, and mortality of Pacific halibut bycatch following careful release by Pacific cod and sablefish longline fisheries. Fisheries Research 38, 131-144.

Karagiannakos, A. (1996) Total Allowable Catch (TAC) and quota management system in the European Union. Marine Policy 20, 235-248.

Karlsen, K.M., Dreyer, B., Olsen, P. and Elvevoll, E.O. (2012) Granularity and its role in implementation of seafood traceability. Journal of Food Engineering 112, 78-85.

Karlsen, K.M., Sørensen, C.F., Forås, F. and Olsen, P. (2011) Critical criteria when implementing electronic chain traceability in a fish supply chain. Food Control 22, 1339-1347.

Kerstetter, D.W. and Graves, J.E. (2006a) Effects of circle versus J-style hooks on target and non-target species in a pelagic longline fishery. Fisheries Research 80, 239-250.

Kerstetter, D.W. and Graves, J.E. (2006b) Survival of white marlin (Tetrapturus albidus) released from commercial pelagic longline gear in the western North Atlantic. Fishery Bulletin 104, 434-444.

Kerstetter, D.W. and Graves, J.E. (2008) Postrelease survival of sailfish caught by commercial pelagic longline gear in the southern Gulf of Mexico. North American Journal of Fisheries Management 28, 1578-1586.

Kestin, S.C., Wotton, S.B. and Gregory, N.G. (1991) Effect of slaughter by removal from water on visual evoked activity in the brain and reflex movement of rainbow trout (Oncorhynchus mykiss). Veterinary Record 128, 443-446.

Key, B. (2014) Fish do not feel pain and its implications for understanding phenomenal consciousness. Biology and Philosophy 30, 149-165.

Kloepffer, W. (2008) Life cycle sustainability assessment of products (with Comments by Helias A. Udo de Haes, p. 95). International Journal of Life Cycle Assessment 13, 8994 . 
Kruse, S.A., Flysjö, A., Kasperczyk, N. and Scholz, A.J. (2009) Socioeconomic indicators as a complement to life cycle assessment - An application to salmon production systems. International Journal of Life Cycle Assessment 14, 8-18.

Kuhfeld, W.F. (2010) Marketing research methods in SAS: Experimental design, choice, conjoint, and graphical techniques. SAS Institute Inc., Cary.

Lambooij, E., Digre, H., Reimert, H.G.M., Aursand, I.G., Grimsmo, L. and van de Vis, J.W. (2012) Effects of on-board storage and electrical stunning of wild cod (Gadus morhua) and haddock (Melanogrammus aeglefinus) on brain and heart activity. Fisheries Research 127-128, 1-8.

Langlois, J., Fréon, P., Delgenes, J.P., Steyer, J.P. and Hélias, A. (2014) New methods for impact assessment of biotic-resource depletion in life cycle assessment of fisheries: Theory and application. Journal of Cleaner Production 73, 63-71.

Lockwood, S.J., Pawson, M.G. and Eaton, D.R. (1983) The effects of crowding on mackerel (Scomber scombrus L.) - Physical condition and mortality. Fisheries Research 2, 129-147.

Louviere, J.J., Hensher, D.A. and Swait, J.D. (2000) Stated choice methods: Analysis and application. Cambridge University Press, Cambridge.

Lozano, R. and Huisingh, D. (2011) Inter-linking issues and dimensions in sustainability reporting. Journal of Cleaner Production 19, 99-107.

Lundin, M., Calamnius, L. and Lunneryd, S.G. (2012) Survival of juvenile herring (Clupea harengas membras) after passing through a selection grid in a pontoon trap. Fisheries Research 127-128, 83-87.

MacMillan, E. and Roth, B. (2012) By-catch in the Saginaw Bay, Lake Huron commercial trap net fishery. Journal of Great Lakes Research 38, 353-361.

Mapleston, A., Welch, D., Begg, G.A., McLennan, M., Mayer, D. and Brown, I. (2008) Effect of changes in hook pattern and size on catch rate, hooking location, injury and bleeding for a number of tropical reef fish species. Fisheries Research 91, 203-211.

Marçalo, A., Marques, T.A., Araújo, J., Pousão-Ferreira, P., Erzini, K. and Stratoudakis, Y. (2010) Fishing simulation experiments for predicting the effects of purse-seine capture on sardine (Sardina pilchardus). ICES Journal of Marine Science 67, 334344 .

Marçalo, A., Pousão-Ferreira, P., Mateus, L., Duarte Correia, J.H. and Stratoudakis, Y. (2008) Sardine early survival, physical condition and stress after introduction to captivity. Journal of Fish Biology 72, 103-120.

Martínez-Blanco, J., Lehmann, A., Muñoz, P., Antón, A., Traverso, M., Rieradevall, J. and Finkbeiner, M. (2014) Application challenges for the social Life Cycle Assessment of fertilizers within life cycle sustainability assessment. Journal of Cleaner Production 69, 34-48.

Maslow, A.H. (1954) Motivation and personality. Harper and Row, New York.

Mauracher, C., Tempesta, T. and Vecchiato, D. (2013) Consumer preferences regarding the introduction of new organic products. The case of the Mediterranean sea bass (Dicentrarchus labrax) in Italy. Appetite 63, 84-91.

Mayer, R.C., Davis, J.H. and Schoorman, F.D. (1995) An Integrative Model of Organizational Trust. The Academy of Management Review 20, 709-734. 
McClenachan, L., Dissanayake, S.T.M. and Chen, X. (2016) Fair trade fish: Consumer support for broader seafood sustainability. Fish and Fisheries 17, 825-838.

McFadden, D. (1974) Conditional logit analysis of choice behaviour. In: Frontiers of econometrics, (Ed. P. Zarembka), Academic Press, New York, pp. 105-142.

McLennan, M.F., Campbell, M.J. and Sumpton, W.D. (2014) Surviving the effects of barotrauma: Assessing treatment options and a 'natural' remedy to enhance the release survival of line caught pink snapper (Pagrus auratus). Fisheries Management and Ecology 21, 330-337.

Metcalfe, J.D. (2009) Welfare in wild-capture marine fisheries. Journal of Fish Biology $75,2855-2861$.

Meul, M., Passel, S.V., Nevens, F., Dessein, J., Rogge, E., Mulier, A. and Hauwermeiren, A.V. (2008) MOTIFS: A monitoring tool for integrated farm sustainability. Agronomy for Sustainable Development 28, 321-332.

Milliken, H.O., Farrington, M., Arnold Carr, H. and Lent, E. (1999) Survival of atlantic cod (Gadus morhua) in the northwest atlantic longline fishery. Marine Technology Society Journal 33, 19-24.

Milliken, H.O., Farrington, M., Rudolph, T. and Sanderson, M. (2009) Survival of discarded sublegal Atlantic cod in the Northwest Atlantic demersal longline fishery. North American Journal of Fisheries Management 29, 985-995.

Misund, O.A. and Beltestad, A.K. (1995) Survival of herring after simulated net bursts and conventional storage in net pens. Fisheries Research 22, 293-297.

Misund, O.A. and Beltestad, A.K. (2000) Survival of mackerel and saithe that escape through sorting grids in purse seines. Fisheries Research 48, 31-41.

Mitchell, G., May, A. and McDonald, A. (1995) PICABUE: A methodological framework for the development of indicators of sustainable development. International Journal of Sustainable Development and World Ecology 2, 104-123.

Mitchell, R.W., Blight, S.J., Gaughan, D.J. and Wright, I.W. (2002) Does the mortality of released Sardinops sagax increase if rolled over the headline of a purse seine net? Fisheries Research 57, 279-285.

Mol, M. and Pleijers, A. (2014) Ongelukken op de werkvloer [in Dutch]. Sociaaleconomische trends 2014, (Ed. CBS), Centraal Bureau voor de Statistiek, Den Haag.

Mollenhorst, H., Berentsen, P.B.M. and De Boer, I.J.M. (2006) On-farm quantification of sustainability indicators: An application to egg production systems. British Poultry Science 47, 405-417.

Mollenhorst, H. and De Boer, I.J.M. (2004) Identifying sustainability issues using participatory SWOT analysis: A case study of egg production in the Netherlands. Outlook on Agriculture 33, 267-276.

Mood, A. (2010) Worse things happen at sea: The welfare of wild-caught fish. Fishcount.

Moosmayer, D.C. (2012) Negativity bias in consumer price response to ethical information. Business Ethics 21, 198-208.

MSC (2015a) MSC Chain of Custody Standard. MSC, London.

MSC (2015b) MSC fisheries standard, accessible via: https://www.msc.org/aboutus/standards/fisheries-standard, accessed on: 18 August 2015. 
Murphy, J.J., Allen, P.G., Stevens, T.H. and Weatherhead, D. (2005) A meta-analysis of hypothetical bias in stated preference valuation. Environmental and Resource Economics 30, 313-325.

Napolitano, F., Girolami, A. and Braghieri, A. (2010) Consumer liking and willingness to pay for high welfare animal-based products. Trends in Food Science \& Technology 21, 537-543.

Nédélec, C. and Prado, J. (1990) Definition and classification of fishing gear categories. FAO, Rome.

NNN (2014) Overenskomst 2014 Fiskeindustribedrifter [in Norwegian], accessible via: http://nnn.no/wpcontent/uploads/2012/11/Overenskomst_Fiskeindustribedrifter_2014-2016.pdf, accessed on.

Nocella, G., Hubbard, L. and Scarpa, R. (2010) Farm animal welfare, consumer willingness to pay, and trust: Results of a cross-national survey. Applied Economic Perspectives and Policy 32, 275-297.

Norwegian Directorate of Fisheries (2014) Norwegian fishing vessels, fishermen and licenses, accessible via: http://www.fiskeridir.no/english/statistics/norwegianfisheries/norwegian-fishing-vessels-fishermen-and-licenses, accessed on: 12 February 2015.

Olla, B.L., Davis, M.W. and Schreck, C.B. (1997) Effects of simulated trawling on sablefish and walleye pollock: The role of light intensity, net velocity and towing duration. Journal of Fish Biology 50, 1181-1194.

Olla, B.L., Davis, M.W. and Schreck, C.B. (1998) Temperature magnified postcapture mortality in adult sablefish after simulated trawling. Journal of Fish Biology 53, 743751.

Olsen, R.E., Oppedal, F., Tenningen, M. and Vold, A. (2012) Physiological response and mortality caused by scale loss in Atlantic herring. Fisheries Research 129-130, 21-27.

Olsen, S.H., Tobiassen, T., Akse, L., Evensen, T.H. and Midling, K.T. (2013) Capture induced stress and live storage of Atlantic cod (Gadus morhua) caught by trawl: Consequences for the flesh quality. Fisheries Research 147, 446-453.

Orme, B.K. (2010) Getting started with conjoint analysis: Strategies for product design and pricing research, 2nd edition. Research Publishers, Madison.

Orsi, J.A., Wertheimer, A.C. and Jaenicke, H.W. (1993) Influence of selected hook and lure types on catch, size, and mortality of commercially troll-caught chinook salmon. North American Journal of Fisheries Management 13, 709-722.

Pacifical (2016) Social accountability guidelines For purse seine tuna fishing vessels accessible via: http://www.pacifical.com/guidelines.html, accessed on: 16 September 2016.

Pálsson Ó, K., Einarsson, H.A. and Björnsson, H. (2003) Survival experiments of undersized cod in a hand-line fishery at Iceland. Fisheries Research 61, 73-86.

Parkes, G., Young, J.A., Walmsley, S.F., Abel, R., Harman, J., Horvat, P., Lem, A., Macfarlane, A., Mens, M. and Nolan, C. (2010) Behind the signs - A global review of fish sustainability information schemes. Reviews in Fisheries Science 18, 344-356.

Parris, T.M. and Kates, R.W. (2003) Characterizing and measuring sustainable development. Annual Review of Environment and Resources 28, 559-586. 
Pelletier, D., Mahevas, S., Drouineau, H., Vermard, Y., Thebaud, O., Guyader, O. and Poussin, B. (2009) Evaluation of the bioeconomic sustainability of multi-species multi-fleet fisheries under a wide range of policy options using ISIS-Fish. Ecological Modelling 220, 1013-1033.

Pelletier, N.L., Ayer, N.W., Tyedmers, P.H., Kruse, S.A., Flysjo, A., Robillard, G., Ziegler, F., Scholz, A.J. and Sonesson, U. (2007) Impact categories for life cycle assessment research of seafood production systems: Review and prospectus. International Journal of Life Cycle Assessment 12, 414-421.

Piñeiro, C., Barros-Velázquez, J. and Aubourg, S.P. (2004) Effects of newer slurry ice systems on the quality of aquatic food products: A comparative review versus flakeice chilling methods. Trends in Food Science \& Technology 15, 575-582.

Pitcher, T.J., Bundy, A., Preikshot, D., Hutton, T. and Pauly, D. (1998) Measuring the unmeasurable: A multivariate and interdisciplinary method for rapid appraisal of the health of fisheries. In: Reinventing fisheries management, (Eds. T.J. Pitcher, J.B. Hart, D. Pauly), Kluwer Academic Publishers, London, pp. 31-54.

Pitcher, T.J., Lam, M.E., Ainsworth, C., Martindale, A., Nakamura, K., Perry, R.I. and Ward, T. (2013) Improvements to Rapfish: A rapid evaluation technique for fisheries integrating ecological and human dimensions. Journal of Fish Biology 83, 865-889.

Pitcher, T.J. and Preikshot, D. (2001) RAPFISH: A rapid appraisal technique to evaluate the sustainability status of fisheries. Fisheries Research 49, 255-270.

Pope, J., Annandale, D. and Morrison-Saunders, A. (2004) Conceptualising sustainability assessment. Environmental Impact Assessment Review 24, 595-616.

Pribyl, A.L., Kent, M.L., Parker, S.J. and Schreck, C.B. (2011) The response to forced decompression in six species of pacific rockfish. Transactions of the American Fisheries Society 140, 374-383.

Purbayanto, A., Tsunoda, A., Akiyama, S., Arimoto, T. and Tokai, T. (2001) Survival of Japanese whiting Sillago japonica and by-catch species captured by a sweeping trammel net. Fisheries Science 67, 21-29.

Raby, G.D., Hinch, S.G., Patterson, D.A., Hills, J.A., Thompson, L.A. and Cooke, S.J. (2015) Mechanisms to explain purse seine bycatch mortality of coho salmon. Ecological Applications 25, 1757-1775.

Ragonese, S. and Morara, U. (2012) Evidence of short-term discard mortality of trawled Sphoeroides pachygaster (Osteichthyes, Tetraodontidae) off the southern coast of Sicily (Central Mediterranean Sea). Pan-American Journal of Aquatic Sciences 7, 7376.

Reed, M., Courtney, P., Urquhart, J. and Ross, N. (2013) Beyond fish as commodities: Understanding the socio-cultural role of inshore fisheries in England. Marine Policy $37,62-68$.

Rice, P.H., Serafy, J.E., Snodgrass, D. and Prince, E.D. (2012) Performance of non-offset and $10^{\circ}$ offset $18 / 0$ circle hooks in the United states pelagic longline fishery. Bulletin of Marine Science 88, 571-587.

Richards, L.J., Jeff, J. and Schnute, J.T. (1995) Factors influencing bycatch mortality of trawl-caught Pacific halibut. North American Journal of Fisheries Management 15, 266-276. 
RNS (2011) Skýrsla Rannsóknarnefnd Sjóslysa fyrir árið 2011 [in Icelandic], accessible via:

http://rns.is/LesaArsskyrslu.php?skyrsla_pdf=pdfs/201308310831010.rns2011.pdf \&arsskyrsla_nr=33, accessed on: 22 May 2015.

Robb, D.H.F. and Kestin, S.C. (2002) Methods used to kill fish: Field observations and literature reviewed. Animal Welfare 11, 269-282.

Roberts, S.E. (2010) Britain's most hazardous occupation: Commercial fishing. Accident Analysis and Prevention 42, 44-49.

Roheim, C.A., Asche, F. and Santos, J.I. (2011) The elusive price premium for ecolabelled products: Evidence from seafood in the UK market. Journal of Agricultural Economics 62, 655-668.

Roininen, K., Arvola, A. and Lähteenmäki, L. (2006) Exploring consumers' perceptions of local food with two different qualitative techniques: Laddering and word association. Food Quality and Preference 17, 20-30.

Rose, J.D., Arlinghaus, R., Cooke, S.J., Diggles, B.K., Sawynok, W., Stevens, E.D. and Wynne, C.D.L. (2014) Can fish really feel pain? Fish and Fisheries 15, 97-133.

Rudershausen, P.J., Baker Jr, M.S. and Buckel, J.A. (2008) Catch rates and selectivity among three trap types in the U.S. South Atlantic black sea bass commercial trap fishery. North American Journal of Fisheries Management 28, 1099-1107.

Rudershausen, P.J., Buckel, J.A. and Hightower, J.E. (2014) Estimating reef fish discard mortality using surface and bottom tagging: Effects of hook injury and barotrauma. Canadian Journal of Fisheries and Aquatic Sciences 71, 514-520.

Schwartz, S.H. (1992) Universals in the content and structure of values: Theoretical advances and empirical tests in 20 countries. In: Advances in experimental social psychology, (Ed. M. Zanna), Academic Press, Orlando, pp. 1-65.

Seafish (2011) Seafood freshness quality, accessible via: http://www.seafish.org/media/Publications/SeafishFactSheet_SeafoodFreshnessQu ality_201101.pdf, accessed on: 12 February 2015.

Sen, A.K. (1984) Rights and capabilities. In: Resources, Values and Development, (Ed. A.K. Sen), Harvard University Press, Cambridge, MA, pp. 307-325.

Sen, A.K. (1993) Capability and well-being. In: The quality of life, (Eds. M.C. Nussbaum, A.K. Sen), Clarendon Press, Oxford, pp. 30-53.

Sev, A. (2011) A comparative analysis of building environmental assessment tools and suggestions for regional adaptations. Civil Engineering and Environmental Systems $28,231-245$.

Seves, S.M., Temme, E.H.M., Brosens, M.C.C., Zijp, M.C., Hoekstra, J. and Hollander, A. (2016) Sustainability aspects and nutritional composition of fish: Evaluation of wild and cultivated fish species consumed in the Netherlands. Climatic Change 135, 597610.

Sharp, B. and Dawes, J. (2001) What is differentiation and how does it work ? Journal of Marketing Management 17, 739-759.

Smit, J. and Taal, K. (2007) Sociaaleconomische indicatoren van de Nederlandse vissector [in Dutch]. LEI, Den Haag. 
Smith, W.E. and Scharf, F.S. (2011) Postrelease survival of sublegal southern flounder captured in a commercial gill-net fishery. North American Journal of Fisheries Management 31, 445-454.

Sneddon, L.U., Braithwaite, V.A. and Gentle, M.J. (2003) Do fishes have nociceptors? Evidence for the evolution of a vertebrate sensory system. Proceedings of the Royal Society B: Biological Sciences 270, 1115-1121.

Sogn-Grundvåg, G., Larsen, T.A. and Young, J.A. (2013) The value of line-caught and other attributes: An exploration of price premiums for chilled fish in UK supermarkets. Marine Policy 38, 41-44.

Stachura, M.M., Lunsford, C.R., Rodgveller, C.J. and Heifetz, J. (2012) Estimation of discard mortality of sablefish (Anoplopoma fimbria) in Alaska longline fisheries. Fishery Bulletin 110, 271-279.

StataCorp. (2013) Stata: Release 13. StataCorp LP, College Station.

Statistics Norway (2014a) Marine casualities. Persons killed or injured, by category and vessel type, accessible via:

https://www.ssb.no/statistikkbanken/selecttable/hovedtabellHjem.asp?KortNavnW $\mathrm{eb}=$ sjoulykker\&CMSSubjectArea $=$ transport-ogreiseliv\&PLanguage $=1 \&$ checked=true, accessed on: 22 May 2015 .

Statistics Norway (2014b) Mean, median and quartile monthly earnings for full-time employees, by industry section (SIC2007) and sex, accessible via: https://www.ssb.no/statistikkbanken/selecttable/hovedtabellHjem.asp?KortNavnW $\mathrm{eb}=$ lonnansatt\&CMSSubjectArea $=$ arbeid-og-lonn\&PLanguage $=1 \&$ checked $=$ true, accessed on.

Statistics Office Iceland (2013a) Total catch in the Northeast Atlantic by species 19502011, accessible via: http://www.statice.is/Statistics/Fisheries-andagriculture/World-catch, accessed on.

Statistics Office Iceland (2013b) World catch by fishing areas 1950-2011, accessible via: http://www.statice.is/Statistics/Fisheries-and-agriculture/World-catch, accessed on: 22 May 2015.

Statistics office Iceland (2015) Catch in the North Atlantic by species 1950-2013, accessible via: http://px.hagstofa.is/pxen/pxweb/en/Atvinnuvegir/Atvinnuvegir__sjavarutvegur_ _aflatolur_ heimsafli/SJA03008.px/?rxid=3f538743-5714-4f21-834af5316eb21010 accessed on: 13 June 2016.

Stein, A.B., Friedland, K.D. and Sutherland, M. (2004) Atlantic sturgeon marine bycatch and mortality on the continental shelf of the northeast United States. North American Journal of Fisheries Management 24, 171-183.

Stephen, J.A. and Harris, P.J. (2010) Commercial catch composition with discard and immediate release mortality proportions off the southeastern coast of the United States. Fisheries Research 103, 18-24.

Stewart, J. (2008) Capture depth related mortality of discarded snapper (Pagrus auratus) and implications for management. Fisheries Research 90, 289-295.

Suuronen, P. and Erickson, D.L. (2010) Mortality of animals that escape fishing gears or are discarded after capture: Approaches to reduce mortality. In: Behavior of Marine Fishes, Wiley-Blackwell, pp. 265-293. 
Suuronen, P., Erickson, D.L. and Orrensalo, A. (1996a) Mortality of herring escaping from pelagic trawl codends. Fisheries Research 25, 305-321.

Suuronen, P., Lehtonen, E. and Jounela, P. (2005) Escape mortality of trawl caught Baltic cod (Gadus morhua) - The effect of water temperature, fish size and codend catch. Fisheries Research 71, 151-163.

Suuronen, P., Lehtonen, E., Tschernij, V. and Larsson, P.O. (1996b) Skin injury and mortality of Baltic cod escaping from trawl codends equipped with exit windows. Archive of Fishery and Marine Research 44, 165-178.

Suuronen, P., Perez-Comas, J.A., Lehtonen, E. and Tschernij, V. (1996c) Size-related mortality of herring (Clupea harengus L.) escaping through a rigid sorting grid and trawl codend meshes. ICES Journal of Marine Science 53, 691-700.

Taoukis, P.S., Koutsoumanis, K. and Nychas, G.J.E. (1999) Use of time-temperature integrators and predictive modelling for shelf life control of chilled fish under dynamic storage conditions. International Journal of Food Microbiology 53, 21-31.

Tenningen, M., Vold, A. and Olsen, R.E. (2012) The response of herring to high crowding densities in purse-seines: Survival and stress reaction. ICES Journal of Marine Science 69, 1523-1531.

Thøgersen, J., Haugaard, P. and Olesen, A. (2010) Consumer responses to ecolabels. European Journal of Marketing 44, 1787-1810.

Thrane, M. (2006) LCA of Danish fish products: New methods and insights. International Journal of Life Cycle Assessment 11, 66-74.

Toma, L., McVittie, A., Hubbard, C. and Stott, A.W. (2011) A structural equation model of the factors influencing British consumers' behaviour toward animal welfare. Journal of Food Products Marketing 17, 261-278.

Trudel, R. and Cotte, J. (2009) Does it pay to be good? MIT Sloan Management Review 50, 61-68+93.

Tully, S.M. and Winer, R.S. (2014) The role of the beneficiary in willingness to pay for socially responsible products: A meta-analysis. Journal of Retailing 90, 255-274.

Turunen, T., Käkelä, A. and Hyvärinen, H. (1994) Trawling stress and mortality in undersized $(<40 \mathrm{~cm}$ ) brown trout (Salmo trutta L.). Fisheries Research 19, 51-64.

UNEP/SETAC (2009) Guidelines for social life cycle assessment of products. United Nations Environment Programme, Paris.

UNEP/SETAC (2010a) Sheets for the stakeholder group: Local community. Methodological Sheets for Sub-Categories of Impact for consultation, (Ed. C. BenoîtNorris), Life Cycle Initiative.

UNEP/SETAC (2010b) Sheets for the stakeholder group: Workers. Methodological Sheets for Sub-Categories of Impact for consultation, (Ed. C. Benoît-Norris), Life Cycle Initiative.

United Nations Population Division (2015) World population prospects: The 2015 revision, key findings and advance tables. United Nations, New York.

Utne, I.B. (2007) System evaluation of sustainability in the Norwegian cod-fisheries. Marine Policy 31, 390-401. 
Van Beek, F.A., Van Leeuwen, P.I. and Rijnsdorp, A.D. (1990) On the survival of plaice and sole discards in the otter-trawl and beam-trawl fisheries in the North Sea. Netherlands Journal of Sea Research 26, 151-160.

Van Calker, K.J., Berentsen, P.B.M., De Boer, I.J.M., Giesen, G.W.J. and Huirne, R.B.M. (2004) An LP-model to analyse economic and ecological sustainability on Dutch dairy farms: Model presentation and application for experimental farm "de Marke". Agricultural Systems 82, 139-160.

Van Calker, K.J., Berentsen, P.B.M., De Boer, I.J.M., Giesen, G.W.J. and Huirne, R.B.M. (2007) Modelling worker physical health and societal sustainability at farm level: An application to conventional and organic dairy farming. Agricultural Systems 94, 205219.

Van Calker, K.J., Berentsen, P.B.M., Giesen, G.W.J. and Huirne, R.B.M. (2005) Identifying and ranking attributes that determine sustainability in Dutch dairy farming. Agriculture and Human Values 22, 53-63.

Van Dam, Y.K. and Van Trijp, H.C.M. (2011) Cognitive and motivational structure of sustainability. Journal of Economic Psychology 32, 726-741.

Van Dam, Y.K. and Van Trijp, H.C.M. (2013) Relevant or determinant: Importance in certified sustainable food consumption. Food Quality and Preference 30, 93-101.

Van Holt, T., Weisman, W., Johnson, J.C., Käll, S., Whalen, J., Spear, B. and Sousa, P. (2016) A social wellbeing in fisheries tool (SWIFT) to help improve fisheries performance. Sustainability (Switzerland) 8, 667.

Van Loo, E.J., Caputo, V., Nayga Jr, R.M. and Verbeke, W. (2014) Consumers' valuation of sustainability labels on meat. Food Policy 49, 137-150.

Vander Haegen, G.E., Ashbrook, C.E., Yi, K.W. and Dixon, J.F. (2004) Survival of spring chinook salmon captured and released in a selective commercial fishery using gill nets and tangle nets. Fisheries Research 68, 123-133.

Vázquez-Rowe, I., Moreira, M.T. and Feijoo, G. (2010) Life cycle assessment of horse mackerel fisheries in Galicia (NW Spain): Comparative analysis of two major fishing methods. Fisheries Research 106, 517-527.

Veldhuizen, L.J.L., Berentsen, P.B.M., Bokkers, E.A.M. and De Boer, I.J.M. (2015) Social sustainability of cod and haddock fisheries in the northeast Atlantic: What issues are important? Journal of Cleaner Production 94, 76-85.

Verbeke, W. and Viaene, J. (1999) Beliefs, attitude and behaviour towards fresh meat consumption in Belgium: Empirical evidence from a consumer survey. Food Quality and Preference 10, 437-445.

Vilhjálmsson, H. and Hoel, A.H. (2005a) Fisheries and aquaculture in the Central North Atlantic (Iceland and Greenland). In: Arctic Climate Impact Assessment, (Eds. C. Symon, L. Arris, B. Heal), Cambridge University Press, Cambridge, pp. 709-730.

Vilhjálmsson, H. and Hoel, A.H. (2005b) Fisheries and aquaculture in the Northeast Atlantic (Barents and Norwegian Seas) In: Arctic Climate Impact Assessment (Eds. C. Symon, L. Arris, B. Heal), Cambridge University Press, Cambridge, pp. 695-709.

Ward, T.J. and Philips, B. (2008) Anecdotes and lessons of a decade. In: Seafood ecolabelling: principles and practice, (Eds. T.J. Ward, B. Philips), Wiley-Blackwell, Oxford, pp. 416-435. 
Watson, R., Revenga, C. and Kura, Y. (2006) Fishing gear associated with global marine catches. I. Database development. Fisheries Research 79, 97-102.

Weidema, B.P. (2006) The intergration of economic and social aspects in life cycle impact assessment. International Journal of Life Cycle Assessment 11, 89-96.

Weidema, B.P. (2009) Using the budget constraint to monetarise impact assessment results. Ecological Economics 68, 1591-1598.

Weidema, B.P. (2016) The social footprint-a practical approach to comprehensive and consistent social LCA. International Journal of Life Cycle Assessment, 1-10.

Whitmarsh, D., Pipitone, C., Badalamenti, F. and D'Anna, G. (2003) The economic sustainability of artisanal fisheries: The case of the trawl ban in the Gulf of Castellammare, NW Sicily. Marine Policy 27, 489-497.

WHO and FAO (2003) Diet, nutrition and the prevention of chronic diseases. WHO, Geneva.

Willis, T.J. and Millar, R.B. (2001) Modified hooks reduce incidental mortality of snapper (Pagrus auratus: Sparidae) in the New Zealand commercial longline fishery. ICES Journal of Marine Science 58, 830-841.

Wilson Jr, R.R. and Burns, K.M. (1996) Potential survival of released groupers caught deeper than $40 \mathrm{~m}$ based on shipboard and in-situ observations, and tag-recapture data. Bulletin of Marine Science 58, 234-247.

World Bank and FAO (2009) The sunken billions: The economic justification for fisheries reform. World Bank, Washington.

Worm, B., Hilborn, R., Baum, J.K., Branch, T.A., Collie, J.S., Costello, C., Fogarty, M.J., Fulton, E.A., Hutchings, J.A., Jennings, S., et al. (2009) Rebuilding global fisheries. Science 325, 578-585.

Yergey, M.E., Grothues, T.M., Able, K.W., Crawford, C. and DeCristofer, K. (2012) Evaluating discard mortality of summer flounder (Paralichthys dentatus) in the commercial trawl fishery: Developing acoustic telemetry techniques. Fisheries Research 115-116, 72-81.

Zahm, F., Viaux, P., Vilain, L., Girardin, P. and Mouchet, C. (2008) Assessing farm sustainability with the IDEA method - From the concept of agriculture sustainability to case studies on farms. Sustainable Development 16, 271-281.

Ziegler, F., Emanuelsson, A., Eichelsheim, J.L., Flysjö, A., Ndiaye, V. and Thrane, M. (2011) Extended Life Cycle Assessment of southern pink shrimp products originating in Senegalese artisanal and industrial fisheries for export to Europe. Journal of Industrial Ecology 15, 527-538.

Ziegler, F., Nilsson, P., Mattsson, B. and Walther, Y. (2003) Life Cycle Assessment of frozen cod fillets including fishery-specific environmental impacts. International Journal of Life Cycle Assessment 8, 39-47.

Ziegler, F., Veldhuizen, L.J.L., Hornborg, S., Groen, E.A., Viðarsson, J.R., Bokkers, E.A.M., Berentsen, P.B.M., De Boer, I.J.M., Krewer, C., Sund, V., et al. (2014) D4.2 BCSI second run impact assessment from all cases. 


\section{Summary}

Fishing companies are experiencing decreasing profitability and increasing competition. Companies faced with increasing competition can try to gain a competitive advantage by differentiating their products, e.g. by marketing new product attributes that consumers are interested in. In recent years, consumers have displayed increasing interest in products with attributes relating to sustainability, making it likely that consumers are also interested in sustainability of fish. Although consumers could be considerably interested in social sustainability of fish, this sustainability dimension has received little research interest. This thesis, therefore, aimed to understand social sustainability of capture fisheries.

Social sustainability can be understood by applying the framework for social sustainability assessment, which consists of stakeholder consultation and issue selection, indicator development and quantification, and interpretation, to the case considered. The case considered in this thesis was capture fisheries in the northeast Atlantic. Stakeholder consultation in Chapter 2 resulted in the identification of 27 social sustainability issues relevant for capture fisheries in the northeast Atlantic. Overall, social sustainability issues concerning working conditions, employees' job fulfilment and fish welfare were seen as more important than other social sustainability issues. The importance of issues varied between stakeholder groups, depending on the relation between the stakeholder and each issue, which demonstrates the importance of consulting a heterogeneous group of stakeholders. The importance of issues also seemed to depend on the type of need that the issue relates to (i.e. issues relating to basic needs were seen as more important than other issues) and the state of this issue in the case considered.

In Chapter 3, indicators were defined for the most important social sustainability issues of capture fisheries in the northeast Atlantic that followed from Chapter 2. To interpret indicator values for each indicator, rubrics were developed that articulated levels of performance. Application of these indicators and their accompanying rubrics to a Norwegian trawler demonstrated that the indicators and rubrics provide insight into social sustainability at the level of the vessel, which can be used to identify potential room for improvement. These indicators and rubrics, and the approach used to develop them can be used to assess social sustainability of other fisheries as well. 
To determine whether outcomes from a social sustainability assessment can be used for product differentiation, consumer interest in social sustainability issues of whitefish from the northeast Atlantic was studied in Chapter 4. Results from a choice modelling survey demonstrated that consumers prefer the issue fish welfare over the issues product quality, worker safety and local employment. These preferences were mainly explained by the general psychographic characteristic personal relevance, which means that these preferences were predominantly based on consumers' everyday decisions on food purchases in general. This result is likely explained by the principal focus on certification by the marine stewardship council (MSC) in markets for fish products, which caused consumers to form opinions on environmental sustainability (i.e. MSC certification), but not on social sustainability. The introduction of social sustainability of fish products could result in growing consumer interest through increased exposure.

Given the lack of overview of the knowledge on fish welfare, the most important social sustainability issue for consumers, the literature on this topic was reviewed in Chapter 5 to determine how the capture process in capture fisheries affects fish welfare, using the function-based indicators injuries and mortality. This review showed that scale, skin and fin injuries occur more frequently in trawls, purse seines, gillnets, traps and seines than in hooks, whereas hooking injuries occur in hooks only. Pressure injuries can occur in all gear types when deployed at greater depth. In general, trawls, purse seines and seines result in more mortality than gillnets, hooks and traps. Besides gear type (and corresponding gear characteristics), fish characteristics and context variables influence injuries and mortality from capture fisheries as well. Fish characteristics that influence injuries and mortality are species and length, with higher mortality in smaller than in larger fish. Context variables that result in higher mortality are greater capture depth, longer fishing duration, larger change in water temperature, longer duration of air exposure, higher density in the net and landing procedure.

This thesis is the first study to apply the framework for social sustainability assessment of animal husbandry systems to capture fisheries. Application of this framework to the case of capture fisheries in the northeast Atlantic demonstrated the importance of stakeholder inclusion and of transparency in interpreting results. Social sustainability assessment at the company level can be extended to include impacts along the value chain using social life cycle assessment, or to include the other dimensions of sustainability using the guidelines from the global reporting initiative or life cycle sustainability assessment. Fishing companies that want to use outcomes from social sustainability assessment can focus on specific issues such as fish welfare or on social sustainability as a whole. Such information, however, cannot be passed down the value chain by individual fishing companies due to traceability issues. The inclusion of social sustainability in existing labels for environmental sustainability and local origin of fish, 
therefore, is a more promising option to promote social sustainability of fish products. Fishing companies that want to reduce their impact on fish welfare could make changes to their gear (sub-)type or characteristics, improve their size selectivity, fish at lower surface water temperatures to reduce changes in temperature, change their landing procedure, or reduce capture depth, fishing duration, duration of air exposure or density in the net.

To conclude, application of the framework for social sustainability assessment of animal husbandry systems to capture fisheries in the northeast Atlantic shows that this application leads to an understanding of social sustainability that companies can use to their advantage. In addition, this application shows that fishing companies in the northeast Atlantic need to start paying attention to fish welfare because currently, they do not give priority to this issue, whereas consumers consider fish welfare the most important social sustainability issue of capture fisheries in the northeast Atlantic. 


\section{Samenvatting}

Veel visserijbedrijven hebben te maken met afnemende winst en met toenemende concurrentie. Deze bedrijven kunnen proberen de concurrentie voor te blijven door producteigenschappen zoals kwaliteit en smaak te promoten. Wanneer consumenten geïnteresseerd zijn in zulke producteigenschappen, is de kans groter dat zij dit product kopen in plaats van het product van de concurrent.

In de afgelopen jaren is de interesse van consumenten in de duurzaamheid van producten, en met name in de sociale duurzaamheid van producten, toegenomen. Sociale duurzaamheid gaat over de impact van bijvoorbeeld een bedrijf op thema's die belanghebbenden zoals werknemers en consumenten belangrijk vinden. Voorbeelden van zulke thema's zijn lokale werkgelegenheid, voedselveiligheid en dierenwelzijn. Dit proefschrift gaat over de sociale duurzaamheid van de visserij, een onderwerp waar tot nu toe weinig onderzoek naar is gedaan. Het doel van dit proefschrift is om inzicht te krijgen in de sociale duurzaamheid van de visserij.

Om inzicht te krijgen in de sociale duurzaamheid van de visserij is het raamwerk voor sociale duurzaamheidsanalyse gebruikt. De eerste stap in dit raamwerk is om belanghebbenden te raadplegen over de sociale thema's die volgens hen belangrijk zijn. De volgende stap is om indicatoren te ontwikkelen voor deze thema's die vervolgens gebruikt worden om informatie te verzamelen over de verschillende thema's binnen sociale duurzaamheid. De thema's die belangrijk zijn, en dus ook de indicatoren hiervoor, verschillen per casus. De specifieke casus in dit proefschrift is een visserij in de noordoost Atlantische Oceaan.

In Hoofdstuk 2 zijn belanghebbenden zoals vissers, lokale gemeenschappen en handelaars gevraagd naar de belangrijke thema's voor de sociale duurzaamheid van een visserij in de noordoost Atlantische Oceaan. Daaruit zijn 27 thema's naar voren gekomen. Over het algemeen vonden belanghebbenden thema's die gingen over arbeidsomstandigheden, tevredenheid van werknemers en viswelzijn belangrijker dan andere thema's. Het belang van deze thema's hing af van de belanghebbende en zijn relatie tot het thema. Zo waren bijvoorbeeld werkomstandigheden belangrijk voor werknemers en was productkwaliteit belangrijk voor verkooporganisaties. Het belang van thema's hing ook af van het soort behoefte waar het thema aan relateert. Zo waren thema's die gingen over basisbehoeften zoals lonen en ergonomie belangrijk voor alle belanghebbenden. 
Tot slot hing het belang van thema's af van de huidige staat van het thema, met een groter belang voor thema's die er minder goed voor stonden.

In Hoofdstuk 3 zijn indicatoren vastgesteld voor de meest belangrijke thema's van de visserij in de noordoost Atlantische Oceaan op basis van Hoofdstuk 2. Om de informatie van deze indicatoren te kunnen interpreteren, zijn ook rubrieken ontwikkeld die prestatieniveaus voor deze indicatoren aangeven die variëren van minst tot meest wenselijk. De indicatoren en rubrieken zijn vervolgens toegepast op een Noorse vissersboot. Deze toepassing liet zien dat de indicatoren en rubrieken inzicht geven in sociale duurzaamheid op het niveau van de individuele vissersboot. Zo bleek dat de Noorse vissersboot het bijvoorbeeld goed doet op het gebied van de veiligheid van werknemers. Toepassing van de indicatoren en rubrieken op de Noorse vissersboot liet ook zien dat vissers de uitkomsten kunnen gebruiken om ruimte voor verbetering te identificeren. Deze vissersboot kon bijvoorbeeld nog verbeteren op het gebied van viswelzijn en ergonomie. De indicatoren en rubrieken, en de aanpak die is gebruikt om ze te ontwikkelen, kunnen ook gebruikt worden om de sociale duurzaamheid van andere visserijen te beoordelen.

In Hoofdstuk 4 is de interesse van consumenten in sociale duurzaamheidsthema's van vis afkomstig uit de noordoost Atlantische Oceaan onderzocht. Kennis over dergelijke interesse kan visserijbedrijven de mogelijkheid geven om zich te onderscheiden van de concurrentie. Een enquête onder Nederlandse consumenten toonde aan dat consumenten meer interesse hebben in viswelzijn dan in productkwaliteit, in veiligheid van medewerkers of in lokale werkgelegenheid. De interesse van consumenten in sociale duurzaamheidsthema's werd voornamelijk verklaard door hun gewoontes. Consumenten die bij hun aankopen meestal al op dierenwelzijn letten, hadden ook een sterkere voorkeur voor viswelzijn.

Hoewel viswelzijn het belangrijkste thema is voor consumenten, is er geen overzicht van de kennis hierover. Daarom is in Hoofdstuk 5 een literatuurstudie gedaan om vast te stellen welke impact het vangstproces in de visserij heeft op viswelzijn door te kijken naar verwondingen en sterfte. Deze literatuurstudie liet zien dat verwondingen aan de schubben, huid en vinnen vaker voorkomen in vissen die zijn gevangen met sleepnetten, kieuwnetten en fuiken dan met haken, hoewel haken zelf ook voor specifieke verwondingen zorgen. Verwondingen door verschillen in druk komen voor bij alle soorten vistuig als die op grotere diepte worden ingezet. In het algemeen zorgen sleepnetten voor meer sterfte dan kieuwnetten, haken en fuiken. De mate van sterfte hangt niet alleen af van het soort vistuig, maar ook van vissoort en vislengte, met meer sterfte bij kleinere vissen. Verder is er meer sterfte bij het vissen op een grotere diepte, bij een langere duur van het vissen, bij een grotere verandering in watertemperatuur, bij een langere blootstelling aan lucht en bij een grotere hoeveelheid vis in het net. 
Dit proefschrift is de eerste studie die het raamwerk voor sociale duurzaamheidsanalyse toepast op de visserij. De toepassing van dit raamwerk in de noordoost Atlantische Oceaan heeft laten zien dat dit raamwerk inzicht geeft in sociale duurzaamheid. Bedrijven kunnen zulk inzicht gebruiken om zich te onderscheiden van de concurrentie. De uitdaging hierbij is om ervoor te zorgen dat informatie over sociale duurzaamheid de consument daadwerkelijk bereikt. Een goede manier om consumenten te kunnen informeren over de sociale duurzaamheid van vis is om sociale duurzaamheid op te nemen in bestaande keurmerken zoals het MSC-keurmerk.

De resultaten in dit proefschrift laten zien dat er een tegenstelling is tussen visserijbedrijven en consumenten van vis. Consumenten vinden viswelzijn een belangrijk thema terwijl visserijbedrijven dit belang (nog) niet zien. Hier ligt een kans voor visserijbedrijven om zich te onderscheiden ten opzichte van concurrenten. Visserijbedrijven kunnen hun impact op viswelzijn verminderen door veranderingen aan te brengen in hun vistuig, door nog selectiever te vissen op grotere vissen, door te vissen bij lagere watertemperaturen of door de diepte, duur van het vissen, duur van blootstelling aan lucht of de hoeveelheid vis in het net te beperken. 


\section{Dankwoord | Acknowledgements}

Dit proefschrift was er nooit gekomen zonder de hulp en steun van de mensen om mij heen, te beginnen met mijn promotor Imke de Boer en mijn co-promotoren Paul Berentsen en Eddie Bokkers. Jullie hebben me de kans gegeven deze PhD te doen en daar ben ik jullie ontzettend dankbaar voor. Imke, dankjewel voor alles wat je me geleerd hebt over duurzaamheid en voor je helikopterblik op mijn werk van begin tot eind. Paul, dankjewel voor je altijd scherpe opmerkingen waardoor ik heb geleerd om helderder te redeneren en formuleren. Eddie, bedankt dat jouw deur altijd openstond voor vragen en discussies tussen besprekingen door, en ook voor vakantieverhalen en andere belevenissen.

This research would not have been possible without support from the WhiteFish project. I would, therefore, like to thank all the project participants at Nofima, SP, Matís and the SMEs and SME-AGs for their contribution to this project and therewith to this thesis. Evelyne Groen, ontzettend bedankt voor al je gezelligheid en steun tijdens en na het WhiteFish project. Niet alleen is onze roadtrip door IJsland een bijzonder gekoesterde herinnering geworden, maar ook de vele andere bijzondere momenten die we gedeeld hebben (that have been done).

$\mathrm{Al}$ vanaf het begin van mijn $\mathrm{PhD}$ wilde ik een consumentenstudie doen en die studie is er uiteindelijk gekomen dankzij Ivo van der Lans. Ivo, bedankt voor je onmisbare bijdrage aan Hoofdstuk 4. Je hebt me niet alleen veel geleerd over de specifieke methode die we gebruikt hebben, maar ook over marktonderzoek en alles wat daarbij komt kijken.

Tijdens mijn PhD heb ik vele kantoorgenoten gehad die ik allemaal wil bedanken voor hun steun en gezelschap. Marion, jouw enthousiasme werkt aanstekelijk, zo zijn we gaan squashen en hebben we zelfs een survivalrun gedaan - onvergetelijk! Kebebe, thank you for choosing me as your paranymph, it was wonderful to experience your special day from up close. Afva and Brain, it was great having you as roommates, thank you for your warmth and kindness. Corina en Laura, het was geweldig om jullie als kantoorgenoten te hebben, maar vooral om jullie buiten kantoortijd te zien. Akke, bedankt voor al die keren squash tijdens de lunchpauze, hopelijk blijven we daar nog lang mee doorgaan. Pim, Ollie, Nicole and Abigail, thank you for making each day so much more fun.

Verder wil ik ook al mijn andere collega's bedanken voor hun vrolijke noot tijdens iedere werkdag: Ymkje, Raimon, Iris, Cindy, Charles, Sally, Wenjuan, Hannah, 
Aart, Simon, Fokje, Theo en Henk. Ook wil ik alle mensen bedanken met wie ik tijdens mijn jaar in de WUR Council heb samengewerkt, en in het bijzonder Joost, Marian, Clementine en Anneke.

Mijn PhD is altijd belangrijk voor me geweest, maar niets is zo belangrijk als de vrienden en familie om je heen. Daarom wil ik mijn studiemaatjes en goede vriendinnen Marloes, Marlien, Astrid en Iris bedanken voor alles. Het is teveel om op te noemen, maar bedankt voor de vele Vlaamavonden, festivals, vakanties, squashpotjes, lunches, spelletjesavonden en vooral voor al het plezier en de steun die jullie me gegeven hebben. Leonie en Renske, vanaf het moment dat we $11 \mathrm{C}$ op zijn kop zetten, zijn we beste maatjes. Dank voor alle high teas, shopmiddagen, stedentrips, terrasjes en vele andere fijne dingen waar we zo goed in zijn - dat er nog maar veel moois mag volgen :) Erwin en Laura, het is altijd fijn om bij jullie langs te komen, niet in de laatste plaats vanwege Heel Holland Bakt-creaties ;) Sandra, Pauline en Marjolein, ik ben blij dat wij elkaar na zoveel jaren nog steeds regelmatig zien, laten we daar vooral mee doorgaan want jullie zijn top! Eva en Martijn, bedankt voor de vele heerlijke etentjes op de maandagavond, ik ben zeker niet voor niks met theatersport gestopt.

Ik was nooit zo ver gekomen zonder mijn lieve ouders. Bedankt dat jullie altijd in me hebben geloofd en me in alles hebben gesteund - ik hou van jullie. Marloes, ik kan me geen betere zus wensen. Niet alleen omdat je me altijd weet te vinden voor kolonistenavonden, dagjes Den Bosch, concerten en ga zo maar door, maar vooral omdat je de tante in me hebt losgemaakt - Sepp en Finn zijn echt mijn oogappeltjes. Tante Ria en ome Wim, jullie zijn de liefste mensen die ik ken en ik hoop dat jullie nog vaak op bezoek komen. Dayenne en Alex, bedankt dat jullie die heerlijke meiden Naomi en Nala af en toe loslaten in onze keuken, dat zijn nu al dierbare momenten. Rody, ik ben blij dat je graag bij ons over de vloer komt, je bent altijd welkom. Annie en Ties, ik heb jullie in mijn hart gesloten, jullie zijn geweldig! Verder wil ik mijn Oma en al mijn ooms, tantes, neven en nichten bedanken voor hun belangstelling, ook al is het maar weinigen (behalve misschien Conny en Wim) duidelijk wat ik nou precies doe ;)

Dan wil ik nog twee belangrijke dames bedanken, mijn paranimfen en goede vriendinnen Marloes en Heleen. Marloes, ik weet nog goed hoe wij allebei naar hetzelfde AID-groepje op zoek waren, inmiddels elf jaar geleden. Sinds die tijd hebben we veel meegemaakt, met onze reis door Amerika als (voorlopig) hoogtepunt. Bedankt dat je er altijd voor me bent. Heleen, mijn blonde plukjes boven de computer, je bent sinds de eerste dag dat ik bij APS binnenstapte mijn maatje. Niemand snapt waar onze grappen over gaan en ze gaan soms echt te ver, maar ik heb genoten van de afgelopen jaren en kijk uit naar wat nog komt.

Tot slot wil ik mijn meneer bedanken. Lieve Dylan, door het zelfvertrouwen en de liefde die je me hebt gegeven, voel ik me sinds twee jaar on top of the world. 


\section{About the author}

Linda Veldhuizen was born in IJsselstein in 1987. She obtained her BSc degree in International Development with a specialization in Economics of Development from Wageningen University in 2008. After a working holiday of one year in New Zealand and Australia, she started with her MSc in 2009. During her MSc, she did a minor in environmental systems analysis and an internship at CSIRO Perth. She wrote her major thesis on willingness to pay for climate change mitigation in Australia. She obtained her MSc degree in International Development with a specialization in Economics of Development from Wageningen University in 2011.

In 2012, Linda started as a $\mathrm{PhD}$ candidate at the Animal Production Systems group of Wageningen University. During the first 3 years of her $\mathrm{PhD}$, she was responsible for the research on social and economic sustainability within the WhiteFish project, which aimed to enable fishers to document their sustainability impact. Her own $\mathrm{PhD}$ research focused on social sustainability of capture fisheries in the northeast Atlantic. She identified the issues that are at stake in these fisheries, developed a method to assess these issues, determined consumer interest in these issues, and performed a literature review on the most important social sustainability issue for consumers, i.e. fish welfare. Her research on these topics has been disseminated at international conferences and in top peerreviewed journals. During the last year of her PhD, she was a member of the WUR Council, the central participation council of Wageningen UR. She chaired the committee on Education and Research and was the secretary of the Student Staff Council, a sub-council of the WUR Council.

After completion of her thesis, Linda plans to work in the field of sustainability reporting and corporate social responsibility. 


\section{Publications}

\section{Peer-reviewed scientific journal articles}

Veldhuizen, L.J.L., Berentsen, P.B.M., Bokkers, E.A.M., De Boer, I.J.M. 2015. Social sustainability of cod and haddock fisheries in the northeast Atlantic: what issues are important? Journal of Cleaner Production, 94, pp. 76-85

Veldhuizen, L.J.L., Berentsen, P.B.M., Bokkers, E.A.M., De Boer, I.J.M. 2015. A method to assess social sustainability of capture fisheries: an application to a Norwegian trawler. Environmental Impact Assessment Review, 53, pp. 31-39

Veldhuizen, L.J.L., van der Lans, I.A., Berentsen, P.B.M., De Boer, I.J.M., Bokkers, E.A.M. 2016. Consumer interest in social sustainability issues of whitefish from capture fisheries in the northeast Atlantic. Accepted for publication in Fish and Fisheries

Veldhuizen, L.J.L., De Boer, I.J.M., Berentsen, P.B.M., Bokkers, E.A.M. 2016. Fish welfare in capture fisheries: a review of injuries and mortality. Submitted

\section{Conference proceedings and abstracts}

Veldhuizen L.J.L., Berentsen, P.B.M., Bokkers, E.A.M., De Boer, I.J.M. 2013. Identifying and ranking social sustainability issues for cod and haddock fisheries in the northeast Atlantic. In: Programme Book of the 7th People and the Sea conference of the Centre for Maritime Research (MARE), June 26-28, Amsterdam, Netherlands, pp. 101.

Bokkers, E.A.M., Pauw, W.H., Veldhuizen, L.J.L.. 2014. Improving welfare of cod and haddock by adapting current practices in trawl fishing. In: Proceedings of the 6th international conference on the assessment of animal welfare at farm and group level (WAFL), 3-5 September, Clermont-Ferrand, France, pp. 207.

Veldhuizen L.J.L., Berentsen, P.B.M., Bokkers, E.A.M., De Boer, I.J.M. 2014. Social sustainability of cod and haddock fisheries in the northeast Atlantic: what issues are important? In: Proceedings of the 9th International Conference on Life Cycle Assessment in the Agri-Food Sector (LCA Food), 8-10 October, San Francisco, US, pp. 1477.

Veldhuizen, L.J.L., Berentsen, P.B.M., Bokkers, E.A.M., De Boer, I.J.M. 2015. A method to assess social sustainability of capture fisheries: an application to a Norwegian trawler. In: Program and Abstract Book of the 5th World Sustainability Forum (WSF), 7-9 September, Basel, Switzerland, pp. 136. 


\section{Education certificate}

\section{Completed training and supervision plan ${ }^{1}$}

\section{Basic package (3.0 ECTS)}

- WIAS introduction course (2012)

- WGS course 'ethics and philosophy in life sciences' (2013)

\section{International conferences (3.6 ECTS)}

- LCA Food, Saint Malo, France (2012)

- MARE conference, Amsterdam, Netherlands (2013)

- LCA Food, San Francisco, US (2014)

- World Sustainability Forum, Basel, Switzerland (2015)

\section{Seminars and workshops (2.0 ECTS)}

- Seminar 'welfare of fish', Nijmegen (2012)

- WIAS science day, Wageningen (2013-2016)

- WaCASA day on family farming, Wageningen (2014)

- WGS workshop carousel, Wageningen (2015)

\section{Presentations (13.0 ECTS)}

- WhiteFish consortium, Wageningen, oral (2012)

- WIAS science day, Wageningen, poster (2013)

- WhiteFish consortium, Reykjavik, oral (2013)

- MARE conference, Amsterdam, oral (2013)

- WhiteFish consortium, Grimsby, oral (2013)

- WhiteFish consortium, Gothenburg, oral (2014)

- WIAS science day, Wageningen, poster (2014)

- WhiteFish open meeting, Tromsø, oral (2014)

- LCA Food, San Francisco, oral (2014)

- CWA open meeting, Reykjavik, oral (2014)

- WIAS science day, Wageningen, poster (2015)

- World Sustainability Forum, Basel, oral (2015)

- WIAS science day, Wageningen, oral (2016) 


\section{In-depth courses (13.0 ECTS)}

- Social life cycle assessment, Barcelona (2013)

- Advanced statistics, Wageningen (2013)

- Systematic approaches to reviewing literature, Wageningen (2015)

- Pain in animals, Copenhagen (2016)

\section{Professional skills support courses (4.5 ECTS)}

- Scientific writing (2013)

- Supervising MSc thesis work (2013)

- Effective behaviour in your professional surroundings (2014)

- Career orientation (2015)

\section{Research skills training (7.0 ECTS)}

- Preparing own PhD research proposal (2012)

- Reviewing scientific paper for Journal of Cleaner Production (2016)

\section{Didactic skills training (8.5 ECTS)}

- Supervising practical in BSc course 'inleiding dierwetenschappen' (2012-2014)

- Supervising MSc major thesis Woutine Pauw (2013)

- Supervising MSc minor thesis Sophie Poinot (2015)

- Supervising BSc thesis Sharine Smeets (2015-2016)

- Lecture in BSc course 'systems approach in animal sciences' (2016)

\section{Management skills training (1.0 ECTS)}

- Organizing WhiteFish meeting Wageningen (2013)

${ }^{1}$ With the activities listed, the $\mathrm{PhD}$ candidate has complied with the educational requirements set by the Graduate School of Wageningen Institute of Animal Sciences (WIAS). One ECTS equals a study load of 28 hours. 


\section{Colophon}

The research described in this thesis was financially supported by the Seventh Framework Programme (FP7) project entitled WhiteFish, grant number 286141.

Cover design by Studio Yoni - www.studioyoni.com

Printed by ProefschriftMaken - www.proefschriftmaken.nl 